\title{
Other Allergic Skin Disorders
}

\section{A Skin Panorama}

In this chapter we discuss allergic skin disorders other than atopic dermatitis $(\mathrm{AD})$ : the urticaria-angioedema syndrome, allergic contact dermatitis (ACD), protein contact dermatitis (PCD), phytodermatitis, allergic photodermatitis and allergic vasculitis.

\section{Urticaria-Angioedema Syndrome}

Urticaria and angioedema comprise a unique syndrome, with the two frequently associated. Angioedema may be isolated: when associated with urticaria it is commonly underdiagnosed. Such disorders are well known to pediatricians and allergists and often are a manifestation of type I IgE-mediated reaction.

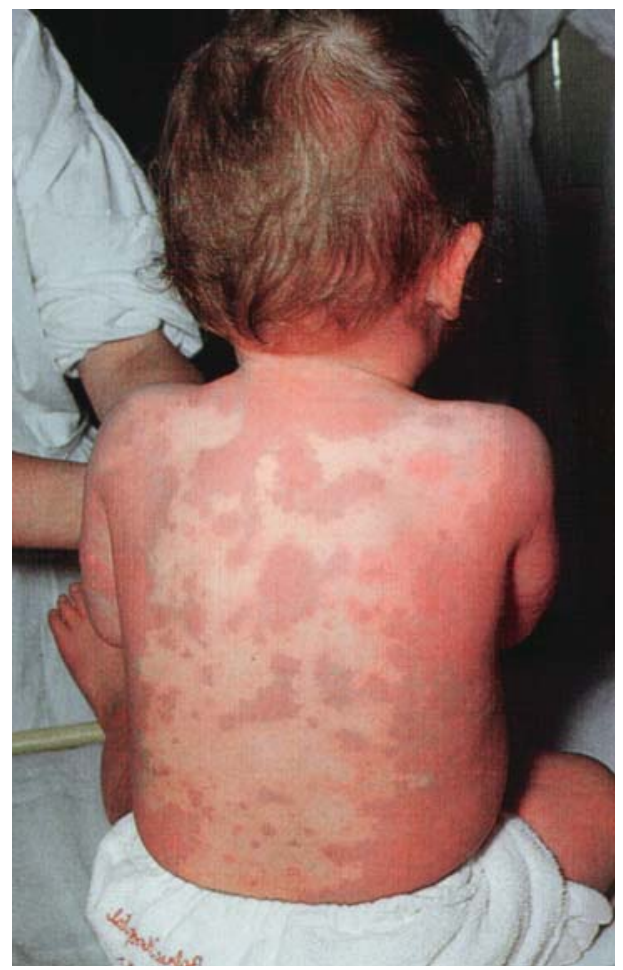

Fig. 8.1. Urticaria (for details see text)

\section{Definitions}

Urticaria (Fig. 8.1) is a cutaneous vascular reaction characterized by transient localized areas of edema (lasting from 2-3 min to $<24 \mathrm{~h}$ ) on hairless or hairy skin. Wheals, lesions that affect the superficial dermis, are circumscribed and slightly prominent, surrounded by a variable rings of erythema (flare) with a flat surface or a raised border. Hives have a variable form and size and are accompanied by more or less intense itching. Angioedema (Figs. 5.12 and 8.2) is a "urticaria involving the deep dermis and subcutaneous tissues," with deeper and less localized edematous swelling, which affects both skin and mucosal sites, preferring areas of loose connective tissue such as the face, eyelids, tongue, lips, extremities and genitalia, but may occur anywhere. These lesions are typically painful, rather than pruritic. Superficial mast cell degranulation induces wheal manifestations, whereas that of deeper mast cells induces extended vascular edema [117].

Urticaria can be divided into four main types based on a chronological outcome of clinical manifestations:

Acute urticaria (recurring <6 weeks), certainly the more frequent urticaria in pediatric populations

Chronic urticaria (recurring more times for a total of 6 weeks)

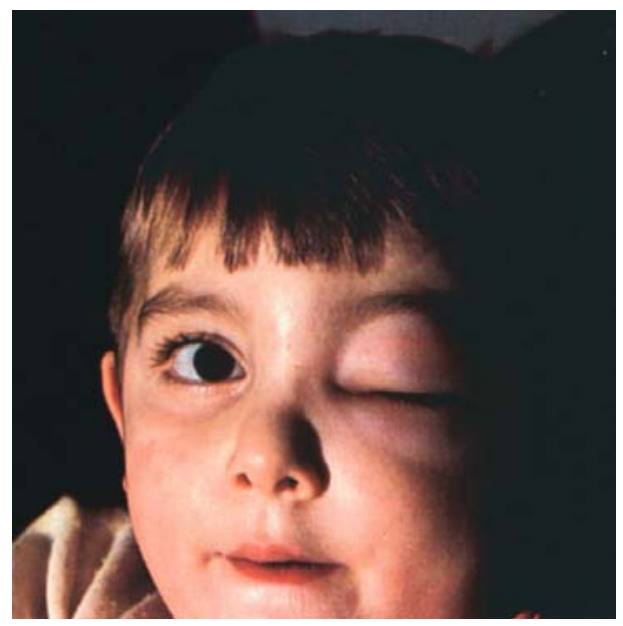

Fig. 8.2. Angioedema in a child sensitive to Fel $d 1$ after having stroked a cat during a visit to the house of a cat-loving friend 
Recurrent chronic urticaria with sporadic manifestations recurring 2-3 times/year

Idiopathic urticaria, usually chronic: most cases are thus considered since no precipitating cause can be identified after having excluded all potential causes of urticaria $(70 \%-80 \%$ of cases $)[18,37]$

\section{Prevalence}

Pediatric urticaria is credited with a $2 \%-5 \%$ prevalence [60], with a total value of $3.9 \%$ (Figs. $5.5,5.9$ ) or at $0.5-$ 1 year (Table 5.5). Isolated angioedema is present in up to $9.6 \%$ of allergic children [60]. Higher incidences are found in cohort studies. Urticaria was seen in 28 (49\%) and angioedema in 34 children aged $1-3$ years $(60 \%)$ [144]. Urticaria was associated with angioedema in $38.6 \%$ of children [29]. Urticaria manifested mostly in male children $(59.8 \%)$, mainly of preschool and school age rather than the under-1-year age group [13]. Acute urticaria may have an even higher prevalence $(91.7 \%)$ [13] than that seen in $\mathrm{AD}$ : probably its frequency is underestimated since often, above all when caused by foods, a specialist is not consulted, the parents or the patients having recognized the evident cause-effect correlation (Chap. 7).

\section{Classification}

Table $8.1[37,42,45,117]$ shows the division into hereditary and acquired types, further subdivided into types that are apparently primary and secondary to other disorders.

\section{Etiopathogenesis}

\section{Genetic Factors}

A genetic influence was demonstrated in 56 children with urticaria-angioedema subjected to challenge with additives: the 25 children with positive challenge showed a positivity, with statistically significant differences, of family $(64.2 \%)$ and personal history (80\%) and elevated IgE levels (40\%) [59]. A 67\% rate of food urticaria occurred in atopic children $[67,90]$. Children are more likely than controls to have a personal or family history (FH) of atopy (FHA) [169]. As a consequence, children affected by IgE-mediated atopic disease are more at risk of urticarial manifestations compared to the general population; likewise dermographism and aquagenic urticaria are significantly more frequent in atopic children than in nonatopic children [60]. Recently, Muckle-Wells syndrome and familial cold urticaria, two rare autosomal dominant disorders, both localized on chromosomal region $1 q 44$ [50] have been found to be associated with mutations, all located in exon 3 of the CIAS1 gene [62].

\section{Pathogenic Mechanisms}

Several pathogenic mechanisms are operative in urticaria, either immunological or nonimmunological (Table 8.1), which may be involved in acquired types of this syndrome.

The urticaria-angioedema caused by an immunological pathogenesis include [44]:

- IgE-mediated urticaria:

- Foods, inhalants, insect bites, etc.

- Exercise-induced anaphylaxis (EIA)

- Physical urticaria (by external stimuli: cold, sun rays, pressure, vibrations, etc.)

- Non-IgE-mediated urticaria

- Complement and circulating immune complexes (CIC)-mediated urticaria

- Cutaneous vasculitis

- Serum sickness

- Infections

Urticaria caused by a nonimmunological pathogenesis includes:

- Non-IgE-mediated mast cell activation

- Anaphylactoid reactions

- Chronic/idiopathic urticaria

\section{Immunological Mechanisms}

Several pathogenetic mechanisms may involve types I-III immune reactions $[45,175]$.

Type I mechanism is fulfilled once specific $\operatorname{IgE}$ is bound to basophils or skin mast cells. Contact with allergens leads to consequent degranulation, mediator release and development of typical skin and mucosal lesions. This IgE-mediated mechanism is operative on reactions to foods such as cow's milk (CM), egg, fish, wheat, parasites (helminths), some protozoa, insect venom, pollens, pet dander [53, 103], $\beta$-lactamine metabolites, insulin, enzymes, sera [227] and latex [112]. T-cell expression of cutaneous lymphocyte antigen (CLA), a unique skin-homing receptor, was selectively up-regulated in patients with CM-induced urticaria and may play an important role in the pathogenesis of this disease [28].

Type II mechanism involves complement-fixing IgG or IgM antibodies, complement activates $\mathrm{C} 3 \mathrm{a}, \mathrm{C} 4 \mathrm{a}$, and C5a components capable of directly activating mast cell degranulation. Known examples are the hemolytic reactions after blood transfusions (due to incompatible groups) and immunoglobulins (mainly IgA) and sulfamide administration [227]. This mechanism has been found in physical urticaria such as cold-induced, cholinergic and dermographic types [53]. 
Table 8.1. Urticaria-angioedema syndrome: pathogenic classification and classification of acquired forms

\section{A. Pathogenic classification}

1. Immune-mediated urticaria FcERI cross-linkage

Allergens

Autoantibodies

Anti-lgE

Anti-FceRI

Polyvalent lectins

Anaphylotoxins

Most common etiological agents causing IgE-mediated reactions

Foods

Beans

Celery

Cow's milk and dairy products

Fish (cod)

Nuts

Parsley

Seafood

Spices

Tomato

Inhalant allergens

Animal danders

Molds

Pollens

Physical stimuli

Cold

Exercise

Heat

Pressure

Sunlight, etc.

Insect venom

More common etiological agents causing immune complex-mediated reactions

Virus

Coxsackie virus

Cytomegalovirus

Hepatitis virus

Infectious mononucleosis

Psittacosis virus

Bacteria

Mycobacterium

Staphylococcus

Streptococcus

Molds

Candida albicans

Trichophyton

Antigens deriving from neoplastic cells

Cryoglobulins

Nuclear antigens

LES or other autoimmune diseases

2. Nonimmunological mediated urticaria

Substances with histamine-releasing activity

Drugs

ASA

NSAIDs

Penicillin

Pyrazolone

Radiocontrast materials

Sulfonamides, etc.
Proteolytic enzymes

Trypsin

Papain, etc.

Substances on the cell surface

Biliary salts

Dehydrocholic acid

Tween 20

Compounds with high MW

Dextran

Egg-white

Polyvinylpyrrolidone

Agents causing mast cell histamine release

(see Chap. 10)

Chemically defined substances contained in foods Tyramine, etc.

Chemically undefined substances contained in foods Complement activation

(nonimmunological pathway)

Complement activation (classic pathway)

Bacterial endotoxins

Immunoglobulin aggregates

(myeloma, dermatomyositis)

Proteolytic enzymes

Staphylococcal A protein

Uric acid crystals

Complement activation (alternative pathway)

Lipopolysaccharide complexes

(dextran, zymosan, agar)

Na dehydrocholate

Polysaccharides of cell wall

of Gram-positive organisms

Polyvinylpyrrolidone

Snake venom

\section{B. Classification of acquired forms}

1. Apparently primitive acquired forms

Drugs

ACE inhibitors

Amphetamine

Antibiotics

ASA and NSAIDs

Codeine and morphine

Curare and derivatives

Hemoderivatives, plasma expanders,

gammaglobulins

Heterogenic proteins

(organ extracts, specific antiserum, etc.)

High-molecular-weight substances

(dextran, polyvinylpyrrolidone, $\mathrm{Na}$ dehydrocholate,

etc.)

Hormones

lodinated radiocontrast materials

Local anesthetics

Opiates

Oral antidiabetics

Proteolytic enzymes

(trypsin, chymotrypsin, streptokinase, etc.)

Radiocontrast dyes

Sulfonamides

Vitamins (thiamine, polymyxin b) 
Table 8.1. (Continued)

\begin{tabular}{ll} 
Foods & 2. $\begin{array}{l}\text { Urticaria associated with other affections } \\
\text { Cocoa and chocolate }\end{array}$ \\
Cow's milk and dairy products & Cryoglobulinemia \\
Egg & Endocrinopathies (diabetes mellitus, hyper- \\
Fermented cheese & and hypothyroidism, hyperparathyroidism) \\
Fish (cod) & Infections (bacterial, viral, mycotic, etc.) \\
Fruits (strawberry, banana, etc.) & Neoplastic disease \\
Peanuts, nuts, hazelnuts, etc. & Parasitosis \\
Shellfish, shrimp & Serum sickness \\
Tomato & Physical urticaria \\
Food additives & Aquagenic urticaria \\
Na benzoate & Cholinergic cold urticaria \\
Na metabisulfite & Cholinergic urticaria \\
Na salicylate & Cold urticaria \\
Tartrazine yellow & Contact urticaria \\
Venoms & Delayed pressure urticaria \\
Insect & Dermographism, urticaria factitia \\
Snake & Exercise-induced urticaria (anaphylaxis) \\
Contactants & Localized heat urticaria \\
Cosmetics & Pressure urticaria \\
Topical medications & Solar urticaria \\
Idiopathic urticaria & Vibratory angioedema \\
Psychogenic urticaria & \\
& \\
\hline
\end{tabular}

Data from [37, 42, 45, 117].

ASA acetylsalicylic acid, ACE angiotensin converting enzyme, LES lupus erythematosus, systemic, NSAIDs nonsteroidal antiinflammatory drugs.

Type III mechanism is manifest via an interplay between CIC, activated complement and kinins and the anaphylotoxin system, which is seen with serum sickness. This mechanism is observed in childhood infections [7], urticarial vasculitis, Schönlein-Henoch syndrome (SHS), panarteritis nodosa, cryoglobulinemia, hereditary complement deficiencies, autoimmunity etc. [53]. Such a pathogenic mechanism has been considered in food-induced reactions, since elimination of $\mathrm{CM}$ from the diet of a patient with angioedema and bronchospasm resulted in CIC disappearance, and reintroduction of CM caused a return to previous CIC levels within $24 \mathrm{~h}$ [119]. These II and III types are objectively rare in children.

Several investigators consider that a type IV mechanism may be operative via $\mathrm{IL}_{3}$ and $\mathrm{IL}_{5}$ generation, which are capable of acting on both mast cell degranulation and eosinophil recruitment, thus explaining some types of chronic urticaria [37], especially eotaxin-driven allergic acute urticaria [95].

The skin is particularly rich in mast cells. In Chap. 7 we described their origin in bone marrow and subsequent migration into the skin aided by chemoattractants and adhesion molecules [37]. In immediate-type hypersensitivity, mast cell activation is triggered by allergen cross-linkage of high-affinity IgE receptors (FceRI) borne on their cytoplasmic membrane and on peripheral blood basophils. Mast cells may be activated by specific allergens or by HRFs (histamine release factors) [46] or chemokines, produced by peripheral blood mononuclear cells (PBMCs) that are part of the cell infiltrate causing skin inflammatory lesions. Cutaneous mast cells are tryptase and chymase-containing mast cells (TC) (Table 1.27) and contain in the granules both types of proteases, tryptase and kinase [194], which are able to induce further degranulation [53]. Tryptase in particular can be viewed as a marker of mast cell activation, since its concentration in lesional skin increases proportionately to histamine concentration [103]. Leukocyte emigration is regulated by vasoactive and chemotactic mediators released from mast cells, inducing a sequential up-regulation of endothelial adhesion molecules (CD62P, CD62E, CD54 = ICAM-1, and CD106 $=\mathrm{VCAM}), \beta 2$-integrins on leukocytes, and ILs on endothelial, epithelial, and infiltrating cells [91]. In chronic/ idiopathic forms, T lymphocytes (50\%) are characteristically found with perivascular distribution, monocytes (20\%), mast cells (10\%) and no B lymphocytes [103]. CD4 prevails over CD8 [19]. One hypothesis postulates that there is a predominance of activated CD4, as seen in delayed pressure urticaria (DPU) [103]. However, a more likely hypothesis shows no evidence of CD4 activation, although it confirms the unbalanced $\mathrm{CD} 4 / \mathrm{CD} 8$ ratio [19]. CD62E has been found in both groups of patients, but CD54 only in DPU patients [19]. Both CD62E and CD54 act as T-lymphocyte adhesion receptors and their increase found in DPU patients may reflect the inflammatory nature of this disorder [19].

In chronic urticaria, IgG Aabs (autoantibodies) directed against IgE in function of anti-IgE and/or anti- 
FceRI have been detected. These Aabs selectively directed against the receptor $\alpha$ subunit are of the $\operatorname{IgG}_{1}$ or $\mathrm{IgG}_{3}$ subclass and effectively fix complement and in the absence of IgE induce basophil and mast cell histamine release in both instances [92]. The number of mast cells is not significantly different compared to controls, so the histamine increase may be due to circulating basophils recruited into skin lesions [194]. Moreover, the serum of $\leq 60 \%$ of patients reacting with basophils of healthy donors stimulated in vitro basophil releasability $[88,89$, 92]. Consequently, cross-linkage of Aab IgG to FcERI is a pathogenic mechanism peculiar to chronic urticaria, which operates by stimulating or facilitating metachromatic cell degranulation [88] with consequent histamine release [67]. Such Aabs could correspond to HRFs with molecular weight (MW) $>100 \mathrm{kD}$, equally provided with IgG anti-IgE Aabs able to interact with IgE [252]. These data explain why some patients suffer from severe and ongoing symptoms [89]. Basophil histamine release plays a significantly pathogenic role because basophils, when stimulated with anti-IgE that interact with $\operatorname{IgE}$ present on basophils, release less histamine [249], even if the levels are variable between subjects [88,252]. The easy basophil degranulability acts as an opening key to the gaps between endothelial cells, which allows allergen and CIC to break into the perivascular tissue [225]. The skin histamine content and its releasability are increased in vivo during active disease and in remission. Mast cell release following an allergen challenge is not different between patients with chronic urticaria and normal controls [67]. Therefore, the histamine level increment could depend on a transient functional imbalance more than on an intrinsic mast cell defect [194]. To reconcile apparently conflicting data, we should admit that histamine may derive from mast cell nonimmunological stimulation.

Although eosinophils are not the most prominent cell type found in urticarial lesions, several eosinophil-derived mediators, including EDN (eosinophil-derived neurotoxin) and MBP (major basic protein) have been detected in late-phase reactions (LPR) in chronic urticaria between 2 and $5 \mathrm{~h}$ after allergen challenge [251]. These cationic proteins have been shown to elicit wheal and flare when directly injected into the skin. Eosinophils may also comprise a part of the inflammatory cell infiltrate, along with neutrophils, in DPU and solar urticaria [121]. Moreover, eosinophils are major $\mathrm{LTC}_{4}$ producers in allergic inflammation [103].

Histamine plays a central role in urticarial lesions by increasing vascular permeability and intensely itching wheals on clinical grounds [231]. The classic Lewis triple responses (Fig. 8.3), produced by subcutaneous histamine injection or by gentle stroking with a smooth object, are paradigmatic of what occurs in urticaria linear erythema; flare and wheal are due, respectively, to vasodilatory $\left(\mathrm{H}_{1}\right.$ and $\mathrm{H}_{2}$ action) and vasopermeability ( $\mathrm{H}_{1}$ action) histamine action, to which is added (for the

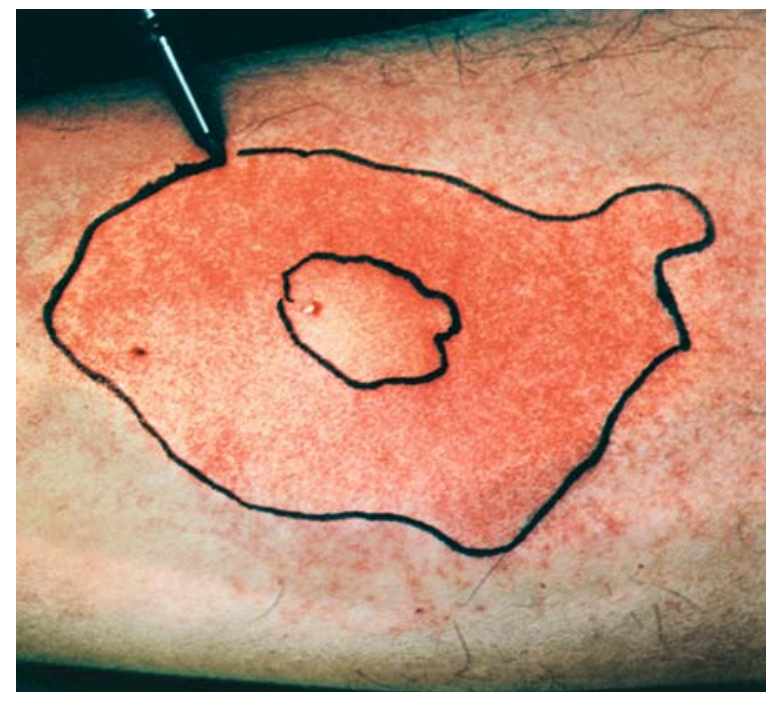

Fig. 8.3. Triple Lewis response: the inner circle is the wheal, the outer one the flare

vasodilatory phase) a local axon reflex with dilation of small perilesional arteries, a neurogenic response of the short-circuit type, sending a stimulus back to the cutaneous nerve endings of the involved area. The increased vascular permeability leads to activation of the plasma kinin-forming system and production of bradykinin, which is especially important in hereditary angioedema. Likely the histamine-mediated stimulation of neural sensorial fibers provokes the release of substance $P$ (SP) and of tachykinins with histamine-release action, with consequent amplification of symptoms [103]. Additional mediators important in the pathogenesis are both PG (prostaglandins) and LT (leukotrienes), deriving from arachidonic acid metabolism, $\mathrm{PGD}_{2}$ is active in mastocytosis, $\mathrm{LTB}_{4}$ and $\mathrm{LTC}_{4}$ in pressure urticaria, $\mathrm{LTB}_{4}$ and PAF in cold, heat, and cholinergic urticaria [103]. With the advent of LT-receptor antagonists, the $\mathrm{LTC}_{4}$ contribution to chronic urticaria symptoms is more evident [103].

In other urticarial types, the immunological mechanism is not always identified: allergens may be produced in solar urticaria, both in serum and epidermis, triggered by solar ray exposure, which in aquagenic urticaria in contact with water become soluble in the corneum layer, and diffuse to dermal mast cells. Cryoglobulins, cold hemolysins and cryofibrinogen are observed in some cases of cold urticaria [60].

Serotonin chemotactic factors, kinins, derivatives of tissue and plasma kininogen with an inflammatory action, tenfold more pronounced than that of histamine and MIF (monocyte-macrophage migration inhibiting factor), and 15-HETE (15-hydroxyeicosatetraenoic acid) in LPRs may also participate in the wheal formation process [37]. 


\section{Immunohistopathology}

Urticaria is histologically characterized by dilation of venules and capillaries, tissular edema and a predominant perivascular infiltrate, of variable composition and intensity. The histological peculiarity of urticarial wheals is common to all types, independently of etiology; mast cells and related mediators are the cornerstone of the lesions [166]. The more evident alteration is the dermal edema with vascular turgor, secondary to an increased size of endothelial cells: edema and infiltrate preferentially involve the dermal deeper strata, extending in certain cases to subcutaneous tissues, where flushing and itching stimuli are lacking because of the scarcity of capillary bed and nerve endings. The perivascular cell infiltrate is represented, especially in chronic forms, by T-activated lymphocytes, monocytes, eosinophils and mast cells; the clear-cut prevalence of neutrophils is characteristic. Activated T cells are predominant compared to all other cells, followed by mast cells and both B lymphocytes; NK cells are absent [117]. Since this pathology involves the vascular compartment, the etiological agents more frequently responsible are internally transported. In immune processes persistent for $>30 \mathrm{~min}$, numerous leukocytes are active, among which neutrophils are disposed between the walls of capillary and post-capillary venules which, if their number increases, may lead to urticarial vasculitis more frequently associated with chronic forms [89]. Eosinophils are seen more rarely, and perivascular infiltrations by lymphocytes expressing the CD4 phenotype are frequently detected [19]. Histopathological evidence in chronic lesions is similar to what is seen in $\mathrm{AD}$ and ACD LPRs: vasoactive mediators and chemotactic factors recruit PBMCs, neutrophils, and eosinophils into the cutaneous microenvironment; inflammatory cells in turn stimulate mast cells to dismiss HRFs [46]. It is tempting to speculate whether the initial stimulus comes from activated $\mathrm{T}$ cells or from mast cells $[19,103]$.

\section{Nonimmunological Mechanisms}

Several naturally occurring and exogenous nonimmunological compounds have histamine-releasing action via nonspecific mast cell activation. These compounds include (Table 8.1) ASA (acetylsalicylic acid), which, in common with NSAIDs (nonsteroidal anti-inflammatory drugs), generally inhibits the cyclooxygenase pathway, resulting in derailment of the arachidonic acid pathway towards LT production (Fig. 1.57). These drugs have a short half-life; thus possible plasma increments are sporadically detected, unlike in patients with mastocytosis or urticaria pigmentosa, who are primarily susceptible because of an increased skin mast cell population [61]. Nonimmunological activation has been demonstrated in several types of idiopathic, heat- and cold-induced, cholinergic, etc. urticaria [60], which respond to $\mathrm{H}_{1}$ anti-histamines in the absence of allergens [44]. Urticaria may be caused by a host of agents, including detergents, foods, and endogenous peptides such as endorphins, neuropeptides or tachykinins [131]; but compound $48 / 80$ and codeine cause histamine release only in the skin mast cell [45]. Likewise, physical stimuli may act on peripheral skin nociceptors, thus inducing neuropeptide release. Experimental evidence demonstrates that SP has a vaso-permeabilizing effect on epithelial cells. Tachykinin release into the skin may explain the functional aspects of several types of physical urticaria and the lack of response to anti-histamines and corticosteroids (CSs) [225].

Nonimmunological mechanisms activating mast cells should be re-examined in light of the new acquisitions on neuropeptides, and interactions between the peptidergic nervous system and immunocompetent leukocytes, thus suggesting that mast cells fall in the neuroimmunological axis. SP, NKA (neurokinin A) and CGRP (calcitonin gene-related peptide), via a retrograde axon reflex stimulating mast cells to release histamine (Chap. 10), act moreover on blood vessels. Alternatively the reflex may originate from mast cells, by leading to a tachykinin antidromic stimulation [115]. Abnormalities of skin mast cell responses to neuropeptides may underlie pathological manifestations in several types of cutaneous urticaria, for example in patients affected with cold or heat urticaria, in areas devoid of tachykinins following application of capsaicin (stimulating SP release from sensorial termination and provoking an equal increase in vascular permeability), vascular responses to thermal challenge are reduced. Similarly, patients with chronic urticaria show an increase in cutaneous symptoms in response to codeine. As a consequence, such mechanisms activating mast cells nonimmunologically may have great weight from a physiopathological point of view [166], probably in several cases of chronic urticaria.

\section{Pathogenesis of Hereditary Angioedema}

Hereditary angioedema includes [155]:

- Genetic deficiency of $\mathrm{C} 1$ inhibitor (C1-INH)

- Hereditary angioedema type I and type II

- Five other genetic syndromes

- Acquired forms

The gene for human C1-INH is localized to chromosome 11q11-q13.1 [204].

Hereditary angioedema is inherited as an autosomal dominant trait with incomplete penetrance and is relatively uncommon $(0.1 \%)$. Type I ( $85 \%$ of patients) results from a complement esterase inhibitor deficiency (C1-INH), with MW of $104 \mathrm{kD}$, produced in liver, monocytes, megakaryoblasts, fibroblasts and placental cells, acting as a regulator of coagulative, fibrinolytic, inflammatory processes, etc. Owing to $\mathrm{C} 1-\mathrm{INH}$ deficiency, 
complement is also activated after minimal stimuli, often of a traumatic nature, with formation of $\mathrm{C} 3 \mathrm{a}$ and C5a, activation of kinin-like C2 factor, and secretion of more chemical mediators, associated with angioedema onset. In Type II (10\%-15\% of patients), C1-INH levels are normal, since the deficiency is functional. More precisely, in Type I patients, C1-INH-deficient production results from one chromosome 11 gene, which is defined as unproductive; in Type II patients, a gene mutation leads to a functionally inactive C1-INH $(\mathrm{MW}=96 \mathrm{kD})$ : therefore the product of a solely normal gene is insufficient to ensure a C1-INH adequate concentration [155]. Consequently, in both cases $\mathrm{C} 2$ and $\mathrm{C} 4$ are reduced, the $\mathrm{C} 4 \mathrm{~d} / \mathrm{C} 4$ ratio is elevated, and Clq and C3 levels are normal [250]. A type III has been recently described in women with normal C1-inhibitor protein, C1-inhibitor function, and C4 levels [35].

Twenty-one children with hereditary angioedema had Type I and five suffered from Type II [70]. In either type, the onset age is between 6 and 20 years in subjects with positive $\mathrm{FH}$ [250], or within 2.5-12 years of age [70], but acquired forms develop in adults aged $>50$ [250]. In 11 members of a family, the mean age at onset of symptoms was 11 years [247]. In children $<10$, intestinal colic and edema of the extremities are the most frequent manifestations [69]. Edema formation primarily afflicted subcutaneous tissues. Mechanical trauma was identified as a precipitating factor in $80 \%$ of children [70]. A 10-year-old child died from laryngeal asphyxia, and an 8-year-old had membrano-proliferative glomerulonephritis [69]. C1-INH deficiency is evident when C1-INH concentrations fall under $15 \%-20 \%$ of normal and occurs frequently in patients with reduced inhibitor activity, in whom the lacking control of complement C1-esterase enzyme activity, and of activated Hageman factor, plasmin and kallikrein, lead to release of vascular permeability factors [60].

The additional five genetic syndromes are as follows [166]:

- Familial deficiency of C3b inactivator, autosomal recessive; the alternative pathway is activated with production of anaphylotoxins.

- Familial deficiency of carboxypeptidase-N, inactivator enzyme of anaphylotoxins and kinins.

- Muckle-Wells syndrome, autosomal dominant, with painful urticarial dermatitis, deafness of the perceptive type and renal amyloidosis.

- Melkersson-Rosenthal syndrome, with chronic orofacial noninflammatory tumefaction (tapiroid face), usually limited to lips, characteristic fissured tongue and relapsing facial palsies. Several patients reported with this autosomal dominant syndrome have no FH of the disease [142, 202]. Additives might be implicated in the pathogenesis [202].

- Episodic angioedema (from 1 week to 1 month) associated with eosinophilia, periodic attacks of fever, myalgia and oliguria; 8 out of 12 patients were aged between 2.5 and 18 [168]. Eosinophilia is usually associated with an increase in IgE and/or IgM levels; the pathogenesis is based on T-lymphocyte activation with production of interleukins $\left(\mathrm{IL}_{1}\right.$ and $\left.\mathrm{IL}_{2} \mathrm{R}\right)$ [168]. An adolescent had similar symptoms and an $\mathrm{IL}_{5}$ elevation [8]. An increased $\mathrm{IL}_{6}$ production could be related to blood monocytes and endothelial cells stimulated by an eosinophil mediator [208].

Vibratory angioedema described within the physical urticaria is also hereditary.

\section{Acquired C1-INH Deficiency}

Type I acquired C1-INH deficiency (35 cases) has been shown in patients with lymphoproliferative disease, especially B cell-mediated, such as chronic lymphocytic leukemia, macroglobulinemia, essential cryoglobulinemia, or lymphocytic lymphoma. These patients may have a nonfunctioning C1-INH, and extremely low C3 levels, or by C1-INH consumption at a higher level than that of re-synthesis. This is caused by an excessive $\mathrm{C} 1$ activation, with consequent $\mathrm{C} 1$ reduced serum levels, either via particular CIC (idiotype-anti-idiotope), which appear to fix C1q, or via anti-C1-INH Aabs, which block the normal activity of $\mathrm{C} 1$ inhibitor. The clinical manifestations are shared with those of hereditary forms [155].

Type II acquired C1-INH deficiency with C1-INH deficiency and IgA/IgG 1 Aabs directed at C1-INH: the resulting C1-INH functional block could lead to an uncontrolled activation.

Rare cases not belonging to either type may be recorded [155]. Briefly, these deficiencies depend on anti-C1-INH Aabs interfering with normal interactions between C1-INH and proteases, thus increasing C1-INH catabolism. Moreover, there is the risk that some patients may be associated with autoimmune disease, including LES, autoimmune hemolytic anemia, diabetes mellitus, rheumatoid arthritis, etc. [250].

\section{Pathogenesis of Urticaria}

Possible types of urticaria $[60,156]$ include:

1. Prevalently IgE-mediated

2. Complement-mediated

3. Drug- and/or additive-induced

4. Pseudoallergic (by agents directly releasing histamine)

5. Infection-induced

\section{Prevalently IgE- or Non-IgE-Mediated Urticaria}

\section{Apparently Primitive Urticaria}

Foods are common causes of urticaria in children, the mechanisms are immunological of type I [90], or nonIgE-mediated, or aspecific. There is insufficient proof to confirm a CIC role in urticaria syndrome. Glycoproteins with MW of $10-50 \mathrm{kD}$ are often responsible, since they resist enzyme digestion and heat denaturation. The 
foods most frequently implicated are fish (mostly cod), seafood $>\mathrm{CM}$ and dairy products $>$ peanuts and nuts $>$ egg $>$ fruits, etc., in some cases with IgE-mediated (55\%) or aspecific mechanisms (75\%) [90], and acute urticaria provoked by caresses after peanut contact (Table 7.22). In pediatric cohorts, urticaria was secondary to foods from $11 \%$ [144] to $57 \%$ [90] of cases. In young infants, CM and egg play a role [184], with cases of urticaria and shock by CM, peach and wheat at 4-6 months of life [90]. A wheat allergic boy experienced systemic urticaria and angioedema within $40 \mathrm{~min}$ after the ingestion of $9 \mathrm{~g}$ of packed rice crackers contaminated by $1.50 \mu \mathrm{g} / \mathrm{g}$ of wheat [137]. Two children seen by us showed severe urticaria while touching or eating a peach. The mother of one boy had urticaria by maize, pollens, and fruit in general. A drop of CM fell on the foot of a 10-month-old child and a generalized urticaria was spread to the whole leg. In two pediatric cohorts, urticaria was caused by CM in $18 \%-26 \%[40,60]$, peanuts in $63.6 \%$, tomato in $37.3 \%$ and egg white in $26.2 \%$ of cases [60]. In $67 \%$ of 100 children, the foods were implicated in this frequency order: eggs and nuts, fruit, CM, vegetables, fish and shellfish [67]. Fish often induces IgE-mediated urticaria-angioedema in children (60\%$92 \%$ of cases) $[41,49,164]$; urticaria on the face and arms in one boy following hand immersion in water used to wash codfish and in another after handling a raw peach, complicated the latter by glottis edema [184], have also been noted. As in our cases [41], if a fish-allergic child with $\mathrm{AD}$ eats a few milligrams of fish, he does not show worsening AD but persisting angioedema despite an elimination diet (Fig. 8.4). Fish provoked urticaria in $23.8 \%$ and urticaria-angioedema in $33.3 \%$ of 21 children by inhalation of airborne particles [49]. An uncommon case was elicited by a hemostatic sponge of bovine fibrin used in tooth extraction [242]. Immediate reactions have been reported after contact with apple, endive, lettuce, flour, garlic, honey, lamb, pear, potato, turkey, and wheat [184] (Table 8.1).

Inhalant allergens may occasion urticaria since they cross-react with food allergens (Table 1.73), or by direct skin contact: above all, exposure to inhalant allergens in children with AD may cause lesion flare-ups, preceded by urticarial lesions (Chap. 7). There might be a reduction at the threshold by which release of mast cell products can be induced (priming effect) during hay fever season. Grass pollens cross-react with peanut and tomato: in a pediatric study [60]: skin prick tests (SPTs) were positive to grasses more frequently than to Der p. A case similar to peanuts was angioedema, which occurred after stroking a cat (Fig. 8.2).

Urticaria associated with other conditions such as urticaria associated with $\mathrm{AD}$ may reach an elevated prevalence in children (Chaps. 5 and 7).

Insect bites and stings cause acute urticaria. Urticarial reactions can be part of a systemic reaction to Hymenoptera stings heralding potentially fatal anaphylactic reactions on subsequent stings.
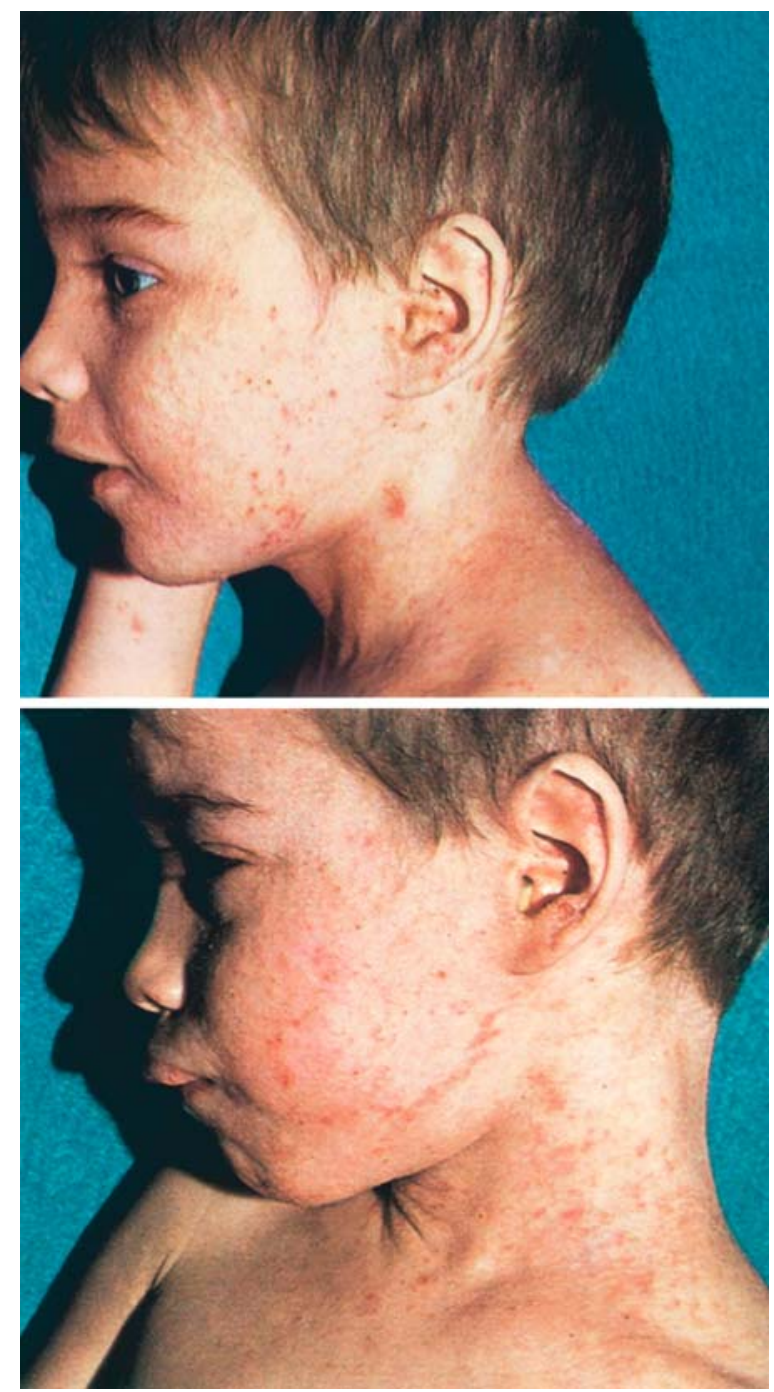

Fig. 8.4. Angioedema provoked by the ingestion of a few milligrams of fish in a fish-allergic child (for details see text)

\section{Complement-Mediated Urticaria}

Complement may be activated in different ways in urticaria [45, 157] (Table 8.1).

Classic pathway activation via aggregated immunoglobulins such as IgG and IgM in CICs, and the same mechanism may be active to a varying degree in other forms of urticaria, as well as in cases of myeloma or dermomyositis, etc.

Alternative pathway activation might result from venoms, antigens, radiological contrast media, complex carbohydrates (agar, dextran, polyvinylpyrrolidone, zymosan), polysaccharides and lipopolysaccharides (LPS) of the cell wall of Gram+ and Gram- organisms. Moreover, activated complement C3a, C4a, and C5a anaphylotoxins are capable of triggering mast cell histamine release, thus playing the pivotal role of possible mediators of urticaria [45]. 
Urticaria Induced by Drugs and/or Presumed Arachidonic Acid Metabolism Abnormalities and/or Additives

The whole spectrum of drugs are the most common causes of urticaria by pseudoallergic mechanisms in $29.8 \%$ [13] and in $22 \%$ of children [90]. ASA is the most usual and best studied drug that acts directly and even provokes relapses in subjects with chronic urticaria secondary to different causes. ASA was the most frequently used antipyretic [53.8\%) [13]. ASA also cross-reacts with NSAIDs in ASA-sensitive patients suffering from clinical manifestations following NSAID treatment, in addition to colorings and preservatives [59]. Other causative drugs were antibiotics (60.9\%) [13] or $47.7 \%$ [29], antipyretics $(35.1 \%)$, or a combination of antibiotics and antipyretics (16.2\%) [13]. Contaminant penicillin derivatives in CM or poultry meat routinely penicillin-treated may cause immediate allergic reactions or chronic urticaria [156], prevalently in highly sensitized subjects [157]; gastrointestinal symptoms are frequently elicited, but the food challenge test (FCT) is rarely positive [156].

The additives (Chap. 10) most often incriminated are as follows [59]: E102 (70\%), E110 (64.2\%), E127 (35.7\%), E160b (60.7\%), E211 (57.1\%), aspartame $(48.2 \%)$ and ASA (12.6\%). A cause-effect ratio is more evident in chronic urticaria, that is $30 \%-50 \%$ [60]. The pertinent role in children is unknown, since the related FCTs have rarely been done.

\section{Pseudoallergic Urticaria}

Several histamine-releaser foods, if ingested in sufficient amount, have the ability to act on mast cells by an aspecific mechanism, thus inducing urticarial reactions also in nonsensitized subjects. In both cases (immunological and nonimmunological mechanisms), the symptoms are practically overlapping, but a nonimmunological response is best defined as a pseudoallergic reaction $[18,60]$. Urticaria provoked by additives contained in prepared foods is a frequent finding among children consulting in our department.

\section{Infection-Induced Urticaria}

Urticaria may occur during parasite and infectious disorders, especially in chronic urticaria [159]. Among infections with helminths, oxyuriasis, and ascariasis are most diffused in infancy [175]. The underlying mechanisms are uncertain, such as urticaria in the prodromes of hepatitis B and infectious mononucleosis (IMN), either spontaneously or following ampicillin treatment [227]. Urticaria has been associated with enterovirus, cytomegalovirus (CMV), and other infections, but clinically these infections are not unlike those of different etiology. Among 44 children aged 1-12 [22 aged 1-2), $90.9 \%$ had symptoms of respiratory tract infection, suggestive of viral infection in $79.5 \%$ [29]. Infection, either associated or not with drug intake, was the cause in 46 children $(81 \%)$. The organisms were enterovirus (50\%), parvovirus B19 (20\%), Epstein-Barr (15\%), and mycoplasma (15\%) [29].

In conclusion, a cause was suspected in 28 out of 52 children $(54 \%)$ such as a viral illness $(19 \%)$, antibiotics ( $15 \%)$, or a combination (35\%) [169]. Even if the pathogenic mechanisms appear to be numerous, conflicting with clinical monomorphism, they may actually be related to a few vasoactive factors that play a role of potential mediators [175].

\section{Clinical Presentation}

Urticaria (Fig. 8.1) is a skin eruption characterized by raised, erythematous wheals, with defined or serpiginous borders, irregular form (usually oval), color varying from pink or reddish to whitish, surrounded by normal skin or by a bright-red flare, and with variable form, seat extension and duration. These lesions, accompanied by intense itching, are fleeting and resolve completely within $24 \mathrm{~h}$ of onset, especially after Hymenoptera stings, without leaving any trace, even if new elements may follow while the old ones clear. Lesions lasting longer should raise suspicion for the diagnosis of vasculitis presenting as urticarial lesions Wheals vary in size (from 1-2 mm to $1-2 \mathrm{~cm}$ ) and number and in some cases undergo a coalescence involving very large areas (giant urticaria) up to $10 \mathrm{~cm}$ in diameter and assuming the aspect of a geographical map. Urticaria may be generalized or localized and in the latter case the lesions affect preferentially the trunk and limbs, but also the palms and soles, the face and scalp. An important characteristic is that the color typically blanches with pressure; this simple test is helpful to differentiate an erythema from a skin hemorrhage [117].

Acute allergic urticaria is an IgE-mediated allergic reaction associated with systemic anaphylaxis. It is extremely common, possibly affecting about $10 \%-20 \%$ of the general population. Most frequently, this a self-limited disorder [103]. However, excluding drug reactions and insect stings, acute allergic urticaria comprises $2 \%-6 \%$ of the total number of urticaria cases seen in a dermatology clinic [117]. This is an eosinophil-driven disease, as demonstrated by a study on 19 infants and children aged from 9 months to 8 years and recruited from the emergency room while presenting with acute attacks of wheals and itching, accompanied by angioedema in seven subjects. Total serum IgE levels were above the highest normal for their age. The eotaxin values were significantly higher than the controls' corresponding values. As a potent eosinophil selective chemoattractant, eotaxin is a chemokine that promotes the selective recruitment of eosinophils, the major effec- 
tor cells in allergic inflammation. Eotaxin is thus implied in the causation of the tissue eosinophilia that characterizes allergic acute urticaria and may also be a biomarker of lesional activity [95].

Angioedema (Figs. 8.2, 8.4) is sometimes referred to as angioneurotic edema, coined by Osler who did not refer to neurosis at this time [158]. Isolated angioedema is rather rare at the pediatric age, is more often a symptom of a generalized anaphylactic manifestation, as when it is caused by an insect sting [175]. In 26 children, pedigree analysis revealed 19 patients with afflicted relatives, and clinical manifestations of the disease first occurred at 2.5-12 years of age [69]. Angioedema was caused by food in $40 \%$ (Fig. 5.12), insect bites in $30 \%$, infection in $20 \%$, and an antibiotic in $10 \%$ of children [187]. The swelling involves deeper skin layers with fewer mast cells and nerve endings, and is thus painless and nonpruritic. It is characterized by gradual onset of circumscribed bouts of edema, localized in subcutaneous tissue, skin and mucosa, more evident in the face, lids, lips, tongue, upper airways, gastrointestinal mucosa and less in the limbs, involving the mucosa to varying degrees and discomfort, accompanied by extreme weakness. Incidence of angioedema of the head or neck, most often facial was $80 \%$, tenderness or pain $40 \%$, dyspnea $30 \%$, dysphagia (including drooling and spitting) $30 \%$, and hoarseness $10 \%$ [187]. The clinical manifestations, self-limited and present in two-thirds of cases in patients up to 13 years of age, are usually preceded by local trauma, also mild, such as local inflammation, minor surgery, dental extraction, fatigue, and emotional stress, sometimes without an apparent cause [60]. It is characterized by recurrent attacks of self-limiting angioedema affecting the face, limbs, gastrointestinal system and upper airways [247]. Additional symptoms are erythematous rashes, pleuritic pains, urinary retention and seizures or hemiparesis, sometimes simulating a cerebral edema. The swelling progresses over hours, commonly increasing over 12-72 $\mathrm{h}$ and then subsiding over 1-3 days, leaving a normal-appearing skin [155]. The frequency may vary from a single episode over the entire life to weekly recurrences.

Gastrointestinal exacerbations may cause vomiting, watery diarrhea, colicky abdominal pain and guarding, but in the absence of fever and leukocytosis there is instead enteritis [103]. When the intestinal mucosa is involved, an occlusive syndrome may occur with subintrant colic and other symptoms mimicking an acute surgical emergency, sometimes resulting in unnecessary exploratory laparotomies and even appendicectomy [237], regardless of signs of peritoneal irritation. Extravascular fluid leakage to gut edema can lead to hypotension and hemoconcentration [155]. The most severe complication is laryngeal edema, which, when not treated quickly and aggressively, can be lethal; the laryngeal involvement provokes death by asphyxia [169]. Usually an asphyxial crisis is not suddenly precipitated, because in certain cases the attack, before the real appearance of swelling, is preceded by dysphagia, dysphonia and other prodromic signs such as subjective sensation of pharyngeal prickling, pruritus or burning. Subsequently a sensation of painful tension precedes the edema. These are warning symptoms allowing the timely institution of medical therapy, thus eluding tracheostomy [103]. In these patients, oral surgery represents a particular danger since edema can easily progress to upper airway obstruction. Trauma precipitates facial and airway edema via dental manipulation or adenotonsillectomy. Normal activity such as writing and/or computer typing are causes precipitating hand edema. In rare cases, symptoms can be triggered by infections [237].

\section{Physical Urticaria}

Physical urticaria can be subdivided into thermal, mechanical and cholinergic urticaria, with an $8 \%$ incidence in children [90]. In some patients more than one type of physical urticaria may be present (Table 8.1, Fig. 8.5) [42].

EIA syndrome with a family tendency, is rather rare and differs from other physical urticaria due to its sporadic occurrence. Four clinical phases have been proposed: (1) the prodromal manifestations are cutaneous (pruritus, warmth, flushing and fatigue), (2) early symptoms include urticaria and angioedema, (3) the full-phase symptoms are respiratory and gastrointestinal and (4) as in phase 1, and less often shock [183]. Occasionally the symptoms occur without a break. Triggering factors are cold and certain foods and drugs [42]. Three clinical forms have been described: one is EIA occurring after jogging started within $2 \mathrm{~h}$ of any meal (postprandial EIA), another form occurs only following a specific food ingestion, and the third when no food is identified [190]. High histamine concentrations and mast cell degranulation were detected in skin biopsies [190] (see Chap. 20).

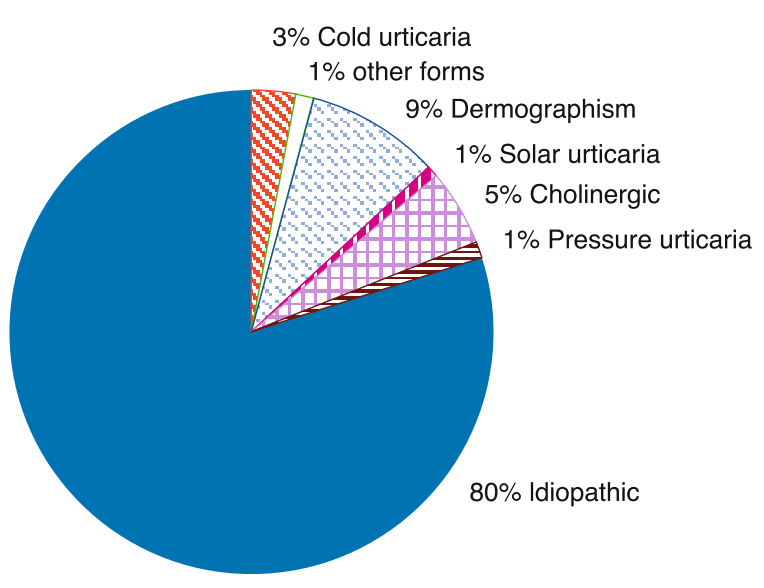

Fig. 8.5. Forms of physical urticaria 
Dermographism or dermographic urticaria, meaning literally writing on the skin, is the commonest physical urticaria, which is seen in about $5 \%-10 \%$ of normal subjects without a sex predilection [103]. In 238 children aged 2-14 years, the prevalence was $24 \%$, with a significant predominance of females (33\%) over males (16\%) [136]. Following the application of a linear pressure or a gentle friction, there is characteristically the production of a wheal (diameter $>2 \mathrm{~mm}$ ) and flare reaction. If the skin is stroked with a wooden tongue-depressor, a fingernail, an instrument with blunted point (a key), or a retracted ball point pen [156], within 2-3 min the usual white line secondary to reflex vasoconstriction is followed by pruritus, flushing and a linear edema, which occur exactly in the distribution of the stimulus $[111,175]$. A positive response occurring at a stroke pressure of $3.6 \mathrm{~g} / \mathrm{mm}^{2}$ of skin surface or less confirms the diagnosis. Less obvious triggers are pressure from clothes or leaning against a chair [117]. Three types of dermographism have been reported according to the chronology of the wheal and flare reaction, following a stimulus application:

$\begin{array}{lll}\begin{array}{l}\text { Type } \\ \text { 1. Immediate } \\ \text { (common) }\end{array} & \begin{array}{l}\text { Onset } \\ 2-5 \mathrm{~min}\end{array} & \begin{array}{l}\text { Duration } \\ 30 \mathrm{~min}\end{array} \\ \begin{array}{l}\text { 2. Intermediate } \\ \begin{array}{l}\text { 3. Late onset, } \\ \text { delayed (rare) }\end{array}\end{array} & 30 \mathrm{~min}-2 \mathrm{~h} & 3-9 \mathrm{~h} \\ & 4-6 \mathrm{~h} & 24-48 \mathrm{~h} \mathrm{[111]}\end{array}$

Symptoms are more common on the trunk and limbs and are differentiated by the classic triple response because minimal stimuli lead to extreme responses. Many subjects are carriers of a mild dermographism, while a wheal response to the mechanical skin stimulus is less frequent. An association between skin and bronchial hyperreactivity (BHR) has been suggested in children with dermographism [136]. In about $70 \%$ of patients, a passive antibody-mediated transfer (Prausnitz-Küstner reaction) has been documented, which underlies an IgEmediated reaction, along with findings of mast cell degranulation histamine release [183] or mechanisms involving IgM antibodies [117].

Variant types of dermographism have been described $[67,183,233]$ :

constitutional, its onset is often in infancy and duration may be lifelong.

acquired primitive, with a sudden onset and a duration of 1-2 years.

acquired secondary, associated with cutaneous mastocytosis, upon challenge with penicillin or insect sting, or in patients with hyperthyroidism, scabies, etc.

cold-dependent, the classic wheal is produced only during skin cooling, but not if the skin is stroked when skin temperature $(\mathrm{T})$ is normal.

delayed form, causes burning and pain instead of pruritic symptoms.

Pressure urticaria, initially classified as a rare familial variant of dermographism. DPU appears commonly after 6-24 h or more after pressure has been applied for a period as short as 2-3 min. Pressure areas are diffused and result from prolonged sitting on a nonupholstered seat; wearing tight clothing and straps, watches, belts; wearing tight shoes; or walking, jogging, and climbing ladders. Swelling of the soles of the feet may limit ambulation and become progressively disabling. The typical lesion is painful as it is deep-seated and edematous [183]. The trunk, buttocks, feet and hands are the regions affected in 95\%-98\% of cases [64]. Reactions persist for $36 \mathrm{~h}$ on average and for $86 \mathrm{~h}$ at most [64], so that the more delayed types are practically indistinguishable from delayed dermographism [42]. Immediate forms are full-blown within $30 \mathrm{~s}$ to $4 \mathrm{~min}$. Skin biopsies reveal signs of vasculitis with neutrophils in the lower dermis and subcutaneous tissue $4-5 \mathrm{~h}$ after peak swelling, then lymphocyte infiltrate after $24-48 \mathrm{~h}$, thus denoting a cellmediated immunity (CMI), with tissue eosinophilia but not in the bloodstream [225]. A mechanism elicited by histamine probably coexists, with participation of axonal reflexes and neuropeptide involvement as SP [156]. The increased $\mathrm{IL}_{1}$ levels may contribute to leukocyte recruitment and systemic symptoms such as fever and malaise [117]. Up-regulation of adhesion molecules CD62E and CD106 has led to the hypothesis that vascular endothelial activation plays an early role in the lesion upsurge [19].

Cold urticaria refers to a group of urticarial manifestations induced by exposure to the cold such as typical (primary, secondary) and atypical, familial immediate or delayed, and acquired systemic or localized:

Primary typical cold urticaria (idiopathic) is characterized by a rapid onset (2-5 min) after a local cooling induced by a blunt decrease, even of $1{ }^{\circ} \mathrm{C}$, of body $\mathrm{T}$, with itching, burning, flushing and edema limited to coldexposed skin (face, limbs) occurring on skin rewarming even after $1 \mathrm{~h} \mathrm{[42].} \mathrm{An} \mathrm{act} \mathrm{of} \mathrm{short} \mathrm{duration} \mathrm{is} \mathrm{sufficient,}$ such as holding cold objects or drinking cold beverages may produce hand or lip swelling, respectively. Eating cold foods may also cause a glottis edema. Total body exposure to cold such as showering or bathing in cold water, especially in open places with further cooling, may produce such widespread vasodilation that severe hypotension and collapse ensue, and in extreme cases even death by drowning for persons diving into cold waters, often labeled "faintness" [111, 233]. Histological findings often overlap with those of other physical forms. In children aged 12.6 years, atopy was present in $67 \%$ of cases, and girls more frequently had cold urticaria, other types of physical urticaria were present in $25 \%$ with no familial inheritance; $83 \%$ of children had localized and generalized symptoms [181]. Among 30 children $<18$ years old, the age of onset was at $\approx 7$ years, with a strikingly high rate of asthma (46.7\%) and AR (50\%), and a FHA of $89.3 \%$; $33 \%$ had anaphylactic reactions [4].

Secondary typical cold urticaria is associated with cryoglobulinemia, cryofibrinogenemia, cold hemagglu- 
tinins and hemolysins; complement deficiencies; urticarial vasculitis; viral infections (IMN); insect stings or drugs (griseofulvin, penicillin) [175].

Atypical cold urticaria has varying manifestations and syndromes:

1. Systemic or generalized cold urticaria has systemic symptoms characterized by giant urticaria and negative ice cube test [110] (ICT).

2. Two rare familial types of cold urticaria (20 cases) plus four large North American families [93], both with autosomal dominant trait: in the immediate type mapped to chromosome 1q44, burning papules or macules appear after $30 \mathrm{~min}$ to $4 \mathrm{~h}$ associated with chills, fever, arthralgias and neutrophil leukocytosis. In the delayed type, they occur in the skin area of cold exposure after 9-18 h, accompanied by burning with absence of pruritus. In several cases, histological features include mast cell degranulation and an increase in blood histamine levels following cold exposure. In other cases, the IgE-mediated reaction is passively transferred $[100,233]$. This syndrome is associated with the CIAS1 gene $[62,93]$.

Acquired cold urticaria manifestations and syndromes:

1. Cold-induced cholinergic urticaria and cold-dependent dermographism, appearing after cold exposure. These forms are linked to both delayed cold urticaria and systemic types by ICT negativity [233].

2. Localized cold urticaria affects certain areas of the body after cold contact under specific predisposing conditions mostly related to cold injuries or insect stings [111].

In most of these syndromes, the most closely studied pathogenic aspect is the participation of histamine; TNF- $\alpha$-induced mast cell release is relevant, which could be implicated in shock-like clinical manifestations [209].

Solar urticaria ( $1 \%-4 \%$ of urticaria cases), rare in children [240] and familial cases, affects both sexes, usually when they are $<30$ [141]. Within $30 \mathrm{~s}$ to $3 \mathrm{~min}$ after skin exposure to sun or UV (ultraviolet) spectrum light, patients note erythema preceded by, or immediately followed by, pruritus and then wheals $(5-10 \mathrm{~mm}$, persisting for $15 \mathrm{~min}$ to $3 \mathrm{~h}$, less if patients take shelter in a shaded place [42]. Patients complain of itchy, pricking, tingling, or burning lesions. If a sufficiently large area of skin is exposed, systemic symptoms up to anaphylaxis may occur [183]. In about $25 \%$ of cases, it is associated with dermographic urticaria or with a history of $\mathrm{AD}$ [141]. A rare delayed form is characterized by a 17- to 72-h time-lag for lesion onset [111]. An axon-induced flare encircles the area with changing borders beyond the involved sites [111]. This disorder has been classified into six different types depending on the wavelengths of light to which patients react: only types I and IV can be passively transferred and may be antibodymediated. In type VI, or erythropoietic protoporphyria, protoporphyrin IX acts as a photosensitizer activated by sun rays with a wavelength of $400 \mathrm{~nm}$ [197]. Skin biop- sies show neutrophils and eosinophils within a time-lag of $5 \mathrm{~min}$ to $2 \mathrm{~h}$, replaced by PBMCs after $24 \mathrm{~h} \mathrm{[151]} \mathrm{and}$ eosinophils degranulate in skin lesions with MBP deposition [121].

Contact urticaria with erythematous and wheal-like eruptions is aroused 30-60 min after normal skin exposure to the offending substance, most often induced by nettles and certain vegetables (see "Phytodermatitis"), some coelenterates such as jellyfish, as well as drugs, foods, cosmetics, fragrances (cinnamic aldehyde), chemical substances (disinfectants and bleaching), cat, dog, horse hair (in order of frequency), etc. [103]. Contact can be achieved via airborne agents, including grass pollen, as in sensitized children walking outdoors during days or in places with notable pollination, or playing in the grass, etc., or indirectly via toy contamination with pollens. Food allergens include egg, CM, tomato, chicken, honey, peanut butter, sunflower seeds, and cooked chick-peas $[1,115]$, also during their manipulation by children affected with oral allergy syndrome (OAS). Symptoms are usually elicited within 30-60 min; cases with onset delayed up to $6 \mathrm{~h}$ have been reported.

There are four clinical forms [117]:

- Contact urticaria, localized, the most frequent, usually caused by foods and pet danders.

- Contact urticaria with angioedema, also with systemic manifestations, often formaldehyde-induced.

- Contact urticaria with asthma, sometimes associated with gastrointestinal and oculorhinitic disorders. the onset is triggered by cephalosporins, various vegetables and processionary caterpillars, whose urticating hairs caused toxic-irritative effects on both skin and mucosa by direct contact as in 60/653 children $(9.18 \%)$ with 4 IgE-mediated cases (6.7\%) [222], and on the airways by aerodispersion (allergen Tha $\mathrm{p} 1$, Table 1.74).

- Contact urticaria with anaphylactic shock, a severe reaction often associated with penicillin, neomycin, bacitracin, etc.

A delayed type of contact urticaria is limited to some families.

Contact urticaria can be categorized into three groups from the pathogenetic point of view [115]:

- Immunological contact urticaria, almost always IgEmediated: Table 8.2 [115].

- Nonimmunological contact urticaria, mostly triggered by preservatives or additives employed the world over (Table 8.2).

- Urticaria characterized by an undefined mechanism including OAS and protein contact dermatitis; see, respectively, Chap. 9 and the second part of this chapter. - Vibratory angioedema, a hereditary disorder more commonly transmitted as an autosomal dominant condition, arising in children and persisting into adult age, decreasing progressively in severity [42]. Patients complain of pruritus, erythema, edema and wheals of 5-10 $\mathrm{mm}$, within minutes in response to the application to the skin of an even gentle vibratory stimulus and lasting up to $24 \mathrm{~h}$, depending on the stimulus and body sur- 
Table 8.2. Substances producing immune contact urticaria and nonimmunological urticaria

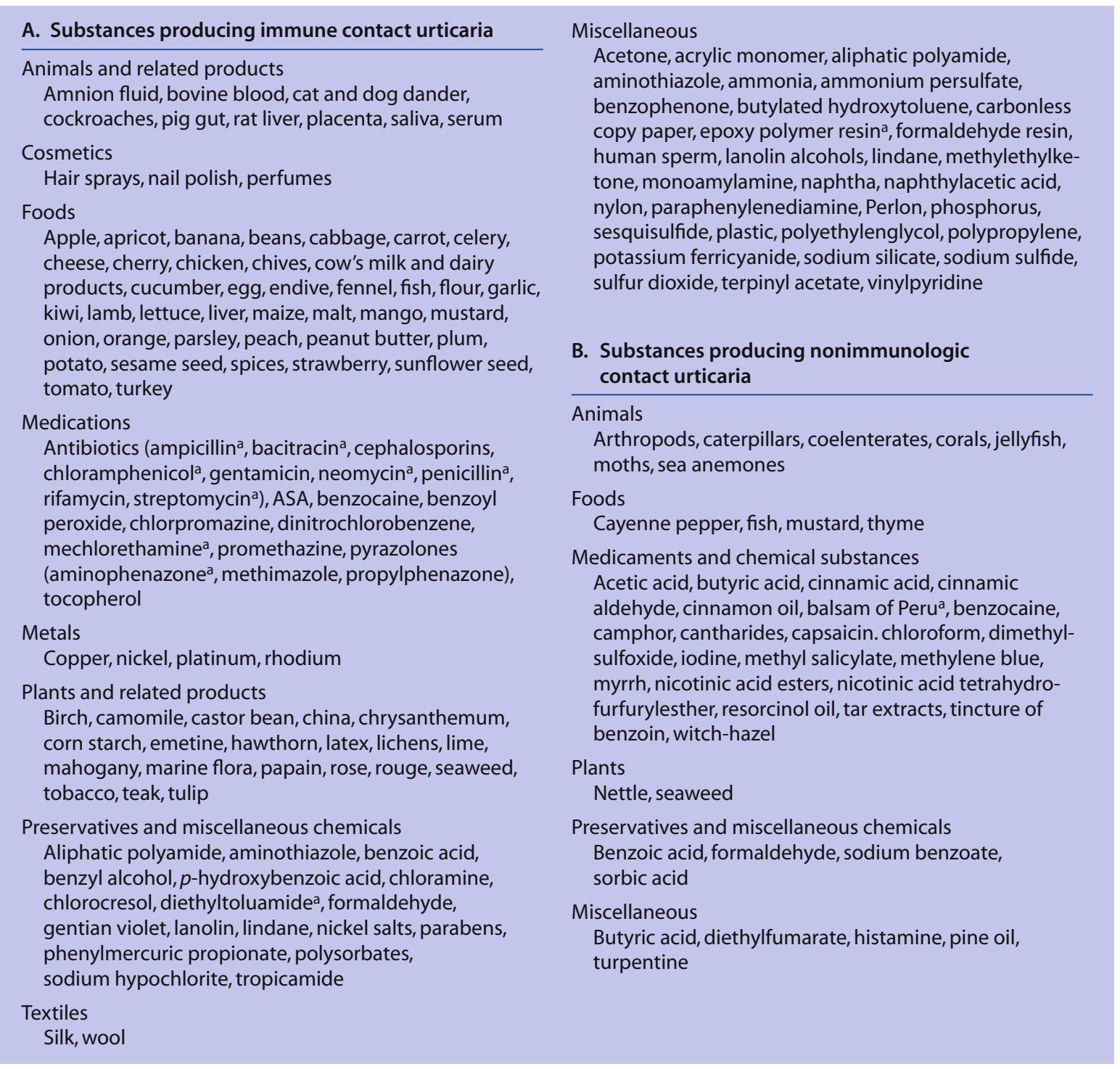

Modified from [115].

a Substances that have caused local reactions and anaphylactic symptoms in skin tests.

face area involved. If the stimulus is appropriately intense a systemic reaction may occur, inciting stimuli are motorcycling, toweling, massaging, and the like. A form with delayed onset (4-8 h) and one acquired idiopathic form have been reported $[42,103,111]$.

- Aquagenic urticaria is another rare form: 15 pediatric cases have been recorded $[129,146,163,236]$. Age ranges from 2-15 months [146] to 7 years [163]; eight children had associated symptomatic dermographism $[146,163]$. A familial tendency has been observed in 11 families $[146,183]$, in one family over three generations in association with familial lactose intolerance [213]. Affected individuals develop pinpoint wheals after skin contact with water, snow, or more or less intense perspiration, regardless of the T [183]. The lesions (pruritic wheals of 1-3 $\mathrm{mm}$ ) predominate on the trunk and, less often on forelimbs, occur from 2-3 min to $30 \mathrm{~min}$ after exposure to water [156]. On immersion, seven babies became pale, hypotonic, still and unreactive [146]. The lesions may subside after $30 \mathrm{~min}$ [156]; however, recovery took a few seconds after withdrawal from the bath and stimulation [146]. These features may even go unnoticed [156]. Biopsy specimens of the lesions reveal mast cell degranulation and hyperhistaminemia; also a cholinergic mechanism seems to play a role [183]. The sex ratio is unfavorable to females (2:1) at puberty or pre-puberty age [238].

- Cholinergic or thermolytic urticaria, also known as generalized heat urticaria, along with dermographism is the most common physical urticaria ( $5 \%-7 \%$ of all urticaria forms), prevalently affecting adolescents and young adults. Prodromic signs may 
Table 8.3. Ascertained causes of chronic urticaria in children (\%)

\begin{tabular}{|llllllllll}
$\begin{array}{l}\text { No. of } \\
\text { children }\end{array}$ & $\begin{array}{l}\text { Age } \\
\text { (years) }\end{array}$ & $\begin{array}{l}\text { Ascertained } \\
\text { causes }\end{array}$ & $\begin{array}{l}\text { Physical } \\
\text { forms }\end{array}$ & $\begin{array}{l}\text { Infec- } \\
\text { tions }\end{array}$ & Foods & $\begin{array}{l}\text { Inhalant } \\
\text { allergens }\end{array}$ & Additives & Drugs & $\begin{array}{l}\text { Refer- } \\
\text { ence }\end{array}$ \\
\hline 226 & $1-14$ & 21.2 & 6.2 & 4.4 & 4.4 & 2.2 & 2.6 & 1.9 & {$[229]$} \\
\hline 97 & 4.5 & 78.5 & 5.1 & 2 & 14.4 & 8.2 & 18 & {$[18]$}
\end{tabular}

arise within 2-30 min of the triggering event, consisting of pruritus, tingling, warmth, or burning of the skin [183]. The ensuing cutaneous manifestations are erythematous and wheal-like, 1-3 mm in diameter, with surrounding bright red flares. These may become confluent to form intensely itching papular wheals, which appear abruptly after variations in ambient $\mathrm{T}$ or changes in body $\mathrm{T}$ following fever, intense sweating after vigorous exercise, hot showers or sauna, intense transient emotional stimuli, often accompanied by symptoms of cholinergic stimulation, such as lacrimation, salivation and diarrhea, with the involved area returning to normal after about $1 \mathrm{~h}[117,175,183]$. In severely ill patients, systemic symptoms such as angioedema and cardiovascular, respiratory or gastrointestinal signs may be associated with anaphylaxis [156]. A similar picture can be produced in affected individuals by acetylcholine: it is postulated that pathogenic mechanisms are based on body $\mathrm{T}$ increase and the following skin exposure to a warm stimulus can affect the higher nerve centers [197]. Thus, acetylcholine release may be evoked along peripheral nerve endings, also inducing histamine release, probably by a direct action of cholinergic receptors on mast cells [197].

- Cholinergic cold urticaria occurs when systemic cold contact produces a form similar to cold urticaria $[4,181]$.

- Localized heat urticaria, also rare (18 cases) is apparent with immediate urticarial reactions within $5 \mathrm{~min}$ after heat application, for example warm water [54] at a $\mathrm{T}$ of $43^{\circ} \mathrm{C}$ and lasting about $1 \mathrm{~h}$, with increased plasma histamine levels [42]. A 5-year-old girl developed sudden-onset episodes of pruritus (after $3 \mathrm{~min}$ of heat exposure), redness, and local skin swelling, which resolved within $90 \mathrm{~min}$. Histamine increased at $3 \mathrm{~min}$ after heat challenge and then declined [134]. A delayed familial localized heat urticaria is very rare; lesions appear 6-18 h after exposure to localized thermal stimuli and last 12-24 h [111].

The mother of a child seen by us experiences urticaria to both cold and warm objects or even the weather.

\section{Chronic Urticaria}

Chronic urticaria is defined as persisting or recurrent urticaria lasting $>6$ weeks, which may be presently considered the most frequent cause of urticaria [18]. In follow- ups, several cases may progress from acute to chronic urticaria, for example $12(30 \%)$ of 40 children in one study [144]. In three studies on 366 children aged 1-14 [18,201, 229], several causes were ascertained, summarized in Table 8.3 [18,229], including physical forms (cholinergic, dermographic, cold and pressure urticaria), infections (parasites and/or streptococci), foods (CM, egg, fish, nuts), food additives (tartrazine, salicylates), aeroallergens (pollens, cat dander) and drugs (penicillin, phenobarbital). In $75 \%$ of children, urticaria was attributed to pseudoallergens such as coloring agents, preservatives, saccharin/cyclamate and monosodium glutamate [65]. In 43 children with additive sensitivity (32 also with angioedema), both SPTs and FCTs were positive in $2 \%-28 \%$ of cases [201]. We stress the cases provoked by yeast extract (Chap. 10) and penicillin [157]. In 132 children, in most cases the cause remained unknown (63.6\%) [13]. Chronic idiopathic urticaria syndrome applies to many patients without an easily identifiable cause; however, frequently these patients suffer from a chronic disease [89]. Recently, two youngsters were reported, one with positive autoimmune markers, the other with juvenile rheumatoid arthritis (JRA), thus opening the door to autoimmunity in the pathogenesis of chronic urticaria [54].

Histopathological features show that the preponderant cell types are $\mathrm{CD} 4^{+} \mathrm{T}$ cells predominant over $\mathrm{CD}^{+}$ $\mathrm{T}$ cells, and that mast cells degranulate [19], thus being considered the primary effector cells in chronic urticaria with a significant increase in number [19]. Significantly increased are intradermal $\mathrm{CD}^{+}, \mathrm{CD}^{+}, \mathrm{CD}^{+}$, and $\mathrm{CD} 25^{+}$ T cells, as well as eosinophils, neutrophils, basophils, and macrophages. T cells from these patients are characterized by a Th0 cytokine profile, with significant increases of $\mathrm{IL}_{4}$ and $\mathrm{IL}_{5}$ mRNA and cells positive for IFN- $\gamma$. A pattern distinct from that seen in the allergen-induced LPR, where IFN- $\gamma$ is absent [248]. An increased histamine release may be induced by nonspecific mast cell activation. It is unlikely that the histamine release is secondary to peripheral blood basophils [45]. Actually, basophils of these patients have a decreased releasability; thus mast cells as the source of spontaneously released histamine in these patients is further substantiated by increased tryptase levels in blister fluid [45]. On skin biopsies, there is evidence of neutrophils within capillary and post-capillary venular walls, but not of structural damage [89]. Spontaneous wheals show expression of CD62E and CD50 on vascular endothelial cells and of CD106 on perivascular cells [89]. 
Algorithm for suspected urticaria angioedema syndrome in children

History + Medical examination

$\downarrow$

Preliminary assessment

(SPT, tests to chemical-physical agents)

$\downarrow$

Clinical diagnosis of UAS

Urticaria predominates?

$\downarrow$

Assess the character of individual wheals
Angioedema predominates?

$\downarrow$

Measure serum C4 component

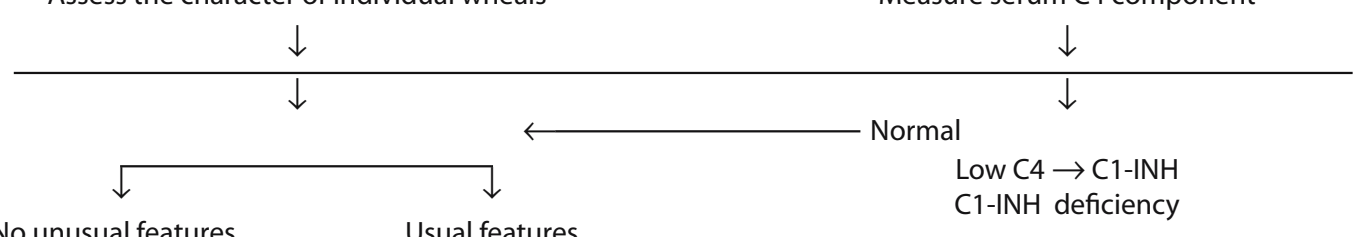

No unusual features

Usual features

$\begin{array}{ccccc} & \downarrow & \downarrow & \downarrow \\ \text { WBC counts } & & \text { CIC assay } & \text { Prist } & \text { Hereditary/acquired } \\ & & \downarrow & \text { RAST } & \text { Angioedema } \\ \downarrow & \downarrow & \text { CIC present } & \text { Diet } & \downarrow \\ \begin{array}{c}\text { Eosinophilia } \\ \downarrow\end{array} & \text { Normal } & \downarrow & \text { Deficiency } \\ \text { Examine } & \downarrow & \text { CIC disease } & \text { FPT } & \text { of C1-INH } \\ \begin{array}{c}\text { stools for ova, } \\ \text { parasites }\end{array} & & & & \end{array}$

Algorithm for diagnostic approach of patients with suspected hereditary angioedema

\begin{tabular}{|c|c|c|c|c|c|}
\hline & \multirow[t]{2}{*}{ C1-INH } & \multirow{2}{*}{$\begin{array}{l}\text { C1-INH } \\
\text { Funct. }\end{array}$} & \multicolumn{3}{|c|}{ Complement components } \\
\hline & & & $\mathrm{C} 1$ & $\mathrm{C} 4$ & $\mathrm{C} 3$ \\
\hline Hereditary angioedema type I & $\mathrm{D}$ & $\mathrm{D}$ & $\mathrm{N}$ & $\mathrm{D}$ & $\mathrm{N}$ \\
\hline Hereditary angioedema type II & $\mathrm{N}$ & $\mathrm{D}$ & $\mathrm{N}$ & $\mathrm{D}$ & $\mathrm{N}$ \\
\hline Acquired C1-INH deficiency type I & $\mathrm{D}$ & $\mathrm{D}$ & $\mathrm{D}$ & $\mathrm{D}$ & $\mathrm{N}$ \\
\hline Acquired C1-INH deficiency type II & $\mathrm{D}(60-70 \%)$ & $\mathrm{D}$ & $\mathrm{D}$ & $\mathrm{D}$ & $\mathrm{N}$ \\
\hline Chronic $\mathrm{ClC}$ disease & $\mathrm{N}$ & $\mathrm{N}$ & $\mathrm{D}$ & $\mathrm{D}$ & $\mathrm{D}$ \\
\hline Idiopathic angioedema & $\mathrm{N} / \mathrm{I}$ & $\mathrm{N} / \mathrm{I}$ & $\mathrm{N}$ & $\mathrm{N}$ & $\mathrm{N}$ \\
\hline ACE inhibitor-induced angioedema & $\mathrm{N}$ & $\mathrm{N}$ & $\mathrm{N}$ & $\mathrm{N}$ & $\mathrm{N}$ \\
\hline
\end{tabular}

Fig. 8.6. Algorithm for diagnostic approach of children with suspected urticaria angioedema syndrome (UAS; top) and suspected hereditary angioedema (bottom). Top: CIC circulating immune complexes, FPT food provocation test, FPT/ad with

\section{Psychogenic Urticaria}

Psychogenic factors may exacerbate symptoms of urticaria-angioedema due to diverse causes; however, it is insufficiently understood whether they are primary or associated with other unidentified factors. additives, WBC white blood cells. (Modified from [89]). Bottom: 1 inhibitor, $A C E$ angiotensin-converting enzyme, Funct functional, $D$ decreased, $N$ normal, $I$ increased. (Modified from [155])

\section{Diagnosis}

A complete etiological diagnosis (Fig. 8.6) [89, 155], with particular attention paid to the patient's history (Table 8.4) [53] and a thorough physical examination $[89,103,155,156,233]$ are necessary tools for the evaluation of children with urticaria. 
Table 8.4. Flowchart for the diagnosis of urticaria and related forms of angioedema

\begin{tabular}{|c|c|c|}
\hline Features & Manifestations & Diagnosis of urticaria (angioedema) \\
\hline Genetic factors & & Hereditary angioedema, some physical urticaria \\
\hline $\begin{array}{l}\text { Duration } \\
\text { of clinical symptoms }\end{array}$ & $\begin{array}{l}<6 \text { weeks } \\
>6 \text { weeks }\end{array}$ & $\begin{array}{l}\text { Acute } \\
\text { Chronic }\end{array}$ \\
\hline $\begin{array}{l}\text { Onset related to the time } \\
\text { of stimulus application } \\
\text { Width of lesions }\end{array}$ & $\begin{array}{l}\text { Rapid } \\
\text { Delayed } \\
\text { Few wheals } \\
\text { Arciform } \\
\text { Giant, involving subcutaneous tissue }\end{array}$ & $\begin{array}{l}\text { All types } \\
\text { Pressure, cold, cholinergic, contact urticaria } \\
\text { Cholinergic, aquagenic, solar urticaria } \\
\text { Drug-induced urticaria } \\
\text { Angioedema, pressure urticaria }\end{array}$ \\
\hline Color & Yellow & Associated with hepatitis B \\
\hline Localization & $\begin{array}{l}\text { Contact and stroking } \\
\text { Contact with foreign substances } \\
\text { Photo-exposed sites } \\
\text { Pigmented sites } \\
\text { Points of pressure }\end{array}$ & $\begin{array}{l}\text { Dermographic urticaria } \\
\text { Contact urticaria } \\
\text { Solar, heat urticaria } \\
\text { Urticaria pigmentosa } \\
\text { Dermographic, pressure urticaria }\end{array}$ \\
\hline Duration of lesions & $\begin{array}{l}\text { Short } \\
\text { Long-term }\end{array}$ & $\begin{array}{l}\text { All types } \\
\text { Vasculitis, familial cold urticaria }\end{array}$ \\
\hline Causative factors & $\begin{array}{l}\text { Aeroallergens } \\
\text { Chronic disease } \\
\text { Cold } \\
\text { Exercise, foods } \\
\text { Exercise, stress } \\
\text { Foods, additives } \\
\text { Heat } \\
\text { Insects } \\
\text { Medications } \\
\text { Natural water } \\
\text { Rx-examinations } \\
\text { Sunlight } \\
\text { Vibrations }\end{array}$ & $\begin{array}{l}\text { Acute and chronic urticaria } \\
\text { Chronic urticaria } \\
\text { Cold contact, familial cold urticaria } \\
\text { Exercise-induced anaphylaxis } \\
\text { Cholinergic urticaria } \\
\text { Acute and chronic urticaria } \\
\text { Heat contact urticaria } \\
\text { Papular urticaria } \\
\text { Acute and chronic urticaria } \\
\text { Aquagenic urticaria } \\
\text { Acute and chronic urticaria } \\
\text { Solar urticaria } \\
\text { Vibratory angioedema }\end{array}$ \\
\hline
\end{tabular}

Modified from [53].

When hereditary angioedema is suspected, the history should be complete (FH may be negative in $20 \%$ of cases), especially investigating previous recurrent episodes of edema. Diagnosis is made by studying the complement components (C4, C3 and C2) and C1-INH levels (algorithm):

- In asymptomatic periods, the C4 level is decreased and the $\mathrm{C} 2$ level is normal; during the attacks the $\mathrm{C} 4 \mathrm{lev}$ el usually cannot be measured, $\mathrm{C} 2$ levels are reduced, C3 turnover is enhanced, and $\mathrm{CH} 50$ (50\% hemolytic complement) may be reduced.

- C1-INH immunochemical assay: the levels are reduced in $85 \%$ of cases; in the remaining $15 \%$ the levels are normal or increased, so that functional studies with enzymatic and immunochemical tests should be done [155].

- If C4 and C1-INH are very low, then C1-INH antigenic protein assay should be done to distinguish type I (low levels) from type II (normal) antigen, despite low functional protein [35].

In one family, $\mathrm{C} 1-\mathrm{INH}$ levels were undetectable or low in some patients and CH50 was undetectable in all of the patients. The C4 level was low, and in a 10-year-old boy diagnosis was based on low C1-INH, CH50 and C4, in addition to his FH [247].

Diagnosis has been successfully made at birth using cord blood and by examining C1-INH functionality [230].

Diagnosis of urticaria (Table 8.4) first requires a distinction between acute and chronic urticaria [44]:

- Genetic factors, atopy

- Aspect of the lesions

- Triggering causes

- Clinical manifestations

- Duration of clinical manifestations

- Associated symptoms

The child's lifestyle should be investigated, particularly food preferences and potential, continuous or occasional drug intake, as well as information on additives, inhalants, recent infections, stress, work, and hobbies [175]. The ability to establish a cause and effect recurrent relationship becomes particularly significant. It should be ascertained whether or not [44]:

- It is a clear-cut type of urticaria

- There is a pathogenic mechanism correlated with what has been ingested, inhaled, or injected 
Table 8.5. Foods that contain ASA, benzoates or colorings to be excluded from the diet

\begin{tabular}{|c|c|}
\hline Almonds, toasted & Fruit juices \\
\hline Apple & Grape \\
\hline Banana & Green peas \\
\hline Beans & Margarine \\
\hline Cabbage & Mayonnaise \\
\hline Carrot & Nuts of all types \\
\hline Cherry & Onion \\
\hline Citrus fruit & Parsley \\
\hline CM, powdered & Peanut \\
\hline Coca-Cola & Potato \\
\hline Cranberry & Red, green peppers \\
\hline Cucumber & Rhubarb \\
\hline Eggplant & Spinach \\
\hline Eggs, powdered & Strawberry \\
\hline Fizzy drinks & Vinegar \\
\hline \multicolumn{2}{|l|}{ In addition } \\
\hline \multicolumn{2}{|c|}{$\begin{array}{l}\text { Processed foods of all kinds, bottled, canned, cased, } \\
\text { dry packaged, frozen }\end{array}$} \\
\hline \multicolumn{2}{|c|}{$\begin{array}{l}\text { Gelatins, marmalade, soft drinks, ice-creams } \\
\text { and sherbets, yogurt }\end{array}$} \\
\hline \multicolumn{2}{|c|}{$\begin{array}{l}\text { Caramels of all kinds, chocolate and chocolate puddings } \\
\text { (not plain chocolate) }\end{array}$} \\
\hline \multicolumn{2}{|c|}{$\begin{array}{l}\text { Bakery foods, candies, cake mixes, chips, puddings } \\
\text { and pie fillers, pancakes, wafers }\end{array}$} \\
\hline \multicolumn{2}{|c|}{$\begin{array}{l}\text { Cheese, processed cream-cheese, macaroni } \\
\text { and cheese of all kinds }\end{array}$} \\
\hline \multicolumn{2}{|c|}{$\begin{array}{l}\text { Salad dressings, ketchup, mustard and other prepared } \\
\text { sauces (bearnaise, curry, hollandaise, tomato, fish) }\end{array}$} \\
\hline \multicolumn{2}{|c|}{ Smoked and frozen fish (anchovy, kipper, sardine) } \\
\hline \multicolumn{2}{|c|}{ Colored toothpaste, chewing-gum } \\
\hline
\end{tabular}

Diet in use in the Division of Pediatric Allergy and Immunology of Rome, University La Sapienza.

- There is a contact reaction (difficult to discern if $\mathrm{AD}$ coexists)

- There is an association with a systemic disease

- There are infectious episodes, past or present

For food-induced urticaria, a possible approach involves:

- When the reactions occur $<2-3$ times/week, it is useful and economic to record the ingested foods in a diary, a practice which focuses the attention of both the family and the child on food factors.

- When the manifestations recur with greater frequency or daily, a diagnostic elimination diet is prescribed, also to detect occult, clinically relevant allergens present in many different foodstuffs. A positive result indicates the opportunity to continue with SPTs or RAST, but
FPTs ensure conclusive evidence to be looked for only in children who have a history of previous food-induced anaphylactic shock. A possible therapeutic elimination diet is discussed in Chap. 9.

In additive-induced urticaria, countless food dyes and preservatives are suspected [59]. An elimination diet such as the one we prescribe should exclude ASA, benzoic acid and dyes (Table 8.5), frequently prescribed to the children seen in our department: a positive result validates the search for causative additives. (See Chap. 10 for a complete list.) A diet free of ASA and other pertinent additives is similarly helpful in children with drug-induced urticaria [227]. In our department we have noted that almost all children improve by eliminating all prepared foods, with no exception.

In the case of pseudoallergic urticaria, the abovementioned causes should be chosen among nonimmunological mechanisms. When aeroallergens are suspected, interventions for allergen avoidance should be scheduled. Total serum IgE levels could increase, with a possible peripheral eosinophilia [117].

\section{Physical Urticaria}

- EIA: it is important to assemble a circumstantial history. Then the patient is invited to run in place or on a treadmill for at least 5-10 min. Positive responses follow the four phases, sometimes a differential diagnosis with cholinergic urticaria may be necessary [190].

- Dermographism: by gentle stroking of the skin, in normal responses an immediate blanching followed by a red flare for $10 \mathrm{~min}$ is detected, in simple forms a linear wheal and flare appear lasting 10-15 $\mathrm{min}$ and in symptomatic forms there are pruritus with linear wheal and flare lasting $30 \mathrm{~min}$ to $3 \mathrm{~h}$. In the delayed variant, the wheal decreases within $20-30 \mathrm{~min}$, recurs in the same site by $3-8 \mathrm{~h}$ and persists for $24-48 \mathrm{~h}$. The diagnosis is confirmed by using the dermographometer (Fig. 8.7), which is pressed on the skin and a typical response occurs at the pressure of $3.6 \mathrm{~g} / \mathrm{mm}^{2}=3.5 \times 10^{5} \mathrm{~Pa}$ [117].

\begin{tabular}{|c|c|c|}
\hline Scale & Pressure equivalent \\
\hline 0 & $2.0 \times 10^{5} \mathrm{~Pa}\left(20.4 \mathrm{~g} / \mathrm{mm}^{2}\right)$ \\
\hline 5 & $5.87 \times 10^{5} \mathrm{~Pa}\left(59.9 \mathrm{~g} / \mathrm{mm}^{2}\right)$ \\
\hline 10 & $9.75 \times 10^{5} \mathrm{~Pa}\left(99.4 \mathrm{~g} / \mathrm{mm}^{2}\right)$ \\
\hline & 15 & $14.12 \times 10^{5} \mathrm{~Pa}\left(144.0 \mathrm{~g} / \mathrm{mm}^{2}\right)$ \\
\hline
\end{tabular}

Fig. 8.7. Dermographometer 


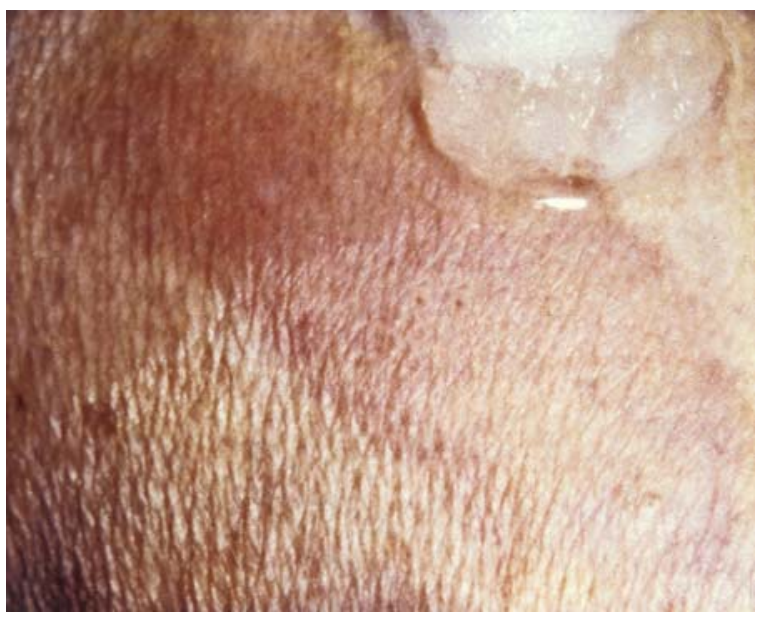

Fig. 8.8. Positivity of ice cube test in cold urticaria

- Pressure urticaria: hanging a 6-10 kg weight across the shoulder or thigh for 10-15 min will produce painful swelling at the pressure site after $4-8 \mathrm{~h}$. In younger children the pressure is adjusted according to age. In delayed pressure urticaria, the dermographometer is set at $9.75 \times 10^{5} \mathrm{~Pa}\left(99.4 \mathrm{~g} / \mathrm{mm}^{2}\right)$ and held firmly against the skin of the back for varying numbers of seconds [117].

- Cold urticaria:

- In the localized form, diagnosis is confirmed by placing an ice cube at $1{ }^{\circ} \mathrm{C}$ on forearm skin for $10-20 \mathrm{~min}$, then rewarming the skin until it returns to a normal T: within 5-20 min an edema appears matching the cube basis (Fig. 8.8). A negative test (and for systemic cold urticaria) is repeated by having the patient stand for $10-20 \mathrm{~min}$ in a cooled room at a $\mathrm{T}$ of $4{ }^{\circ} \mathrm{C}$ [110]. By the end of the test, characteristic wheals and flares develop, especially on the trunk and proximal aspects of the limbs, or giant urticaria [110] in $92 \%$ of cases [181]. Children with negative ICT at $10 \mathrm{~min}$ had similar symptoms and response to antihistamines as patients with positive ICT. All children with cold urticaria and their parents should be cautioned regarding the risk of anaphylaxis [4]. In selected cases it is necessary to test both cryoglobulins and cryofibrinogen [156].

- In systemic cold urticaria, the ICT is negative and the cooled room test positive. Levels of both histamine and $\mathrm{PGD}_{2}$ are increased $[140,156]$. Measuring blood histamine levels after a negative ICT appears to be a sensitive way to diagnose patients without risk of anaphylaxis during generalized cold exposure [140].

- The prevalence of secondary cold urticaria is $1 \%$; however, we recommend the related screening.

- Solar urticaria: a small skin area of $1 \times 1 \mathrm{~cm}$ for 1-2 min is exposed to a source of monochromatic light of various wavelengths for $10 \mathrm{~min}$ at a distance of $10 \mathrm{~cm}$. If the result is negative the exposure time-lag is increased. Fluorescent tubes, carbon arc, etc., in combination with emission of a broad wavelength spectrum, employing different filters to ascertain which one

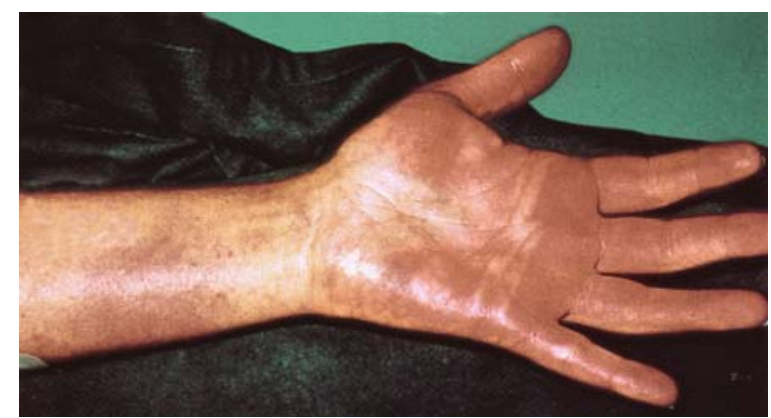

Fig. 8.9. Vibratory angioedema edema and erythema of the palm and forearm after the test

provokes urticaria [111, 183], are used. A differential diagnosis from erythropoietic protoporphyria requires measuring protoporphyrin and coproporphyrin levels [240].

- Contact urticaria: an accurate history and SPTs may disclose some offending agents such as topical drugs, diverse chemical substances, cosmetics, vegetable substances, pet danders, etc. The rub test may confirm the diagnosis, that is the suspected item is rubbed gently on normal skin, and inspected for signs of a reaction at 60 min [117].

- Vibratory angioedema: symptoms may be reproduced by gently stimulating the medial aspect of the forearm with a laboratory vortex for 4-5 min or laying a finger-pad on a common tube mixer for $10 \mathrm{~min}$. Positive responders should develop a pruritic circumferential edema, which distinguishes the condition from delayed dermographism and delayed pressure urticaria [42, 111] (Fig. 8.9).

- Aquagenic urticaria: challenge tests are performed using tap water compresses at $35^{\circ} \mathrm{C}$ or any other $\mathrm{T}$ applied to the upper body for $5-30 \mathrm{~min}$. Whealing is usually evoked at the site of contact with water [129, 238] after $20 \mathrm{~min}$ [129]. The condition responded to treatment with UV-B and oral antihistamines [163].

- Cholinergic urticaria: to reproduce the eruption, exercise such as jogging on the spot, running on a treadmill in a plastic occlusive suit, running up and down stairs with warm clothes or with an exercise bicycle should be continued until it provokes an increase in perspiration, or by half-body immersion in a hot bath $\left(42^{\circ} \mathrm{C}\right)$ to raise body $\mathrm{T}$. In case of a negative response, an intradermal test is done using $0.05 \mathrm{ml}$ of methacholine chloride at $0.02 \%$ or carbachol at $0.002 \%$, which in positive tests induce a localized whealing surrounded by flushing within $20 \mathrm{~min}$. The test is positive in $33 \%-50 \%$ of patients. However, it is rarely a reproducible test $[44,183]$.

- Localized heat urticaria: a heated cylinder with water heated to $50-55^{\circ} \mathrm{C}$ is applied to the skin for $5 \mathrm{~min}$ [42].

Chronic Urticaria. Patients are investigated according to the above-mentioned epidemiological data. Following this evaluation, the diagnosis is by exclusion, apart 
from cases clearly connected with foods [99]. Neither laboratory data nor SPTs to foods are of value in adults in whom up to $90 \%$ of cases remain unassessed [159], whereas the contrary is true in children, both for foods $[18,229]$ and additives $[18,201,229]$. In a 6 -year-old boy with a 3-month history of recurrent, severe angioedema episodes a diagnosis of autoreactive chronic urticaria (ACU) was made after an autologous serum skin test (ASST) [10].

\section{Differential Diagnosis}

The differential diagnosis [45] includes the following disorders:

- Exanthematous infections in children and EBV, CMV, coxsackie, rotavirus infections, certain infestations by parasites and microbial infections.

- Papular urticaria, provoked by insect bites in exposed areas, is characterized by pruritic papules and wheals, with immediate or delayed onset, expressing immunological mechanisms of type I or IV, respectively. The lesions are often located on the lower limbs and tend to persist longer than urticarial lesions, most frequently seen in young children [103].

- Erythema multiforme, a self-limited disorder, typically characterized by pruritic urticarial lesions, wholly similar to urticaria in the earlier stages, which last longer and may have a targetoid aspect evolving into bullous lesions. It is more often located on the dorsal surfaces of both hands and feet, frequently misdiagnosed as urticaria.

- Dermatitis herpetiformis is seen in children aged 3-7 years. The early lesions have an evident urticarial component. Sites of predilection are the shoulders, elbows, knees and buttocks, often confused with cholinergic urticaria.

- Urticaria pigmentosa is a localized mastocytosis occurring in infants and children before the age of 10 , with most cases developing in the 1st year of life [12]. Individual macules or papules, and nodular, lichenoid or plaque-like lesions range in color from pink to salmon, and in size from a few $\mathrm{mm}$ to several $\mathrm{cm}$, which, when stroked, form a linear pruritic wheal, Darier's sign, the hallmark for clinical diagnosis. The condition usually fades at puberty; a skin biopsy may confirm the diagnosis $[45,61]$.

- Juvenile urticaria pigmentosa occurs at birth or in the 1 st months of life and takes the form of a solitary nodule $1-5 \mathrm{~cm}$ in diameter (mastocytoma), most often on the back of the hand, wrist, neck, or the lesions may present as disseminated macule, plaques, or bullae, ranging in color from red-brown to yellow-tan. It most commonly fades at puberty.

- Systemic mastocytosis is similar to urticaria pigmentosa, but uncommon and more severe. It is characterized by onset in the first few months of life and mast cell accumulation in the dermis, bone marrow and gastro- intestinal tract and clinically, by congestion, migraine and hypotension secondary to histamine release [166].

Urticaria as a sign of systemic disease: urticaria may be the only sign of infections caused by bacteria, viruses, yeasts, and molds. Several parasitic infections are causative agents in urticaria and eosinophilia, such as infestations by Ancylostoma, Ascaris, Echinococcus, Fasciola, Filaria, Schistosoma, Strongyloides, Toxocara, Trichinella, etc. Urticaria may be associated with malignancy, endocrine disorders (hyperthyroidism, hypothyroidism), and autoimmune disease.

\section{Treatment}

Specific management consists in the removal of all offending agents, stimuli, or allergens, and the drug management of possible predisposing or concurrent factors (infections, infestations, etc.), or ongoing problems. A truly specific management is not as yet available, since the etiopathogenetic mechanisms underlying urticaria are largely unknown. A stimulating prospective involves the histamine releasing IgG Aab neutralization by means of soluble FceRI- $\alpha$ [92].

An aspecific or second-line management includes the following:

- New-generation nonsedating $\mathrm{H}_{1}$ antihistamines, alone or combined with $\mathrm{H}_{2}$, are the mainstay of symptomatic management, such as chronic urticaria [192], efficaciously controlled in particular by cetirizine [10], levocetirizine and cimetidine associated with hydroxyzine [192]. Cetirizine and levocetirizine dosage schedules are shown in Table 7.19.

- In a double-blind (DB) study, 31 children aged 2-6 years (mean 3.85) with idiopathic chronic urticaria were treated with cetirizine at a dosage of $5 \mathrm{mg}$ daily, which showed a significantly more rapid resolution of symptoms and itching compared with 31 children treated for the same length of time with oxatomide, at a dosage of $25 \mathrm{mg}$ daily [113].

- Membrane stabilizers such as ketotifen (Chap.7), which has been found useful in cold-induced and cholinergic urticaria and dermographism after the demonstration that the drug inhibits histamine release at a specific challenge [103]. Similarly, ketotifen was effective in urticaria refractory to antihistamines and in chronic urticaria [101].

- In more severe cases and/or those resistant to other therapies, systemic CSs are required for transient relief [103].

- For pediatric cases of extreme severity, a resort to Epi-pen may be suggested [4].

A child aged 10 was treated with $\varepsilon$ aminocaproic acid plus montelukast plus ranitidine. This regimen induced a full remission of urticaria in about $48 \mathrm{~h}$. The treatment was gradually tapered in the subsequent months, and after $\approx 13$ months, the boy still remains completely symptom-free [228]. 
Angioedema. The above-mentioned therapeutic options may be followed. In children with the hereditary form, danazol has been demonstrated to be effective at the recommended dose of $20-30 \mathrm{mg} / \mathrm{kg} / \mathrm{day}$, with a maximal dose of $600 \mathrm{mg} /$ day [15] for 5 days before and 2 days after the event [35]. Therapy improved serum complement parameters significantly and reduced the frequency and severity of clinical manifestations [70]. Doses of $0.5 \mathrm{~g} /$ day of $\varepsilon$ aminocaproic acid (EACA) and 1-2 g/day of tranexamic acid are prescribed to prevent episodes in children as needed $[35,69,70]$. Acute, lifethreatening edematous attacks are treated by the administration of C1-INH concentrate, which achieves the resolution of the edema within several hours $[35,70]$. Undesirable adverse effects can be avoided and the child's quality of life enhanced dramatically by administering the lowest effective drug dose [70]. In C1-INH deficiency, both primitive and acquired experimental treatment procedures are under study [155]. In cases of laryngeal edema, a tracheotomy will be indispensable. Patients may die as a result of laryngeal edema before a diagnosis is established [247]. Adequate prophylaxis and follow-up care can spare pediatric patients from edematous attacks.

In some patients with Melkersson-Rosenthal syndrome, a remission was obtained with an avoidance diet free of tartrazine and $\mathrm{Na}$ benzoate [161], but not in others [142]. Clofazimine, $100 \mathrm{mg}$, administered orally 4 times weekly for 3-11 months was shown to be effective in several patients [202].

\section{Prevention}

A paradigmatic example of preventive management is the elimination of stimuli triggering urticaria episodes: - In cold urticaria, cold desensitization by repeated skin exposure to cold until it becomes refractory to challenge has been recommended in motivated patients. A cardinal objective is the prevention of shock reactions during aquatic exposures, including traveling by boat or motor boat, water-skiing and other exposures to cold which lower the body $\mathrm{T}$ [233]. In a child with cold urticaria seen by us, protection by a large hat and a scarf was unsuccessful.

- Patients with cholinergic or generalized heat urticaria should protect the upper part of their body from excessive heating; also these patients may have recourse to a desensitization with warm baths by gradually increasing water $\mathrm{T}$ [44].

- In solar urticaria ordinary window glass $3 \mathrm{~mm}$ thick will absorb most UV radiation $<3,200 \AA$ A Protective garments to cover the skin should be used. Oral $\beta$-carotene was useful for type VI of solar urticaria. Types I-V can be prevented, at least in part, by antihistamines or by PUVA therapy [141].

- Subjects with EIA should select activities requiring a more modest effort, avoid ingestion of foods and drugs (ASA and NSAID) in the 4-6 $\mathrm{h}$ before a planned activity, and carry out physical activity possibly with a partner. Moreover, they should recognize the prodromal signs, to slow down to a minimum or stop exercising [190]. An epinephrine kit (Epi-pen) and medical identification bracelet is mandatory.

In a prospective, $\mathrm{DB}$, parallel-group study of urticaria prevention in 817 children with AD who were 1224 months of age at study entry, acute urticaria occurred in $5.8 \%$ of the children treated with cetirizine, $0.25 \mathrm{mg} / \mathrm{kg}$, and in $16.2 \%$ of the placebo-treated children [191].

\section{Allergic Contact Dermatitis}

$\mathrm{ACD}$ is one of the most frequent skin disorders and the prototype of a delayed type of CMI hypersensitivity reaction: any part of the skin that comes into contact with a relevant sensitizing allergen may be vulnerable. Characteristically, ACD is at first limited to the skin site exposed to the allergen, but the reaction may then spread to other locations. The allergen is brought into skin contact in many ways such as compression, friction, transpiration, humidity and warmth. Lesion severity and persistence are dictated by several factors such as MW, chemical potency, concentration and dose of the allergenic stimuli, site of contact, the frequency, duration and intensity of exposure, and especially the patient's degree of sensitization [82].

\section{Definition}

Dermatitis of variable intensity, due to lymphocytes previously sensitized by antigens making contact with exogenous haptens, mostly chemical haptens, at variance with $A D$, in which allergens arrive by the hematic route. In this reaction, after the first epicutaneous allergen sensitization, Langerhans cells (LCs) take allergens up and migrate from the skin to draining lymph nodes and activate naive T cells in the context of HLA class I or II. Clinical manifestations vary from a transient erythema to edematous papules with vesiculous and occasionally bullous outcome; itching is ACD's distinctive symptom, manifesting with variable intensity [107].

\section{Prevalence}

Pediatric ACD is a much more frequent disease than previously reported (Table 5.9). Epidemiological studies supply an ever-growing body of data pushing out the boundaries of the disease, including prematures [76], a 1-week-old neonate with ACD to the epoxy resin in his vinyl identification band, and a 7-month-old infant who developed nickel dermatitis to the snaps in his sleepwear [75]. Children as young as 6 months of age may be sensitized to contact allergens with a prevalence of sen- 
Fig. 8.10.

Cell interactions in ACD. (Modified from [20])

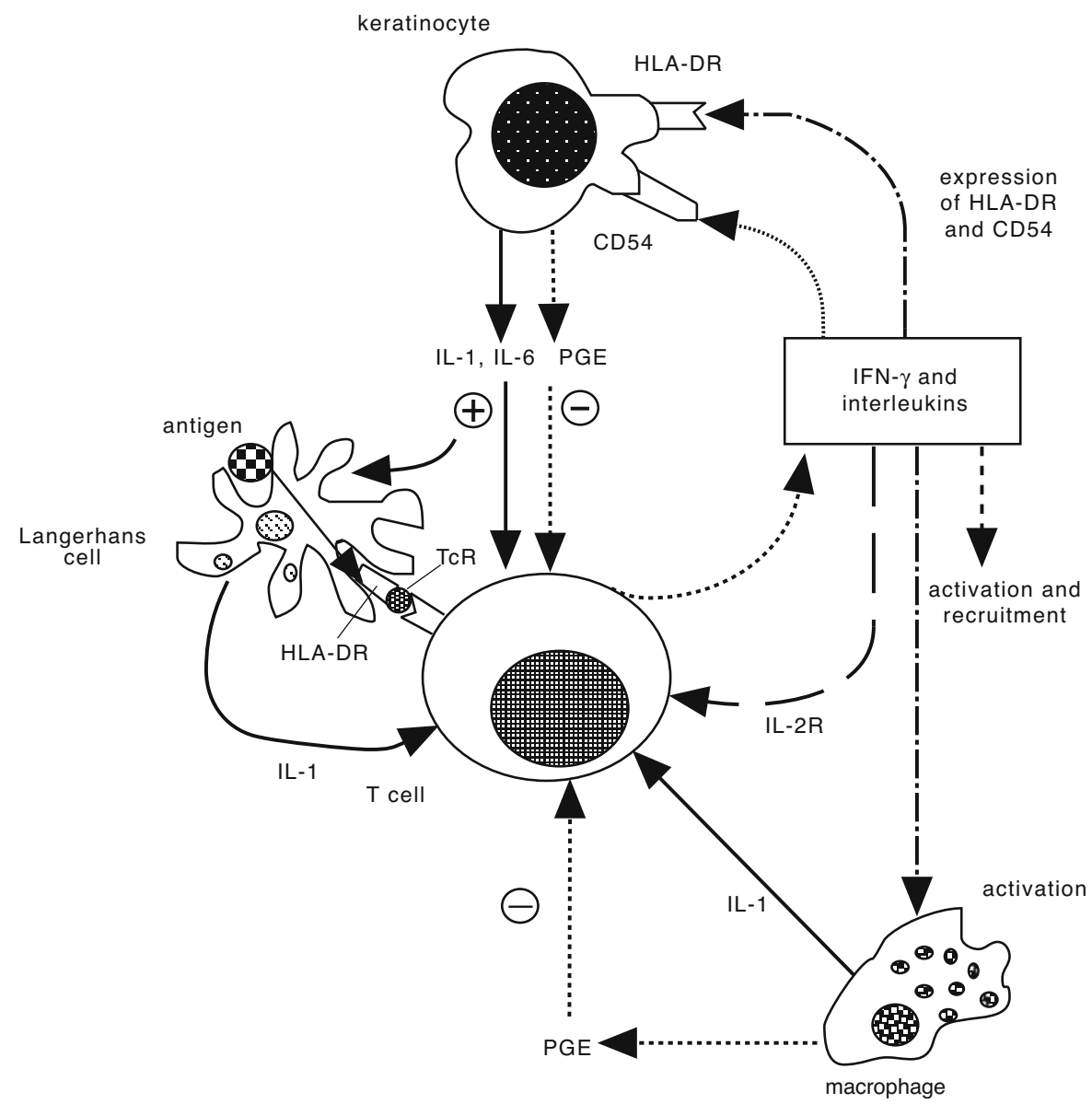

sitization as high as $24.5 \%$ [38]; $43 \%$ of children aged 8 (median) suffered from ACD of the delayed type to metals and the like and $6.6 \%$ of them to patch-test diagnosed foods, increased up to $20 \%$ by an open FCT [154]. The development of contact allergy and ACD increases with age $[145,185]$ In children aged $3-14$, the following positivities were found: $38.8 \%$ preservatives, $25 \%$ topical drugs and $11 \%-16.6 \%$ fragrances and perfumes [56,212]. Also, occupational ACD incidence is increased (21.2\%) in boys and girls helping their parents in domestic work [7] or work outside the home [85, 199]. These data also complete the ACD natural history in Table 5.9.

\section{Etiopathogenesis}

\section{Genetic Factors}

Several textbooks assert that ACD is not linked to atopy. On the contrary, atopic sensitization in children and teenagers ranges from $16.7 \%$ to $32.6 \%[7,56,85,199$, $212,214]$, with peaks of $50 \%$ [63], with positive $\mathrm{FH}$ between 20.7\% [199] and 42.1\% [80]. As discussed earlier, a large share of children with $\mathrm{AD}$ are also affected with ACD, with a prevalence between $16.7 \%$ and $32.4 \%[7,56,63,85,212]$. Genetics was established by the finding of two monozygous girls with contact allergy, thus suggesting a genetically determined selection process during development of the peripheral T-cell system [206].

\section{Histopathological Aspects}

In the acute forms, within $6 \mathrm{~h}$ from allergen exposure, perivascular infiltration of lymphocytes and monocytes are seen in the highest dermal layers. Subsequently an intracellular and intercellular edema develops in the epidermis, thus causing spongiosis. Chronic lesions are characterized instead by hyperkeratosis, and in the dermal superficial layers by a dense monocyte and basophil infiltration [107, 138].

\section{Immunological Aspects}

Though humoral immunity may participate in ACD pathogenesis, this depends above all on allergen-specific $\mathrm{T}$ cell activation stimulated by chemical substances of low MW, which are haptens and therefore need to link with proteins called carriers in the skin before they become antigenic and acquire immunogenicity (Fig. 8.10) 
[20]. These circumstances result in a cascade of inflammatory events leading to the development of dermatitis or, after a diagnostic FCT, to a hypersensitivity reaction [20]. ACD can thus be classified as a delayed type of hypersensitivity (DTH) reaction, in other words, a stage of hypersensitivity associated with an increased number of allergen-specific $\mathrm{T}$ cells able to invade the peripheral tissues [105]. The series of immune events that induce ACD implies the interaction, at an undetermined site, between $\mathrm{T}$ lymphocytes and epidermal $C D 1^{+}$LCs (Figs. 7.1, 7.2), functionally immunocompetent $\left(\mathrm{CD}^{+} / \mathrm{IgE}^{+}\right)$cells. Early and important participants in the induction of ADC, LCs act as APCs in the initiation of a type IV immune reaction [207]. Mobilization of dendritic cells (DCs) occurs in response to local generation of proinflammatory ILs such as $\mathrm{IL}_{1}$ and TNF- $\alpha$. Activated DCs express high levels of CCR7, HLA antigens, and costimulatory molecules (CD40, CD80, CD86) [33]. Sensitizing allergens contacting the skin activate $\mathrm{T}$ lymphocytes. To a subsequent cutaneous contact the duo hapten + carrier is taken up, processed and expressed on the surface of LCs bearing class II HLA-DR molecules [23]. After the allergen-HLA complex presentation, LCs migrate out of the epidermis into the dermis and then into draining lymphatics and on to regional satellite lymph nodes. Within $4-6 \mathrm{~h}$ of hapten application, LCs congregate in T-dependent zones; within 18-24 h a great number of LCs are in the draining lymph nodes to present the processed antigen and transfer the sensitization to a large repertoire of specifically sensitized CD4 T lymphocytes bearing CD3 receptors that undergo proliferation and clonal expansion [207]. The antigens interacting with HLA molecules emit the first signal for lymphocyte activation, and the second signal is represented by $\mathrm{IL}_{1}$ produced by keratinocytes and LCs with the primary function of activating T lymphocytes. This results in the clonal proliferation of antigenspecific memory $\mathrm{T}$ cells with the phenotype of $\mathrm{CD}^{+}$, CD45RO, CD45RA, which yield a number of ILs, including $\mathrm{IL}_{2}$ and IFN- $\gamma$ [207]. The coincident presence of both ILs corroborates the conclusion that they are the product of CD4 Th1 specific for contact antigens, in parallel with the delayed reaction of AD [105]. Keratinocytes with their HLA-DR antigens and CD54 (Fig. 8.11) act as target cells for activated T cells, and the inflammatory IL they produce attract PBMCs in an allergen-nonspecific way [20]. During the induction phase, the CD4 infiltrated in the dermis proliferate and differentiate into effector cells and release Th1-like ILs (Table 1.10), capable of inducing capillary vasodilation and permeability increase, thus leading to the allergic skin inflammation [207].

Th1 T cells dominate and amplify the generation of cytotoxic allergen-specific CD8 lymphocytes (CTLs), which leads in the final analysis to cutaneous lesions. As seen from studies on the animal model, both mediate type IV immune responses, Th1 with class II HLA, and CTLs with class I HLA. Suppressor CD8 T cells are subsequently generated, although in a lesser number,

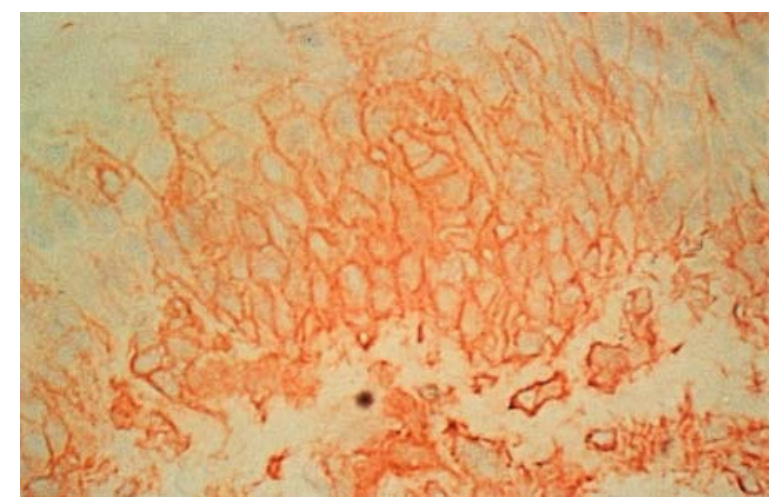

Fig. 8.11. Keratinocytes expressing HLA class II in ACD

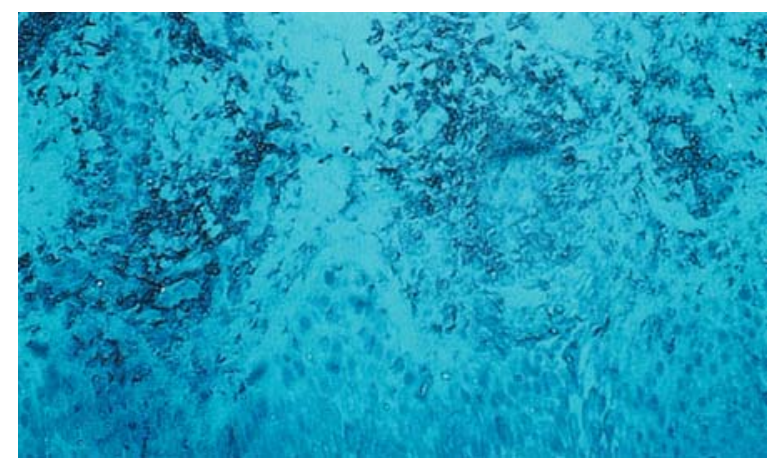

Fig. 8.12. The majority of T cells infiltrating the allergic patch test after $96 \mathrm{~h}$ are CD4

thus achieving a balance between sensitization and tolerance, orchestrated by a complex suppressor circuit acting on both afferent and efferent pathways of the DTH reaction [23]. Looked at in more detail, whether sensitization has an effect either on Th1 or Th2 activity depends on the exposure intensity and LC integrity; however, there is no numerical difference between the different T-cell subpopulations in the various phases so far delineated [211]. Intercellular connections are ensured by $\beta 1-\beta 3$ integrins (Tables $1.45-1.47$ ), which allow cells to migrate into the skin, and IFN- $\gamma$-stimulated endothelial cells express CD54, more adhesion molecules and class II molecules [251]. This leads to preferential PBMC migration from the bloodstream to the inflamed skin lesions, and circulating $\mathrm{T}$ cells, by expressing their ligands such as CD11a/CD18 and CLA, recognize CD54 on endothelial cell and keratinocyte surface membranes activated by $\mathrm{IL}_{1}$ and can bind these cells [20, 251]. Moreover, PBMCs of patients with ACD presenting antigens to autologous $\mathrm{T}$ cells can stimulate the proliferation of the two different subsets, $\mathrm{CD}_{45 \mathrm{RO}^{+}}$and

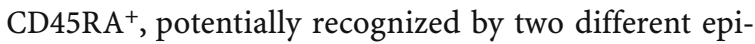
topes. However, $\mathrm{CD}^{+}, \mathrm{CD} 45 \mathrm{RA}$ and CD8 T cell responses are absent [23]. CD45RO ${ }^{+} \mathrm{CD}^{+} \mathrm{T}$ cells stimulated by antigens reach the maximal expression at $96 \mathrm{~h}$ (Fig. 8.12), thus suggesting that they are able to induce immediate cutaneous reactions in patch test sites [23]. 
Table 8.6. Cytokine production by keratinocytes and LC

\begin{tabular}{|c|c|c|}
\hline Cytokines & Keratinocytes & LC \\
\hline $\mathrm{IL}_{1 \alpha}$ & + & + \\
\hline $\mathrm{IL}_{1 \beta}$ & + & + \\
\hline $\mathrm{IL}_{6}$ & + & + \\
\hline $\mathrm{IL}_{7}$ & $?$ & $?$ \\
\hline $\mathrm{IL}_{10}$ & $?$ & $?$ \\
\hline $\mathrm{IL}_{12}$ & + & $?$ \\
\hline \multicolumn{3}{|c|}{ Colony-stimulating factor } \\
\hline $\mathrm{IL}_{3}$ & + & + \\
\hline GM-CSF & + & + \\
\hline G-CSF & + & + \\
\hline $\mathrm{M}-\mathrm{CSF}$ & + & + \\
\hline IFN- $\alpha$ & + & $?$ \\
\hline IFN- $\beta$ & + & $?$ \\
\hline IFN- $\gamma$ & $?$ & \pm \\
\hline TNF- $\alpha$ & + & + \\
\hline TNF- $\beta$ & \pm & \pm \\
\hline TGF- $\alpha$ & \pm & $?$ \\
\hline TGF- $\beta$ & \pm & $?$ \\
\hline
\end{tabular}

Data from $[58,128]$.

Metachromatic cells are involved in ACD: the cellular infiltrate can contain up to $10 \%$ basophils and $40 \%$ mast cells, activated by IL released by $\mathrm{T}$ lymphocytes, and they amplify the reaction by dilating capillaries [107]. Basophils principally are seen transiently: at 48-72 $\mathrm{h}$ large numbers of basophils are seen within the skin blood vessels, but their exact role is far from elucidated [107]. Macrophages invade both dermis and epidermis also at $48 \mathrm{~h}$, and contribute to calming the reaction by producing either PGE, which inhibit $\mathrm{IL}_{1}, \mathrm{IL}_{2}$ and NK cells, or $\mathrm{LTB}_{4}$ inducing T CD8 cells, which further progressively calm the reaction. Therefore both hapten size and its capacity to steadily bind a carrier protein appear to be important factors in immunogenicity [107].

Tables $8.6[58,128]$ and $8.7[104]$ show the production of ILs by keratinocytes and LCs $[82,128]$ and by nickel (Ni)-specific T lymphocyte clones in an ACD response. It is surprising how many ILs are produced by keratinocytes: Ni-sensitive patients produce both $\mathrm{IL}_{4}$ and $\mathrm{IL}_{5}$, but the nonallergic patients have elevated levels of IFN- $\gamma$. A recent study [82] showed that $\mathrm{IL}_{1 \alpha}$, and $\mathrm{IL}_{1 \beta}$ are among the several ILs produced in the skin after contact by an immunizing agent, which potentially primes the synthesis of more chemotactic ILs involved in ACD and $\mathrm{IL}_{10}$ $[71,128]$, which instead inhibits the reaction. In particular the keratinocyte-produced $\mathrm{IL}_{10}$ may down-regulate
Table 8.7. Cytokine production by nickel (Ni)-specific T CD4 lymphocytes in patients with ACD

\begin{tabular}{lll} 
Cytokines & Allergic & Nonallergic \\
$\mathrm{IL}_{2}$ & + & + \\
\hline $\mathrm{IL}_{4}$ & + & + \\
\hline $\mathrm{L}_{5}$ & + & + \\
\hline GM-CSF & ++ & ++ \\
\hline IFN- $\gamma$ & + & +++ \\
\hline TNF- $\alpha$ & ++ & ++
\end{tabular}

Modified from [104].

ND not done.

DTH, thus terminating the response, which is instead up-regulated by its inhibition [71]. TNF- $\alpha$ stimulated with UVB propitiates the reaction by its proinflammatory and vasodilatory effects, but may be critical in inhibiting the migration of epidermal LCs [104], which produce few ILs [128]. Chemokines such as RANTES and MIP-1 $\beta$ may recruit a higher level of T lymphocytes, with a further increase in local mediators [203].

A distinctive type of reaction involves $\mathrm{Ni}$. Ni-specific $\mathrm{T}$ lymphocyte clones recognize the antigen only on the cell surface of LCs in association with HLA class II molecules, whereas they were unable to recognize $\mathrm{Ni}$ when presented by monocytes. Therefore, there may be a direct and non-HLA-restricted recognition by T-cell clones; thus Ni might interact directly on the T cell surface structure, with consequent activation and proliferation of these T cells. Since HLA class II molecules are polymorphous and contain mostly three subtypes, all heterozygotic subjects inherit two different alleles for each of these three subtypes, so Ni may be associated with up to six different HLA class II determinants presented by APC, although it is difficult to identify the precise determinant involved [105]. See in the next section that oral $\mathrm{Ni}$ administration may have important suppressive effects in the recipients [76].

\section{Etiological Agents}

A plethora of compounds hold a top position as ACD causative agents, some, such as dinitrochlorobenzene (DNCB), exercising their action indiscriminately, while others are much more selective. The more frequently induced substances are summarized in Table $8.8[7,56,57$, $63,85,131,149,199,212]$, and Table 8.9 [20,131] shows the sources of sensitization as related to their topography. On the drug panorama, we give concise indications since Chap. 19 discusses the topic at length, and latex dermatitis is analyzed below. We examine the technomarketing particularities related to the most diffused haptens $[7,52,57,80,131,138,173,227]$. 
Table 8.8. Most frequent causes of ACD on a mostly nonimmunological basis and related rates

\begin{tabular}{|c|c|c|c|c|c|c|c|}
\hline Substance and references & {$[57,131]$} & [149] & {$[56,212]$} & [7] & [199] & [85] & [63] \\
\hline Balsam of Peru & $3.3-12$ & $3-3.3$ & $3-10$ & 0.9 & 2.5 & 0.9 & 0 \\
\hline Benzocaine & $1-4.5$ & $0.6-3.1$ & & & & & 0 \\
\hline Chloramphenicol & 0.5 & & & & & & \\
\hline Chrome & $5-8.4$ & & & & & & \\
\hline Cinnamic alcohol & $2.7-4.8$ & $2.5-4.8$ & & & & & \\
\hline Cinnamic aldehyde & $3.1-5.9$ & $4.1-6.8$ & & & & & \\
\hline Cobalt chloride & $6.3-7.1$ & & $3-17$ & $6.6-13.2$ & 10 & 7.2 & 5.7 \\
\hline Colophony & 3.4 & $1.7-4$ & & & & 0.9 & 0.7 \\
\hline Ethylenediamine & $2-7.1$ & $3.9-5.6$ & & $1.7-5.4$ & 5 & 0.3 & 0 \\
\hline Formaldehyde & $1-6.8$ & 4.7 & & & & 0.9 & 0 \\
\hline Fragrance mix & & $4.1-7$ & & 1.5 & 3.7 & 4.2 & \\
\hline Magnesium, inorganic compounds & & & 12 & & & & \\
\hline Mercapto mix & & & 3 & & & & \\
\hline Mercaptobenzothiazole & $0.9-4.8$ & $1.5-2.66$ & & $1.4-7$ & 3.7 & & \\
\hline Mercury & & & & 0.7 & 6.1 & & \\
\hline Neomicyn sulfate & $2-7.2$ & $4.5-5.9$ & & $0.8-1$ & & 0.3 & 1.4 \\
\hline Nickel sulfate & $9.7-34$ & $9-12$ & $5.5-37$ & $2.3-35.1$ & 56.2 & 21.5 & 14.9 \\
\hline Parabens & $1.1-3.5$ & & & $0.3-0.8$ & & 0.6 & 0 \\
\hline Paraphenylenediamine (PPDA) & $3.7-9$ & & $3-12$ & $13.6-17$ & & 1.8 & 0.5 \\
\hline Penicillin & 0.4 & & & & & & \\
\hline Potassium dichromate & $2.4-11$ & & 10 & $11.3-24.8$ & 10 & 2.7 & 1.2 \\
\hline Thimerosal & $6.2-8.7$ & $3.4-6.2$ & & & & 11.2 & \\
\hline Topical steroids & $1.9-2.9$ & & & & & & \\
\hline
\end{tabular}

Data from [131] on 29,499 patients and [57] on 18,822-20,791 (age unknown) [57,131]; on 1,370 patients from the US and 780 from Canada [149]; pediatric data on 244 nonatopic and 47 atopic children aged 4 months to 16 years [7]; [85] on 69 reactions in 53/214 atopic children and two studies in children aged 3-16 years [56, 199, 212], in comparison with 34 reactions in $28 / 143$ nonatopic children and 47 reactions in 424 schoolchildren aged 7-12 years [63].

Balsam of Peru: vegetal fragrance containing principally benzylbenzoate, benzoic acid, cinnamyl alcohol, eugenol and vanillin. It is used in:

- Emollients, medical creams and ointments, powders, tinctures, suppositories, healing preparations and for burns (due to antiseptic and/or keratoplasty actions)

- Straps and paints due to its adhesive action

- Perfumes and cosmetics (after-shave lotions, brilliantine, creams, face powders, deodorants, infantile cosmetics, lipsticks, lotions, perfumes, soaps, toothpastes, etc.) as fragrance

- Tobaccos

- Drugs (balsamics, cough syrups, emollient lozenges, topical drugs); liquid cement for dentists

- Foods (as aromatizing in food industry) such as aperitifs, baked goods, bitters, chewing gums, candies, chocolates, cola, cocktails, ice creams, orange squash, pâté de foie gras, sauces, vanilla, products containing

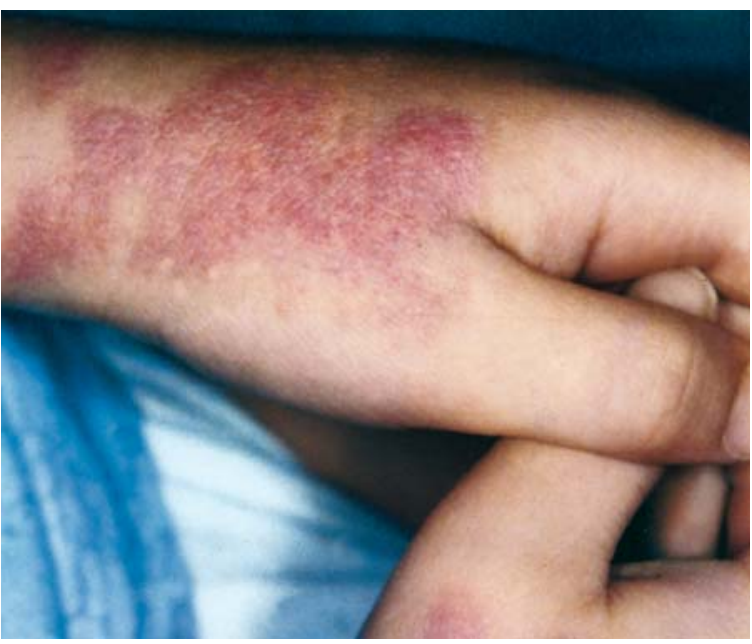

Fig. 8.13. ACD provoked by resin 
Table 8.9. Location of common allergenic ACD contactants in relation to body sites

\begin{tabular}{|c|c|}
\hline Regions & Allergenic substances \\
\hline Face & $\begin{array}{l}\text { Soaps, face powders, cosmetics in general, perfumes, cleansing milks and creams, shaving } \\
\text { creams, razor blades, cosmetic lotions used after and before shaving, crash helmets, frames, } \\
\text { nebulizer masks, antiallergic masks (Chap. 11), sun creams (hand dermatitis usually appears } \\
\text { first), topical medicaments }\end{array}$ \\
\hline Scalp & $\begin{array}{l}\text { Hair lotions, lacquers, lotions, brilliantine, hair tonics, anti-dandruff products, hair dyes } \\
\text { and curling agents, earrings, bobby pins, hair clasps, wig adhesives, hats, caps }\end{array}$ \\
\hline Forehead & Cosmetics, hair lotions and shampoos, hat bands, cap bands, anything applied to hair \\
\hline Eyelids & $\begin{array}{l}\text { Eye and face cosmetics and cleansing milks, facial creams, eye shadows and make-ups, } \\
\text { eyelash dyes and curling agents, medicaments: collyrium, eyewashes and ointments, } \\
\text { contact with fingertips }\end{array}$ \\
\hline Ears & $\begin{array}{l}\text { Earrings and ear piercing, pendants, earpieces for portable radio, etc., earplugs, hearing aids, } \\
\text { earphones and cellular receivers, ear preparations, topical medicaments, medical eardrops }\end{array}$ \\
\hline Lips and perioral areas & $\begin{array}{l}\text { Ointments in general, lipsticks, lip protectants (both sexes) and lip pencils, chewing gums, } \\
\text { toothpastes, mouthwashes, nail polish (contact with fingertips), foods (see contact cheilitis), } \\
\text { toilet paper, tobacco smoke, latex, metals, also related to ear piercing }\end{array}$ \\
\hline Neck & Perfumes, necklaces (nickel), garments, sweaters \\
\hline Armpits & Deodorants, depilatory creams, textile fibers, tinctures, topical medicaments, antiseptics \\
\hline Arms & Watch cases and related watch bands, textile fibers, metals, plants, tinctures \\
\hline Hands & $\begin{array}{l}\text { Cosmetics, lotions, creams and sun creams, metal jewels, metals, plants, cleansing agents, } \\
\text { soaps, leather, rubber and latex gloves, metal, rubber and latex handled objects } \\
\text { and materials and irritants encountered at work, topical medicaments }\end{array}$ \\
\hline Body & $\begin{array}{l}\text { Perfumes, bath salts, cosmetics and detergents in general, metal parts of garments } \\
\text { (buttons, zippers, etc.), shoulder straps, brassiere clips, textile fibers, leather, rubber } \\
\text { and latex dresses, rubber in elastic of garments, dyes, formalin and resins in garments, } \\
\text { douche additives, plants, topical medicaments }\end{array}$ \\
\hline Genitalia & $\begin{array}{l}\text { Infant diapers, briefs, topical antiseptics, antibacterial and antifungal drugs, disinfectants in } \\
\text { general, (women) contraceptive creams or jellies, menstrual pads or tampons, preservatives, } \\
\text { deodorants, rubber diaphragms (men), remedies, latex condom, vaginal agents used } \\
\text { by partner }\end{array}$ \\
\hline Anal area & Textile fibers, topical medicaments, suppositories, remedies and ointments \\
\hline Legs and thighs & $\begin{array}{l}\text { Stockings and drawers, leotards, leather dresses, boots, textile fibers, rubber, clips of garters } \\
\text { and other metal parts, depilatory creams, topical ointments and medicaments }\end{array}$ \\
\hline Feet & $\begin{array}{l}\text { Shoes, rubber shoes, shower sandals and slippers, tinctures, shoe waxes, buckles, textile fibers, } \\
\text { deodorants, topical foot remedies, plants }\end{array}$ \\
\hline
\end{tabular}

Data from $[20,131]$.

a Since the scalp is relatively resistant to dermatitis, hair preparations generally cause dermatitis mostly on the forehead, scalp edges, neck, and sometimes also shoulders, i.e., on hair-free skin.

citrus peels (orange jam, cakes with candied fruits, etc.), confectionery products with spices, perfumed teas

Colophony (Fig. 8.13): a resin obtained from different conifer species, one of its derivatives is turpentine oil. It is found in:

- Electric insulators, pharmaceuticals, soldering materials, such as patches, plasters, and products of common use, including soaps and cosmetics, in addition to adhesives, depilatories, dressings, mastics, nail polish, shoe wax, stickers, tape, varnishes, watercolors; cleaning compounds (furniture and floors), lacquers, surface coating, paints, paper boxes, resins, and printing inks Turpentine: oils, resins and varnish solvents, is found in:
- Perfumes, bath salts, soaps, shaving-creams, toothpastes

- Insecticides

- Expectorants by mouth, antirheumatic and rubefacient liniments

Parabens mix: substances with antioxidant, antifermentative and fungicidal power, found in cosmetics, drugs and foods as preservatives; are present in:

- Preservatives found in many dermological creams, pastes, face powders, cosmetics, sun-creams, toothpastes, cleansing milk and creams, hair lotions, lipsticks, soaps 


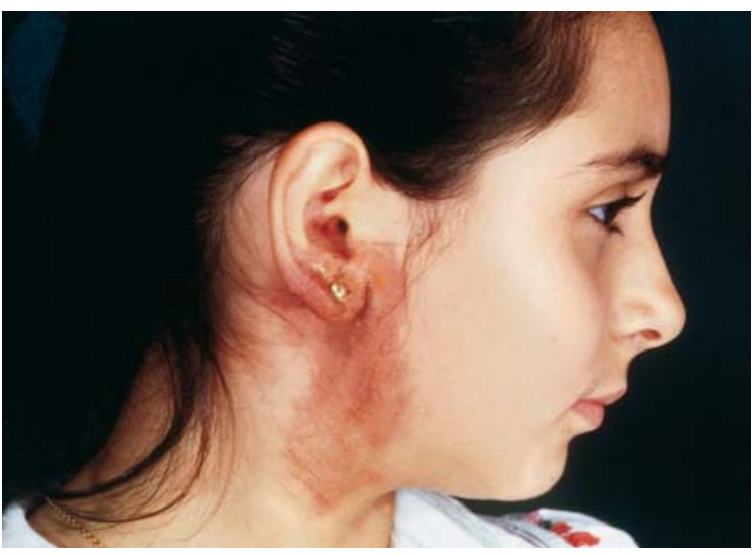

Fig. 8.14. ACD provoked by $\mathrm{Ni}$ in earrings

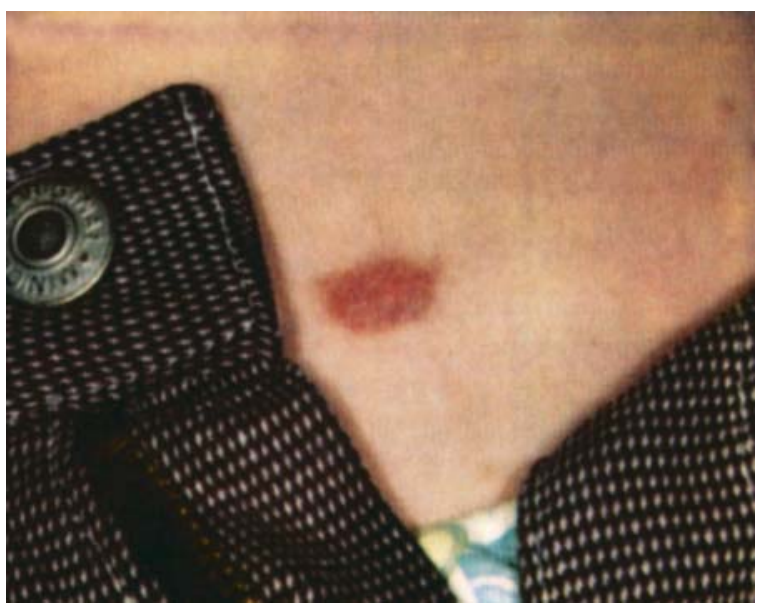

Fig. 8.15. ACD provoked by Ni in fasteners

- Bandages, collyrium, nasal drops, antifungal pomades and for varicose veins, ointments

- Floor wax

- Foods: canned fish, caviar, fruit juices, lemon- and orange-squash, mayonnaise, smoked salmon

- Parabens can also cross-react with compounds of the "para" group (Chap. 19)

Nickel sulfate and chloride (Figs. 8.14, 8.15) is one of the most common sensitizers in our environment contained in nickel-plated manufactured products of common use such as:

- Coins (euro cents), door handles, drawing-pins, earrings, inks, keys, lighters, metallic parts of watch-straps, needles, paper-clips, pencils, pins, safety-pins, scissors, spectacle frames, thimbles, tweezers, utensils, watchcases, etc.

- Identification bracelets (maternity wards), particular groups of patients, also allergic children.

- Dental prostheses, orthodontic instruments, and lowweight gold alloyed with $\mathrm{Ni}$ used in dentistry.
- Clothes accessories such as bobby-pins, buckles, buttons, clips, fasteners, clothing and hair clasps, shoe laces, safety-pins, zippers.

- Costume jewelry since nickel-plating precedes goldplating (bracelets, earrings, jewelry of white and yellow gold, medals, etc.); some children may be exquisitely sensitive to even Ni traces found in gold jewelry.

- Colorings for cosmetics, for example eye-shadows.

- Curling instruments for eyelashes and hair.

- Door handles, handles of electric appliances, stainless steel pots or enameled pots (especially in blue or green), as well as pottery, insecticides, plastics.

- Dyes, metallic paint, mordents, paints, shoe waxes, wallpapers.

- Young children and girls have a high risk of sensitization at the time of ear, nose, and tongue piercing and subsequently [130] (the Italian press reported on March 12,2003 the case of a 24-year-old who probably died of a fulminating hepatitis after a tongue-piercing).

- Ni can contaminate foods cooked in chipped pots or pickled in metallic containers or cans.

- Can be found in raw and canned foods, for some of which we give the Ni content in $\mu \mathrm{g} / \mathrm{hg}$ [173]: lentils 310, white beans 285 , rye 270 , peas 225 , cocoa and chocolate 220 , peanuts 160 , raspberry 40 , herrings 30 , jam 25 , potatoes 25 , white wine $10, \mathrm{CM}$ and derivatives 5 , as well as asparagus, beer, butter, carrots, Brussels sprouts, cabbages, corn flour and whole meal, hazel nuts, margarine, mushrooms, onions, oysters, pears (also cooked), popcorn, raisins, rhubarb, soy, spinach, strawberry, tea, tomatoes, walnuts, yeast (artificial), etc., in addition to traces in cleansing tools.

- It is known that sweating may release $\mathrm{Ni}$ ions from metallic objects. The metallic containers for food preservation should no longer affect $\mathrm{Ni}$ content, since $\mathrm{Ni}$ contact is now avoided by means of an internal coating formed by a layer of acrylic or epoxy polymeric resins, as for enameled pots. Instead, wearing Ni-releasing orthodontic braces induces by immunosuppression tolerance to later $\mathrm{Ni}$ contact, provided that fitting of braces is absolutely not preceded by further Ni contacts, for example ear-piercing [130, 221]. We stress that in Denmark the use of Ni has been banned since June 1989 in belts, buttons, frames for glasses, hair-clips and bobbypins, costume jewelry in general, watch-cases and related watch-straps, zippers, and any object touching the skin; violation of the ban carries a 1-year sentence of imprisonment.

Potassium (K) bichromate: is employed:

- In chromed alloy and manufactures.

- In leather tanning.

- As cloth dye, such as in military green fabric and billiard- and card-tables.

- As anticorrosive in paints, oils and refrigerant fluids.

- As a catalyst in acrylic resin synthesis.

It is contained in:

- Objects of common use such as colored pencils and pens, fragrances and deodorants, magnetic tapes, match 
heads, paper money and wall-paper, shaving-creams and razor-blades.

- Bleaches, cleansing creams, detergents in general, floor waxes and other products, porcelain, pots, shoe polish.

- Leather objects, shoes.

- Fixatives, inks, photographic chemicals.

- Rubber objects and artificial flowers.

- Foods in traces (apples, beer, bread, canned cereals, chocolate, eggs, frozen peas, mushrooms, onions, potatoes, plums, raisins, watercress, wholemeal).

Cobalt chloride $(\mathrm{CoCl})$ is found in almost all bichromate materials, moreover:

- In galvanized manufactured products.

- As catalyzing in rubber synthesis, acrylic resins and polyesters.

- As Ni impurities.

- As an alloy in joint prostheses.

- In adhesives, artists' paints, buttons, ceramic and plastic paints, coins, colored pencils, costume jewelry, eye shadows, inorganic pigments in inks, hair dyes, linseed oil-based paints, tattoo pigments, watch straps, wet cement, zippers.

- In Ni-containing accouterments on clothing.

- In anti-perspiration creams, flypaper.

- In vitamin $B_{12}$ preparations and in mineral tablets.

- In foods, namely apricots, beans, beer, beets, bread, cocoa, cabbages, chocolate, cloves, liver, nut, tea, wine [125].

Chrome $(\mathrm{Cr})$ in small amounts is present in cigarettes and in objects of common use:

- Alloys for tooth prostheses, bleaches, cement, ceramic paints, detergents, flypaper, fireworks, floor wax, green felts, matches, military green fabric, pots, razor blades, safety matches, shaving creams, shoe polish, wood ashes and stain, wallpapers.

- As a water and flour pollutant: small amounts are found in mineral waters.

- In foods: apples, beer, cocoa, canned cereals, chocolate, eggs, fish, frozen peas, meat, mushrooms, onions, potatoes, plums, raisins, spices, tea, watercress, wholemeal, wine [125].

In industry:

- As fore-gilding of raw textiles and chrome-tanned leathers (also with $\mathrm{Cu}$ and tannins).

- In typo-lithography: auto-implants, fixatives, inks, photographic chemicals, special papers.

- In mechanics: anticorrosive oils and greases, antirust dyes, cooling mixtures for motors, metallic alloys, welding materials.

- In galvanizing processes: aluminium coloring, chromium plating, electroplating, polishing.

- In colors, enamels, dyeing, oil paints and distempers.

Copper $(\mathrm{Cu})$ is a minor sensitizer found in bronze, brass, and other alloy objects, also of common use:

- Pots for polenta, coins, costume jewelry, electric materials, green eye shadow, intrauterine contraceptives.
- Acaricides, antiparasitics, astringents for mouthwash and lotions, fertilizers, fungicides.

- Foods in traces: beer, clams, edible mushrooms, lentils, mussels, oysters, shrimps.

Paraphenylenediamine (PPDA): is employed in:

- Color film developers, inexpensive fabrics and furs, lubricating oils, permanent black or dark hair dyes, dyed textiles, etc.

- As an accelerator and antioxidant: rubber, catalyzers for resin synthesis.

- Antioxidant in gasoline, oils, lubricating, printing inks and cartridges for printers (computer), reagents for photography, lithography and radiography.

- Cross-reactivity with other substances of the para group such as local anesthetics (benzocaine, procaine, etc.), sulfonamide drugs, aniline dyes and PABA ( $p$ aminobenzoic acid) used in sun screens (creams, lotions, ointments) and in several cosmetics, including eye shadows, lipsticks, hair balsams, nail varnishes, shampoos. PPDA oxidizes rapidly in contact with atmospheric oxygen, but this reduces its allergenicity only slightly.

Ethylendiamine: stabilizer found in cosmetics and topical drugs (antihistamine ointments, eye drops, nose drops, lotions for itching eczema), in fungicides, insecticides, and preservatives in creams, as a catalyzer for resin synthesis, as well as in anticorrosive and antifreeze agents, solvents, etc. It can cross-react with aminophylline, hydroxyzine, prometazine, etc.

Formaldehyde is a chemical widely used as a disinfectant, while formalin, a $27 \%$ aqueous solution, is used to treat allergens to produce allergoids. Formaldehyde antigenicity was recognized as early as 1914 [116]. It is found in:

- Bactericides, denatured alcohol, fabric softeners, fungicides, oral disinfectants, preservatives, and in antitetanic vaccines.

- Cosmetics in general, deodorizers, nail hardeners, permanent fluids, soaps, shampoos, toothpastes, etc.

- Plastic packing (demopac) for foods prepared in advance, from which residual amounts are naturally released.

- Enamels, glues, pastels, tanning agents, tempera painting, in dry-cleaning as a spot remover, in typography, etc.

- Adhesive strips to apply wall-to-wall carpeting, textile finishes.

- Insulating materials, plywood paneling and wrinkleresistant clothes.

We underline its hidden presence in carpets, cigarettes, insulators, paper tissues and serviettes, towels, and other paper products also for toilet or medical supplies, preservatives employed in the pharmaceutical and other industries, disinfectants also for housework, and as a monomer in butylphenol-formaldehyde resins used in adhesives, corsets, glues, leather goods, products to protect color fading in clothing articles and in underwear elastics or as sizing, crease-resistant and/or waterproof finishes. However, that contained in shampoos 
and liquid soaps is a rare cause of ACD since it is rapidly diluted and rinsed.

Mercury $(\mathrm{Hg}$ ) includes different compounds, all cross-reacting between themselves, employed in medicine and cosmetics:

- Mercurochrome, phenylmercuricborate, etc., are used as disinfectants for small wounds and in lipsticks.

- Thimerosal is a topical antiseptic employed as an ingredient of germicides, cosmetics, eye shadows, preparations for dentists, eyewashes and nasal drops, contact lens cleaning and wetting solutions (Chap. 14), etc., as preservatives in pharmaceutical preparations, including vaccines and sera, and as a rubber accelerator.

- Yellow oxide $(\mathrm{HgO})$ is a topical antimicrobial employed for eye applications and as caustic, cicatrizant, etc. - Bichloride $\left(\mathrm{HgCl}_{2}\right)$ is employed in amalgam fillings, contraceptives, electric materials, lubricants, thermometers, etc.

- It is also found in aniline colors, textiles, etc., for leather, felts, furs, wood preservation, in photography and printing.

Topical medicaments

- Benzocaine, a local anesthetic, can be found more or less commonly in medicaments reducing pain, itching, or stinging, cuts, burns, insect bites, rashes, sunburns, toothaches, and in hemorrhoidal preparations, cough syrups, throat lozenges (cross-reacts with PABA).

- Neomycin is present in over-the-counter antibiotic creams, eyewashes, lotions, many skin, ear and nose products, medication powders, ointments and some types of measles vaccines (Chap. 9). It is also a component of deodorants and toilet soaps. Other aminoglycoside antibiotics such as gentamicin, kanamycin and streptomycin may cross-react.

Benzalkonium chloride is a quaternary ammonium cationic detergent with manifold applications as a preoperative skin disinfectant, for disinfection of surgical instruments, and antimicrobial preservative in nasal sprays, ophthalmic medications, solutions for contact lenses (Chaps. 12 and 14), but also in house cleaning products. However, it frequently induces irritant reactions and may cross-react with curariform preparations employed in general anesthesia (Chap. 20).

Disinfectants include (in addition to thimerosal and benzalkonium chloride):

- Betadine, a skin disinfectant used for burn or wound dressings, etc.

- Chlorhexidine hydrochloride, a topical disinfectant found in skin cleaners, gingival washes, cosmetics, deodorants, etc.

- Dequalinium chloride, employed as benzalkonium chloride, is present in throat lozenges.

- Menthol, alcohol extracted from peppermint, is perfuming and revulsive, used also as antipruritic in cosmetics and pharmaceutics or in inhaled medication for respiratory diseases.

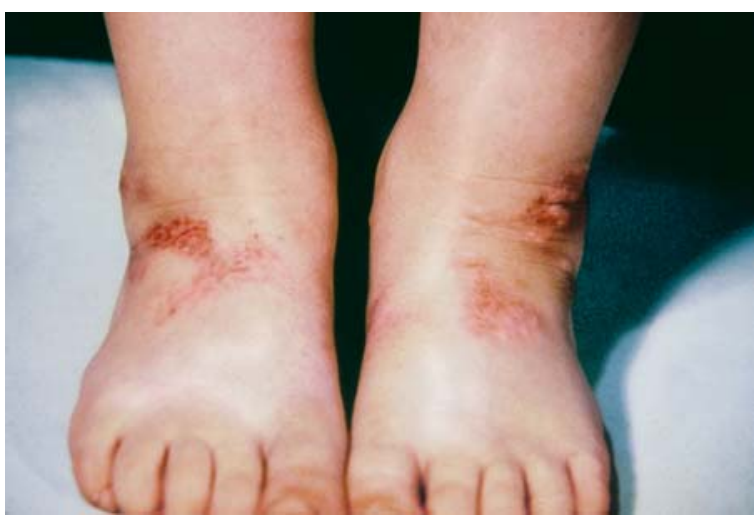

Fig. 8.16. ACD provoked by rubber shoes

- Gentian violet, coloring employed also as an antimycotic mostly in topical applications; however, it is sensitizing, and cross-reacts with bright green.

Fragrance mix is a frequent ingredient of after-shave lotions, beauty creams, cosmetics, soaps, sanitary napkins, shampoos, toiletries, toothpastes, and in household products such as deodorant sprays, detergents, polishes, and solvents. It contains cinnamic alcohol, cinnamic aldehyde, eugenol, geraniol, etc.

- Cinnamic alcohol is utilized as a fixative of mixtures based on jasmine, hyacinth, lilac, narcissus and rose perfumes, as deodorant at $12.5 \%$ solution in glycerin and in the soap industry.

- Cinnamic aldehyde is used to give a cinnamon flavor to foods, drinks, pharmaceutical products (it is a valid anti-mold for syrups) and to formulate synthetic perfumes.

- Geraniol is found in flavors used in foodstuffs and soaps, and is also used in the color composition in rose scale.

Rubber additives (accelerators, antioxidants): essentially thiurams and mercaptobenzothiazole (MBT) and benzothiazole bisulfide (BTS) and diphenylguanidine (DPG). They are found in almost all rubber objects, including boots, galoshes, shoes (Fig. 8.16), adhesives, brushes, condoms, elastic bands of all types, especially for undergarments, electric cords, gaskets, germicides, gloves for housework, physicians, and health care workers, inflatable mattresses, insulating tapes, oil, paints, rubber bands, rubber mattresses, soaps, shampoos, tool handles, etc.

- MBT (mercaptobenzothiazole) is a preservative found in disinfectants, fungicides, bactericides (in foods, creams, soaps, sprays), a vulcanization accelerator, an anticorrosive agent in cutting oils such as antirust and antifreeze fluids, and in tires of black color, such as those of cars.

- Thiurams have fungicide actions, and as bacteriostatics are used in foods, soaps, creams and sprays, and in antiparasitics and pesticides. 
- DPG, a rubber vulcanization accelerator, is found in boots, elastic bands for undergarments, gloves, preservatives, and elasticized fabrics (with textile fibers interwoven with elastic), etc.

Epoxypolymeric resins are found in adhesives, coatings, dental cements, glues, and in the inner coating of tins for preserved foods.

Ni sulfate reached the highest figures in two cohorts, from $14.9 \%$ [84] to $23.7 \%$, with a peak incidence among children aged 1-3 years of $39 \%$ [179]. Two children aged 4-6 elicited positive reactions to $\mathrm{Ni}$ sulfate contained in medication [47], a 4-year-old girl to $\mathrm{Cu}$ present in toys, and a boy aged 11 to turpentine contained in pastels [80]. Several waxes, rubber, spices and flavoring agents provoke contact urticaria and are summarized in the Appendix 8.1 [184].

\section{Allergic Reactions to Ingested Allergens}

Several causative agents of ACD can exacerbate clinical manifestations if ingested with foodstuffs [125]:

Co: Absorption in the gastrointestinal tract appears to be particularly rapid, owing to sudden relapses after FCT.

$\mathrm{Cr}$ : Even if we ingest $25-300 \mu \mathrm{g} /$ day, $\mathrm{Cr}$ concentration in the organism is low, therefore the role of $\mathrm{Cr}$ contained in foodstuffs is controversial.

Ni: High content in the above-mentioned foods. It is estimated that we ingest $150 \mu \mathrm{g} /$ day of $\mathrm{Ni}$ and the absorption in the gastrointestinal tract is $1 \%-5 \%$, sufficient to aggravate ACD and provoke urticaria and/or wheezing ( $\mathrm{Ni}$ asthma) [221]. However, it is unknown how much $\mathrm{Ni}$ is released by orthodontic instruments and the like [221]; remarkably, oral $\mathrm{Ni}$ administration may induce a high frequency of anergic $\mathrm{T}$ cells with persistent suppressor activity [9].

\section{Clinical Presentation}

ACD is initially located in the skin sites exposed to allergen contact, often a diagnostic distribution, although it may subsequently spread to other sites. ACD can be divided into acute and chronic forms [138].

\section{Acute Forms}

At first the lesions appear on the more exposed skin sites, where the contact is easier. Common sites of ACD are under rings, earrings and sites of ear-piercing, spectacle frames, bracelets, necklaces, coins in pockets, jeans studs, and other sites of metal contact (Figs. 8.13-8.16), and clinically the ears, neck, finger interdigital or dorsal aspects, or forearm back, the hand dorsal region, less the palms, face and less obvious sites are the lower limbs. Within 15-20 min of contact the lesion begins to itch.
Dermatitis is characterized by macular erythema and papules due to vasodilation, vesicles or blebs related to intensity of allergic reactions and to the tendency to flood from the contact site. The dermis shows perivascular leukocyte infiltration and edema. In some parts, for example, the eyelids, penis and scrotum, both erythema and edema predominate on the vesicles: above all the edema may be particularly intense. Lesions may remain circumscribed or, due to persisting exposure, spread even to far regions by an involuntary contact or in certain cases by self-contact. By progression of the inflammatory reaction, the skin becomes hyperpigmented, small vesicles appear, which result in exudation, transudation, crusting and subsequent scaling. Itching is a symptom invariably present and mostly intense. The dermatitis may appear later, with different localizations, by hand transfer; palms and soles and scalp are frequently spared, due to either the greater thickness of the corneum layer or an increased barrier function [7].

\section{Chronic Form}

If allergen exposure persists, the skin undergoes an epidermal hyperplasia evolving into hyperkeratosis and acanthosis when the leukocyte infiltration spreads via the epidermis and basal or corneum layers, then to the features of long-standing $\mathrm{AD}$, with lichenification, scaling, fissuring and crusts [7].

Systemic forms include pompholyx (vesiculous-bullous relapsing dermatitis, limited to fingers, palms or soles), the baboon syndrome (common involvement of the buttocks, accompanied by an eczema-like and symmetric eruption on the elbows, armpits, eyelids and lateral neck region) [138], following ingestion or absorption of $\mathrm{Ni}, \mathrm{Cr}, \mathrm{Co}$, due to metal prosthesis [7] or provoked by medications first applied topically and then ingested by mouth [227].

\section{Types of ACD}

Studies on the prevalence of localization of ACD lesions in two pediatric case reports have recorded the lesions as follows: generalized in $15.8 \%-22.5 \%$ of cases, if localized: face $8.3 \%-8.9 \%$, face and neck $42.3 \%$, mouth $35 \%$, limbs $35 \%$, upper limbs $25.2 \%$, hands $13.3 \%-45.9 \%$, lower limbs $3.6 \%$, feet $5.4 \%-20 \%$, hands and feet $3.3 \%-8.9 \%[170,185,199]$. Other children had foot eczema in $27.7 \%$ of cases [7] more often than on their hands [214] and on the hands in 5\%-6\% of cases [63]. The 13 main types of ACD are as follows:

Diaper dermatitis peaks at age 9-12 months. The skin may become erythematous and scaly and in more severe cases exhibits a papulovesicular or bullous reaction, which extends to external genitalia and buttocks, usually sparing the genitocrural folds. The lesions may spread 
beyond the diaper area to the lower abdomen and to the thighs, often complicated by secondary infection. This is certainly the most common contact dermatitis in infants, the prototype of irritant contact dermatitis (ICD), a reaction to the irritant and protracted action of ammonia deriving from urine left too long in the diaper, overly acidic feces, traces of soaps and detergents from an inappropriate cleansing of the diaper area, deodorants and preservatives in the absorbent diapers, ointments and oils, medicated or not, applied several times a day for emollient and anti-irritant purposes, and frictions, washings and wiping, often favored by the occlusive effect of plastic diapers [7]. This dermatitis is commonly treated, over a long period, with various topical medications, some potentially allergizing, for example, casein in a diaper ointment (Chap. 9).

Contact cheilitis is more frequent than stomatitis because the transition epithelium and lesser moistening by saliva facilitate sensitization. Milder cases are caused by lip dryness, chapping and lip licking, and in most severe cases it is intumescent, with erosions and crusts. Cheilitis stems from irritation provoked by:

- Foods, especially artichoke, carrot, cheese, citrus, fennel, kiwi, mango, peach, tomato, fruit juices, etc.

- Topical medications, toothpaste, lip salve, lipsticks, cosmetics.

- Mouthwash and cough syrups, candied fruits and foods containing menthol.

- Preservatives contained even in cold drinks and ices.

- Nail polish, nail enamel and nail hardening for onychophagists; eyelid involvement is unique for nail-polish sensitivity.

- Saliva may be irritant when children lick or bite their lips too often, or suck candies or chewing-gum [172].

- Lip contact with nickel-plated objects [47].

Toothpastes often contain cinnamon, carnation essence, menthol, eugenol, etc. Lipsticks may contain dyestuffs such as fluorescin and eosin, as well as antioxidants, carbamate cinnamon, lanolin, methylethane, oleic alcohol, and perfumes; lipsticks and lip salve contain carmine and lanolin. From cinnamon is derived an oil cross-reacting with balsam of Peru, benzoin, colophony, vanilla and essential oils of orange peel [138].

Contact stomatitis. The skin, differently from mucosa, has several proteins in the keratin layer, which may act as a carrier for hapten-sensitizing molecules. It is characterized by burning, pain, taste reduction up to ageusia and paresthesia. Unlike the substances previously listed, when the contact involves the mouth cavity, the oral mucosa lesions vary from a barely perceptible enanthem up to a dark red coloration with edema and ulceration, which may limit ingestion of foods and drinks, talking, and occasionally breathing. The direct application of offending allergen may provoke local lesions of the urticarial type, generalized and even anaphylactic. Especially at risk in sensitive subjects are the widely used metals in dentistry $[6,224]$, such as, $\mathrm{Ni}, \mathrm{Cr}$ (present in wires and alloy) [224], Hg (capping amalgam) [6], further toothpastes and mouthwashes, rubber, essential oils, preservatives, etc. [6]. Recovery is assured by removing instruments with $\mathrm{Ni}$ and/or $\mathrm{Cr}$ [224].

Other contact dermatitis of the mucosa [138]:

- Conjunctivitis.

- Contact balanitis is a glans pruritic erythema, often accompanied by preputial edema, derived from soaps, products for personal hygiene, condoms and related detergents and lubricants, too close-fitting underwear.

- Contact vulvitis has an onset with pruritus and edematous, erythematous, oozing lesions, limited to the area of contact with the etiological agent, which may become chronic when it persists for a long time. Common causes are soaps, bubble baths (and related additives), hygiene sprays, products for vaginal irrigation if insufficiently diluted or frequently employed, spermicidals, the partner's condom, perfumed toilet paper, too closefitting sanitary napkins, underwear, and contact with clasps, hooks, and zippers with $\mathrm{Ni}$.

Shoe dermatitis, caused by rubber and tennis shoes, boots, etc., due to a combined action of $\mathrm{Cr}$ and $\mathrm{Co}$ (tanned leather), $\mathrm{Ni}$ (metal decorations) and $\mathrm{Hg}$, present in the upper and/or lining parts. It affects the sole (59\%) and dorsum of the feet $(41 \%)$ and toes (29\%), sparing the interdigital spaces [214]. Most often the lesions are symmetric. Common allergens in rubber shoes and boots are thiomersal [214], MBT, BTS [102], thiurams, carbamix [48], mercaptans and PPDA [56], and a shoe glue with $6.2 \%$ of reactions [7]. The condition is worsened by excessive foot sweating.

Clothing dermatitis depends on a wealth of sensitizers, including dyes, fabric finishes, mordents, resins, rubber antioxidants, detergents, especially cleansing solutions, synthetic fibers, wool fabric, linen, garments, socks, shirt collars and cuffs, and elastic in garments. Obese children are more at risk. Nitric substances and poorly fixed dyes may be leached out by sweating. Clothing and accessories are implicated in 17\% [7] and 56\% [56] of pediatric cases.

Dye dermatitis (known since 1938) [86]. As in the clothing dermatitis, the affected areas are those where contact is prominent: neck, trunk, lateral and thigh posteromedial regions, popliteal space, antecubital space, the upper point of contact of stockings, or where other body parts come into contact with bed linen.

Dermatitis from plastic materials particularly include epoxypolymeric resins, diluent and thickenings used in dentistry (epoxyacrylate, methylacrylate and dimethylacrylate metylenglycol) [6]. Artificial nails based on acrylate (similar to that employed in dentistry) can cause long-lasting finger burning, tingling, and paresthesia related to tactile sensitivity [74].

Dermatitis from emollient and emulsifying agents found in cosmetics and topical medications such as oleic alcohol [127].

Dermatitis from topical CSs may be unsuspected, particularly if the medication is being or has been applied for a pre-existing dermatitis, but it is diagnostic when 
the initially improved ACD worsens without any apparent cause [2].

Latex dermatitis, latex hypersensitivity (generalized urticaria by a caoutchouc dental prosthesis), has been recognized since 1927 [198]. Natural latex (a variant of the original term "latice," derived from the Latin root lact, due to its milky aspect) is obtained from Hevea brasiliensis: 17 allergens are listed in Table 1.74 with a MW between 2 and $100 \mathrm{kD}$ (Euphorbiaceae family) and $1 \%$ from Parthenium argentatum [216]. Hev b 12 may be important as a cross-reactive pan-allergen [25]. The basic product contains natural rubber $(33 \%)$, resin $(2 \%)$, proteins $(1.8 \%)$ and water $(65 \%)$, to which ammonia is added up to $0.6 \%$ to prevent premature coagulation during transportation [216]. During the industrial manufacture, many chemicals, such as vulcanizers, stabilizers, accelerators, antioxidants are added [216]. World production is about $6 \times 10^{6}$ tons/year [193]. The worldwide increase in glove production following the advent of AIDS and now the poultry infection precautions has dramatically increased the prevalence of latex dermatitis [216]. All medical personnel at risk, as well as dentists, laboratory and health care workers must wear rubber (latex) gloves to prevent a potential contact with blood or body fluids throughout working hours, thus causing ACD in their patients [193]. For this reason, the use of condoms and diaphragms has also increased, with a great risk of sensitization [193, 218]. Particularly exposed are operating-room workers because, in addition to the gloves, they have contact with catheters, tubes, cannulas, bags for anesthesia, etc. [114]. Among non-health care workers, there are industrial workers, housewives, customers of restaurants and food sales points, as well as consumers if the shopkeepers and dairy workers use latex gloves during their daily work [97].

Pediatric groups at risk are in particular children exposed to some types of latex orthodontic appliance or undergoing surgical procedures, especially children with spina bifida or other urologic conditions, in whom reactions are common, due either to repeated surgery (contact with surgical gloves), or the frequent use of IV infusion sets, catheters and Rx procedures [193]. In children and adolescents affected with myelomeningocele, which is associated with immature defense mechanisms of the mucous membranes [66], the principal risk factors were the number of surgical procedures, atopy and/or sensitization to latex [167]: $60 \%$ of children had reactions outside of the operating room environment [112]. Children become sensitized mainly by direct contact between latex particles and blood vessels and open mucosa, whereas in adults the process takes place transcutaneously or by inhalation of aerosol particles [150]. Tables 8.10-8.12 [97, 109] show how latex allergy also develops to an incredible number of objects in common use [126, 132, 218].

Among the population considered to be at risk are health care professionals, where the incidence is be-
Table 8.10. Common latex sources and number of hypersensitivity reactions provoked in 70 patients: sources of clinical and/or lgE-mediated reactions

\begin{tabular}{lll} 
Sources & $\begin{array}{l}\text { No. of } \\
\text { patients }\end{array}$ & $\begin{array}{l}\text { No. of } \\
\text { reactions }\end{array}$ \\
\hline Surgical and household gloves & 69 & 43 \\
\hline Sticking plaster & 11 & 9 \\
\hline Balloons (any type) & 8 & 6 \\
\hline Elastic bandages & 6 & 5 \\
\hline Rubber contraceptives & 5 & 3 \\
\hline Face masks for anesthesia, & 3 & 2 \\
\hline diving, underwater fishing & 3 & 2 \\
\hline Stretch textiles & 3 & 2 \\
\hline Shoes & 2 & 1 \\
\hline Insulating materials & 1 & 1 \\
\hline Air mattresses & 1 & 1 \\
\hline Sailing equipment & 1 & 1 \\
\hline Stamps & 1 & 1 \\
\hline Colors & & \\
\hline
\end{tabular}

Table 8.11. Common latex sources and number of hypersensitivity reactions provoked in 70 patients: sources of clinical reactions

\begin{tabular}{ll} 
Sources & No. of patients \\
Hot water bottle & 1 \\
\hline Baby pacifiers & 1 \\
\hline Shower curtains & 1
\end{tabular}

Modified from [97].

tween $2.6 \%$ and $16.9 \%$, and in atopic babies (2\%) [218]. The increased incidence in children of latex allergy has recently been highlighted [112]. Atopy as a factor that facilitates sensitization [66] is present in a large group of subjects who are not at risk (41\%-74\%) $[97,112,196]$. Latex-specific IgE have been detected in $0.5 \%-10.2 \%$ of atopic children with IgE antibodies $\pm 1,000 \mathrm{IU} / \mathrm{ml}$; almost nobody was informed of any allergy before the visit [3]. SPTs are positive in $3 \%-6.8 \%$ of atopic children and specific IgE (sIgE) are elevated in positive challenges [152]. The determination of sIgE (CAP) shows that $7.2 \%$ of 282 children are allergic. In this sample, the incidence among the atopic population varied between $1.69 \%$ and $9.5 \%$, depending on the methodology used [66]. The prevalence of IgE-mediated allergy in children with neurological abnormalities is the highest: sensitization is $18 \%-41 \%$, with peaks up to $77.1 \%[112,193]$. Alternatively, atopy is present in $49 \%$ of sensitized and 
Table 8.12. Additional consumer products and hospital latex products provoking clinical and/or lgE reactions

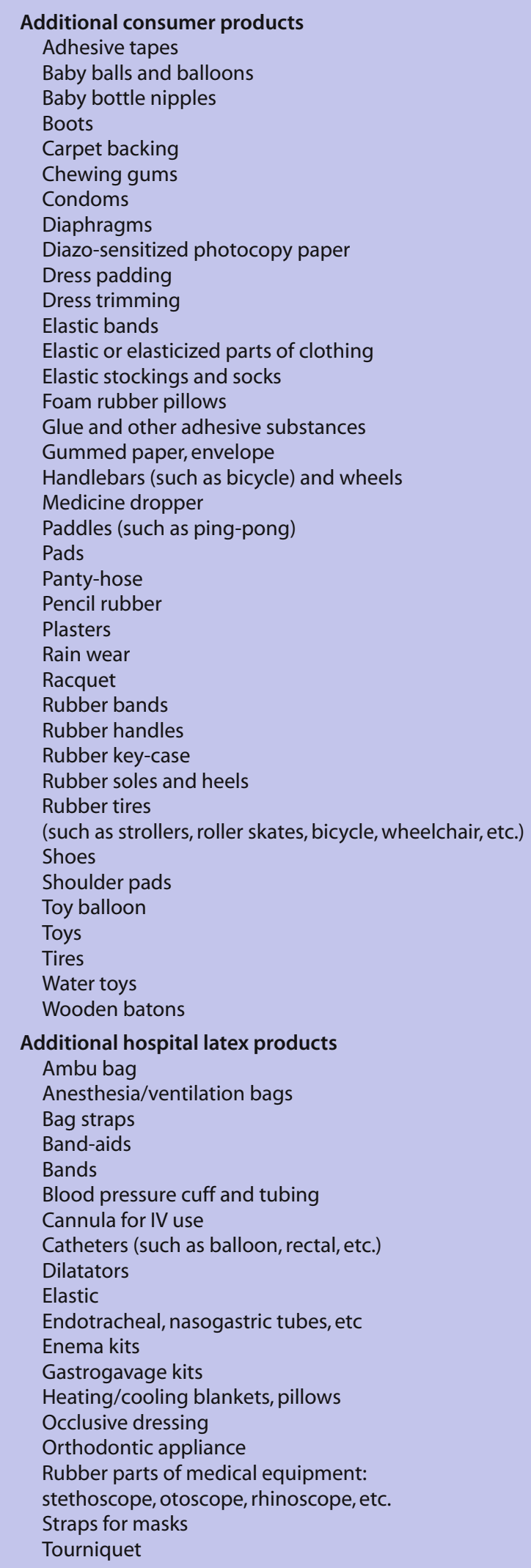

Data from [109].
$30 \%$ of nonsensitized patients, with statistically significant differences related to allergic reactions to latex, in $96 \%$ and $30 \%$ of cases, respectively [193]. The report of one case of anaphylaxis in 646 surgical procedures over 18 years is reassuring [167], but latex-induced anaphylaxis occurred in $10 \%$ of patients $>5$ [124]. A severe anaphylactic shock occurred in an 8-year-old boy who was undergoing elective surgery for an ileostomy [94]. Type IV hypersensitivity to natural rubber latex may be a problem for a proportion of patients with eczema, particularly on their hands [195]. The incidence of latex allergy in the general population is unknown, but it seems to be about $0.001 \%$, with a frequency of $0.125 \%$ in unselected surgical patients [218].

The immunological mechanism is IgE-mediated $[3,43,112,196]$, especially in children: serum sIgE are detected to natural latex [97, 196], SPT, ELISA, and RAST. RAST inhibition is also positive. The allergens are usually peptides found in natural latex [193]. Latex exposure may occur by cutaneous, percutaneous, mucosal, parenteral, and respiratory (from inhaling latex glove powder) routes [97]. By the respiratory route, the reaction is materialized within a few minutes with a progression of symptoms from rhinitis, wheezing, conjunctivitis, facial angioedema, to generalized urticaria and symptoms of anaphylactic reaction up to severe generalized reactions (Table 8.13) [160, 216]. Latex allergens in respirable particulate air pollution from tires rubbing on roads is a cause of significant respiratory reactions [239], as also is cornstarch powder on latex products for glove lubrication [205]. Skin exposure induces prevalently ACD symptoms [97, 152, 193], but the latex-fruit and latex-vegetable syndrome provokes anaphylaxis also in children. Anaphylaxis burst occurred within 5 min in a girl playing ball [126], as well as in a girl and a boy playing with a plastic ball in play areas [73] and in allergic adults [25], and facial edema in a boy blowing up a balloon [196]. Recently, a profilin has been identified as a component of natural latex, structurally correlated to profilins of different origin found in foods and pollens [220] (Table 1.72), and associated with cross-reactivity between latex, taxonomically unrelated plants and several fruits and nonfruits (Table 8.14) [22, 36, 43, $126,160,176]$. A latex-fruit syndrome was reported by $55.9 \%$ of latex-allergic patients [36]. In Appendix 8.2, we indicate [36] the employment procedures of some extracts: papain and chymopapain are associated with anaphylaxis, as analyzed in Chap. 20.

Occupational ACD. In children of 13-14 years, the hairdressers among them were allergic to PPD, Ni, thiuram; construction workers to $\mathrm{Cr}$, cement, $\mathrm{Co}$; in food industry workers, some were allergic to garlic and $\mathrm{Ni}$; in the footwear industry the problem came from $\mathrm{Cr}$, $\mathrm{Co}$, and $\mathrm{Ni}$; in the ceramic industry it was $\mathrm{Co}$ and $\mathrm{Ni}$ [85]. Other working adolescents were allergic to metal accessories (37\%), medicaments $(8.1 \%)$, cosmetics (5.4\%) and shoes (4.5\%) [199]. 
Table 8.13. Manifestations and differential diagnosis is immediate, delayed, and irritant latex reactions

\begin{tabular}{|c|c|c|c|}
\hline $\begin{array}{l}\text { Clinical } \\
\text { manifestations }\end{array}$ & $\begin{array}{l}\text { Immediate type } \\
\text { ( type I) hypersensitivity }\end{array}$ & $\begin{array}{l}\text { Delayed type } \\
\text { (type IV) hypersensitivity }\end{array}$ & Irritant type \\
\hline Causative agent & Latex proteins & $\begin{array}{l}\text { Accelerators: thiurams, } \\
\text { contact with gloves, powder, } \\
\text { surfactants, formaldehyde, etc. }\end{array}$ & $\begin{array}{l}\text { Insufficient hand rinsing, } \\
\text { rubber additives, } \\
\text { glove powder oxidants, } \\
\text { formaldehyde, etc. }\end{array}$ \\
\hline Atopy & Yes & Yes & No \\
\hline Pathophysiology & $\begin{array}{l}\text { Skin/membrane contact, } \\
\text { invasive procedures, injections, } \\
\text { allergen inhalation (powder) }\end{array}$ & Skin contact & Skin contact \\
\hline $\begin{array}{l}\text { Percent }(\%) \\
\text { of vulnerable subjects }\end{array}$ & $\begin{array}{l}\text { General } 0.0001 \% \text {, hospital: non- } \\
\text { surgical 3\%-5\%, surgical } 7 \%-12 \%\end{array}$ & $7 \%-18 \%$ & $100 \%$ \\
\hline Onset time & Minutes, rarely $>2 \mathrm{~h}$ & $6-48 \mathrm{~h}$ after contact & Gradual, over days \\
\hline Initial reaction & Itch, tingling, burning & Itch, then pain & Itch or erythema \\
\hline Dermal reaction, acute & Urticaria & Erythema, vesicles or blisters & Scaling, edema \\
\hline $\begin{array}{l}\text { Dermal reaction, } \\
\text { chronic }\end{array}$ & Urticaria, more extensive & $\begin{array}{l}\text { Dryness, thickening, scaling, } \\
\text { fissuring, peeling crusts, } \\
\text { papules, vesicles }\end{array}$ & $\begin{array}{l}\text { Dryness, thickening, } \\
\text { fissuring, scaling, crusts, } \\
\text { papules, sometimes } \\
\text { vesicles or blisters }\end{array}$ \\
\hline Limits of the reaction & $\begin{array}{l}\text { Whenever part of the body } \\
\text { beyond the contact area }\end{array}$ & $\begin{array}{l}\text { Even beyond the } \\
\text { contact area }\end{array}$ & $\begin{array}{l}\text { Limited to the } \\
\text { contact area }\end{array}$ \\
\hline Facial involvement & Diffused swelling, runny nose & Only if face is touched & Only if face is touched \\
\hline Respiratory involvement & Rhinoconjunctivitis, wheezing & No & No \\
\hline Systemic involvement & Nausea, hypotension, anaphylaxis & No & No \\
\hline Life-threatening & Yes & No & No \\
\hline
\end{tabular}

Data from $[160,216]$.

Table 8.14. Cross-reactions between latex, fruits, and nonfruits in patients with related allergies

\begin{tabular}{ll}
\hline Fruits & Passion fruit \\
\hline Apple & Peach \\
\hline Avocado & Peanut \\
\hline Banana & Pineapple \\
\hline Cherry & Non-fruits \\
\hline Chestnut & Alder \\
\hline Foconut & Buckwheat \\
\hline Grapes & Celery \\
\hline Hazelnut & Chocolate \\
\hline Kiwi & Potato \\
\hline Mango & Pistachio \\
\hline Melon & Sesame \\
\hline Papaya & Tomato \\
\hline
\end{tabular}

Data from $[22,36,43,126,160,176]$.
Skin-diver dermatitis is elicited by the equipment (diving mask, fins, etc.). The effect is caused by constituents such as dithiocarbamates, formaldehyde, isopropyl-phenylparaphenylendiamine, mercaptobenzol, butylphenolformaldehyc resin, thiourams, etc. [7].

\section{Diagnosis}

In establishing an etiological diagnosis, it is crucial to begin with a careful, exhaustive history, the single most important and cost-effective diagnostic tool, including family and personal history, to be completed at subsequent visits. A clinical history of redness, itching, or swelling, or of unexplained urticaria or anaphylaxis after contact with a specific product suggests that a detailed history can be useful for the identification of allergic children. All children and parents should be questioned.

- Does the child have a history of atopic disease?

- What product was there contact with and how often?

- Is a relation with a particular activity or environment suspected? 
- Are diapers, chemical products, detergents, cosmetics, ornaments, etc. used?

- Does the infant use rubber pacifiers or do children play ball?

- What type of clothing, shoes, gloves, etc. are used?

- When a latex allergy is suspected, is there a history of allergy to fruits (Table 8.14)?

- What is the course of the disease?

- Have topical medications been applied for an ongoing episode or an earlier skin disease?

- Was symptom onset after ingestion of foods containing substances that formerly induced a skin disease?

- Is ACD caused by cross-reactivity [56]?

The medical examination is essential to exclude other skin conditions with lesion aspect and distribution similar to those of ACD. In younger children the diagnosis, apart from diaper dermatitis, is facilitated by the restricted panel of age-related foreign substances to be uncovered:

- Babies starting to crawl may develop leg, knee and elbow dermatitis, by contact with wax or detergents for floors, components of rugs and wall-to-wall carpeting, etc.

- Babies and young children may touch or caress parents, relatives, or baby-sitters who use cosmetics, fragrances, deodorants, etc.

Points to be considered:

- Little girls have ear-lobes pierced for earrings.

- Children and adolescents of both sexes wear jeans with metal buttons or other trimmings.

- Early use of cosmetics, etc. In Belgian participants, the mean age of cosmetic allergy was 12.4 years; however, earlier cases were detected at age 4 [56].

- Topical medications, also for trivial skin lesions or ear pain, are typically used more frequently compared to adults.

- Similarly, orthodontic treatments are more frequent in children.

ACD diagnosis related to lesion topography (Table 8.9):

- Face and neck ACD. This localization may disclose diagnostic difficulties because several agents are potentially acting: contact and photocontact substances, cosmetics and costume jewelry should be taken into account [57]. The application of chemical substances to the scalp can induce manifestations in distant sites such as the face, ears and neck. Shampoos and hair gels may provoke helix reactions. ear piercing facilitates $\mathrm{Ni}$ sensitization [47] and is a risk factor for AIDS.

- Hand ACD. About $50 \%$ of cases involve the hand, generally on the back, whereas the wrist is involved when objects are taken. It is chiefly caused by the use of rubber gloves, cleaning products, cosmetics, but any of these substances can be the cause. Hand dermatitis is frequent in girls and boys helping in housework or in family shops (see protein contact dermatitis, PCD), in girls working as apprentice hairdressers, in boys helping bricklayers, mechanics, barmen, and the like [172, 200], and above all the Europeans using Ni-containing coins: euro cents.

- Foot ACD. The typical location on the back and at joints does not offer diagnostic problems. Causative agents are those found in rubber shoes, shoe creams (see description of shoe dermatitis in preceding section) or in the coloring agent both of shoes and stockings.

- Generalized and/or unusual pictures. These are attributable to ubiquitous substances such as those in rubber (see the related additives) able to produce lesions at several sites, including the face (sponges for make-up, ear plugs, etc.), periocular region (goggles for motorcyclists, swimmers, skin-divers, etc.), thorax and belly (elasticized underwear), genitals (underwear, condom, diaphragm, pessary, etc.), legs (elasticized stockings), and dyes and other cloth constituents often unsuspected and difficult to diagnose.

Particular contact lesions are caused in children and adolescents of both sexes by piercing, at all ages by substances employed for oral and dental hygiene and in dentistry: soaps, detergents, toothpaste, anesthetics, metallic plates and screws, and ear drops in children [172]. Dentists in turn can show symptoms after use of an anesthetic or by contact with instruments cleaned with formaldehyde [6], a hidden allergen which gathers in ear canals or under rings during washing with formaldehyde-based products. Inhalation of related steams may induce face and periorbital swelling [16].

- Systemic ACD. It is objectively rare, often dependent on re-exposure to previously used topical medications, thus sensitizing the subjects up to severe systemic reactions [200] by spread of lesions to sites far from the primary exposed region or by oral, inhalation or parenteral exposure to antigens formerly the cause of cell-mediated contact manifestations [227].

\section{Laboratory Studies}

Latex allergy. SPT is the diagnostic procedure of choice not only in young children affected with spina bifida, but also in all subjects with positive history due to frequent exposure to latex, in those allergic to mentioned fruits and in cases of urticaria and/or anaphylaxis by unknown causes [196]. Diagnostic screening is complicated by a number of asymptomatic children with $\mathrm{SPT}^{+}[152]$. SPTs are efficient in children $[152,193]$, in addition to prick + prick testing [126, 152], also with gloves (Chap. 6), RAST inhibition [193], useful for the study of crossed allergenicity [115], and challenge tests, which appear to be correlated to RAST [152]. Latex gloves are the source of great heterogeneity: there are significant (sometimes striking) differences between manufacturers and product lines in the amount of free latex protein that can be released from the glove and the number and types of chemicals used in glove production [196]. Among the stabilizers is also casein [133], so CM allergic children may have false positive reactions to casein [133]. 
ACD diagnosis is confirmed by patch test [14, 77]: Finn chambers [14] or True test [2] (Chap. 6), selecting the haptens that more frequently are causes of ACD (standard series) or those potentially relevant in the surroundings of a single patient (special series) [14]. All children with suspected ACD should undergo patch testing. Dentists should undergo a preventive assessment by this method [6] because of the notable spread of Ni-plated instruments. Patch testing is also helpful to reveal possible cross-reactions or concomitant hypersensitivity to additional haptens [149], and to natural rubber latex [195]. False-positive results may depend on aspecific skin hyperreactivity, following a local increase in LC numbers, or particular conditions of both epidermis and vasculature which contribute to a pro-inflammatory cytokine increase [207].

To verify whether trimmings or worn objects contain $\mathrm{Ni}$, some drops of a diluted ammoniacal solution containing $1 \%$ dimethylglycoxin can be applied: the $\mathrm{Ni}$ presence is revealed by a bright rose dye [138].

\section{Differential Diagnosis}

Differential diagnosis includes the following considerations:

- ICD (Table 8.15) [138] differences with ACD are rare, since both haptens and irritants decrease epidermal LC numbers, HLA-DR, CD54 and CD80 expression is diverse, and RT-PCR (reverse transcriptase-polymerase chain reaction) has shown an impressive overlap between ACD a ICD [82]. The main ICD example in children is diaper dermatitis, but one baby had physical irritation from constant friction due to occlusion by abdominal skin on a metal pin causing physical irritation [143]. Several agents (up to 489 in number) [143] are capable of expressing a direct irritant action on skin cells, affecting the hands in $36.3 \%$ and face in $26.4 \%$ of cases [143]. Their power depends on the chemical nature, concentration, duration of application and individual predisposition. The principal symptoms are a burning sensation (pruritus in ACD), early onset $1 \mathrm{~h}$ after contact,

Table 8.15. Comparison of irritant $(I C D)$ and allergic contact dermatitis $(A C D)$

\begin{tabular}{|c|c|c|}
\hline & Irritant & Allergic \\
\hline \multirow[t]{4}{*}{ Clinical morphology } & $\begin{array}{l}\text { Acute ICD: erythema, edema bullae, } \\
\text { necrosis restricted to the area of necrosis }\end{array}$ & $\begin{array}{l}\text { Dermatitis in acute and chronic ACD } \\
\text { can be similar to ICD, but lesions } \\
\text { are often spreading, papules } \\
\text { and vesicles are seen most often }\end{array}$ \\
\hline & Decreasing phenomenon & Increasing phenomenon \\
\hline & Chronic ICD: lichenification & $\begin{array}{l}\text { Kinetics of resolution may be slower } \\
\text { than ICD during patch testing }\end{array}$ \\
\hline & $\begin{array}{l}\text { Erythema, scaling, hyperkeratosis, } \\
\text { rhagades with less area restriction } \\
\text { than acute ICD }\end{array}$ & \\
\hline \multirow[t]{2}{*}{ Histology } & $\begin{array}{l}\text { In acute ICD, necrosis of epithelial cells } \\
\text { may by present }\end{array}$ & $\begin{array}{l}\text { Same as ICD; but no epidermal necrosis, } \\
\text { neutrophils usually less prominent }\end{array}$ \\
\hline & $\begin{array}{l}\text { In delayed and chronic reactions, } \\
\text { spongiosis, exocytosis, dermal edema } \\
\text { and a mononuclear infiltrate; occasionally, } \\
\text { neutrophil-rich infiltrates }\end{array}$ & \\
\hline \multirow[t]{2}{*}{ Immunochemistry T cells } & Predominantly $\mathrm{CD}^{+}{ }^{+} \mathrm{T}$ cells; & Predominantly $\mathrm{CD}^{+} \mathrm{T}$ cells, some \\
\hline & $\begin{array}{l}\text { Some } \mathrm{CD}^{+} \mathrm{T} \text { cells, activated } \\
\text { by } \mathrm{IL}_{2} \mathrm{R} \text { expression }\end{array}$ & $\begin{array}{l}\mathrm{CD} 8^{+} T \text { cells, activated state indicated } \\
\text { by } \mathrm{IL}_{2} \mathrm{R} \text { expression }\end{array}$ \\
\hline $\begin{array}{l}\text { Frequency of hapten- } \\
\text { specific T cells in infiltrate }\end{array}$ & Not known & Estimated to be approximately $1 \%$ \\
\hline Number of Langerhans cells & No consistent changes & Decreased then recovery \\
\hline Morphology & $\begin{array}{l}\text { Alterations noted, but are highly } \\
\text { dependent on chemical }\end{array}$ & $\begin{array}{l}\text { Alterations noted, particularly with } \\
\text { high doses of hapten }\end{array}$ \\
\hline \multicolumn{3}{|l|}{ Accessory molecules } \\
\hline HLA-DR & Increased & Increased \\
\hline CD54 & Increased & Increased \\
\hline CD80 & Increased & Increased \\
\hline
\end{tabular}




\begin{tabular}{|c|c|c|}
\hline & Irritant & Allergic \\
\hline \multicolumn{3}{|l|}{ Cytokine profiles } \\
\hline TNF- $\alpha$ & Increased & Increased \\
\hline IFN- $\gamma$ & Increased & Increased \\
\hline GM-CSF & Increased & Increased \\
\hline $\mathrm{IL}_{1 \alpha,-\beta}$ & Not detected & Increased \\
\hline $\mathrm{IL}_{4}$ & Not detected & Increased at $24 \mathrm{~h}$, absent by $48 \mathrm{~h}$ \\
\hline \multicolumn{3}{|l|}{ Chemokine profile } \\
\hline IP-10 & Not detected & Increased \\
\hline MIP-2 & Not detected & Increased \\
\hline \multicolumn{3}{|l|}{ Transgenic mice } \\
\hline $\begin{array}{l}\text { Overexpression of } \\
\text { CD80 by keratinocytes } \\
\text { CD54 by keratinocytes }\end{array}$ & $\begin{array}{l}\text { Increased } \\
\text { Increased }\end{array}$ & $\begin{array}{l}\text { Increased } \\
\text { Increased }\end{array}$ \\
\hline $\begin{array}{l}\text { Knock-out mice that lack } \\
\text { TNF- } \alpha \text { R } \\
\text { CD4 } \\
\text { CD8 } \\
\text { CD28 }\end{array}$ & $\begin{array}{l}\text { Not tested } \\
\text { Decreased } \\
\text { Decreased } \\
\text { Decreased }\end{array}$ & $\begin{array}{l}\text { Increased } \\
\text { Decreased } \\
\text { Decreased } \\
\text { Decreased }\end{array}$ \\
\hline \multicolumn{3}{|l|}{ Clinical manifestations } \\
\hline Frequency & Several patients & Few patients \\
\hline Diseased & All exposed & Only sensitized \\
\hline Extension of lesions & Only the contact area & Beyond the contact area \\
\hline Onset of lesions & Within a few hours & $24-72 \mathrm{~h}$ \\
\hline \multirow[t]{2}{*}{ Aspect of lesions } & Erythema, edema & Erythema, papule, itching \\
\hline & Scaling, bullae, necrosis & Vesicles \\
\hline Symptoms & Burning, stinging & Itching \\
\hline
\end{tabular}

Data from [138].

polymorphous aspect with no tendency to generalization, rapid regression after interruption of contact.

- AD is often associated with ACD: $\mathrm{Ni}$ is accused in children with a mean prevalence of $4 \%$ [47]; the hand eczema appearing as a dyshidrotic vesicular eruption may be largely associated with an atopic condition [63].

- To differentiate from PCD, we mention that the pathogenic agents are protein fractions of animal and vegetable origin.

- Mycotic infections (see above).

- Several cutaneous eruptions such as those of SLE, erythema multiforme, dermatomyositis, viral exanthems, pityriasis rosea have mostly a symmetrical aspect rather than eczematous, while ACD has peculiar locations; for example, in feet ACD involves the back (in psoriasis the sole), with a relative sparing of interdigital spaces (unlike viral infections).

- Dyshidrotic eczema often begins with small congested, pruriginous and relapsing vesicular lesions, located on the internal sides of both hands and toes, but then occurs in the soles of the feet and the palms of the hands.

\section{Treatment}

Beyond any rigid schema of the inhibiting effects on LCs, TNF- $\alpha$ [128] and UV rays with an $\mathrm{IL}_{10}$ mediation could be utilized for therapeutic purposes [71].

Local or general management aims to reduce the clinical manifestations and avoid possible infectious complications; in both cases a preventive ascertainment of the composition of products for topic or systemic use will eliminate those containing sensitizing substances. Treatment of allergic reactions to latex begins with immediate removal of any identified source of latex in direct patient contact. In Chap. 13 we discuss SLIT desensitization to latex. Treatment is similar to anaphylaxis from other causes and may require the use of epinephrine [30]. 
In case of acute, congested, edematous, exudative dermatitis, local therapy should be limited to hydrophilic packs with watery solutions at ambient $\mathrm{T}$, repeated from two to four times during the day. A number of solutions with antiseptic and decongestant action, without the danger of unwanted allergization, are detailed in Chap. 7, along with water, oil or glycerin pastes, useful in congested and exudative stages, and inert powders in case of intolerance to wet medications. When the acute and exudative stage subsides, lipophilic ointments such as Lassar paste may be appropriate.

In addition, always for topical use, low or moderate potency CSs can be used (Table 7.16) in different excipients (lotions, creams, gel, ointments), for short-term (7-10 days) exclusive application on the involved cutaneous sites in tandem or alternate therapy, taking into account possible contact reactions [2]. Subsequently, topical nonsteroid medications can be used for the same length of time; this combined treatment should be sufficient to return the skin to a normal state. Oral antihistamines may hold promise in relieving itching (Chap. 7). The newer topical immunosuppressors, tacrolimus and pimecrolimus, may be effective in the treatment [118].

Diaper dermatitis, especially in summer, responds to rigorous hygienic measures, which are useful also for prevention: the use of cloth diapers, washed at home exclusively with Marseille soap.

\section{Prevention}

A unique specific management consists in the prevention of whatever new contact with responsible or suspected substances, especially if they are capable of cross-reacting with other compounds [7], or when feasible substituting, for example, metal wires in orthodontic prostheses with acrylic ones [224], almost always followed by ACD regression. Unfortunately, labels do not fully report product composition [57]: cosmetics, antigens correlated to rubber, textiles and metals are examples. However, several clinics have a complete display of materials that contain the offending allergens, a great aid for the patient, the doctor and the industry, as well as for an exchange of information between experts in the discipline [57].

People allergic to Ni should exclude from their diet the above-mentioned foods and eat small amounts of carrots, cabbages, cauliflower, cucumber, wholemeal wheat or corn, fresh fruits other than pears, and lettuce. Older children should also exclude beer, coffee and wine. Do not cook foods in stainless steel pots, both new and used, in particular foods containing oxalic acid (spinach), malic (apple), or citric (citrus fruit), because the Ni concentration is increased significantly [125]. For metal-induced dermatitis, it is appropriate to prescribe a diet with a low content of foods that are positive to patch testing, which is needed to be supported in chil- dren by open FCT (OFC) [125]. For objects of common use and imitation jewelry containing $\mathrm{Ni}$ and/or $\mathrm{CoCl}$, replacements are available in brass or low-carat gold, and drawer and utensil handles of nonmetallic material. Alternatives to perfumed cosmetics and household detergents are the fragrance-free products. Those who are allergic to these substances should therefore carry out strict dietetic prevention, together with contact prevention, to ensure a clear-cut clinical improvement of ACD lesions [80]. Women have long been encouraged to prefer Ni-free accessories, and men to give up metal watch bands, etc. But is impossible to give up handling metal coins. We hope that the countries of the European Union (EU) conform to the Danish legislation. In our opinion, difficulties will be $\mathrm{Ni}$ is practically irreplaceable in the alloys encountered because since it combines excellent technical properties and low price. Recently, a group of European companies has obtained a Ni-free international patent and the EU has issued directive 94/27 and thereby defined the Ni limit level at $0.5 \mathrm{~g} / \mathrm{cm}^{2}$ for objects in direct and prolonged contact with the epidermis.

People allergic to $\mathrm{Cr}$ should employ leather tanned with vegetable systems, by ascertaining whether tannins are present, and those with ACD to dyes should wear white or plant-fiber clothing.

The data available today show which measures should be suggested to patients with ACD to latex [109]. Latex avoidance should be advocated for all individuals with a positive skin or blood test or a positive history [30]. Because latex glove antigen content varies among brands and among lots from the same manufacturers [193], the allergics and surgeons can wear polyvinyl gloves, or gloves subjected during manufacture to washing after pressing and in-process steam sterilized for $1 \mathrm{~h}$ at $120^{\circ} \mathrm{C}$ [216], or powder-free Biogel Skinsense ${ }^{\mathrm{TM}} \mathrm{N}$. In allergic patients, premedication with $\mathrm{H}_{1}$ or $\mathrm{H}_{2}$ antihistamines or prednisone has been used to prevent untoward side effects, but only as a supplementary measure in addition to discontinuing use of latex gloves, since the results are not always effective [30, 193]. In atopic children, surgical procedures should be undertaken with the greatest caution since they tend to be sensitized even by the slightest contact with latex $[3,126]$ : in children with spina bifida, latex contact should be avoided from birth [193]. In particular, pacifiers should be banished [109], surgeons should manipulate latex gloves outside an allergic patient's room to avoid airborne transmission of latex particles [112], which are also spread by the cornstarch covering gloves and other objects [205], during surgery catheters in silicon (silastic) and for medications tapes and bandages with acrylic adhesives should be preferred [112]. Latex allergy should be investigated not only in multioperated patients but also in children with severe $A D$, fruit allergy and with urticaria or anaphylaxis by unspecified causes [196]. 
A new form of treatment consists in asking a latex patient to wear a latex glove for increasingly longer times, or in a type of SLIT desensitization (Chap. 13).

\section{Protein Contact Dermatitis}

\section{Definition}

PCD is an exquisitely occupational dermatitis seen in individuals exposed to animal and/or vegetable foods: cooks, veterinarians, slaughterhouse workers, housewives, boys and girls helping in family business, etc. [184]. PCD occurs as a chronic eczema accompanied by erythema, swelling and itching on fingers. Immediate recurrences in the same sites are frequent following contact with the causal agent.

\section{Etiopathogenesis}

PCD is another area of increasing interest with only a small rate of patients with positive family and/or personal history for atopy [186].

The causative agents are protein fractions of animal and vegetable origin, handled for a more or less protracted period, but the precise pathogenetic mechanism is as yet largely unexplored [1]. It is proposed that apparently unaffected skin facilitates the passage of protein substances via the epidermis, thus producing a spongiosis, an intercellular edema of the skin's spongy layer. Histological studies have revealed the outcome of these lesions, including superficial vesiculation, parakeratosis and lymphomonocyte infiltrate localized in the superficial dermis and in the perivascular seat. The mononuclear infiltrate delineates full-blown $\mathrm{T}$ lymphocytes with a clear-cut CD4 prevalence on CD8 T cells. Immunohistochemical studies show an increase in the number of LCs in the vesicles, epidermis and superficial dermis [186].

The list of foods, fruits, and vegetables identified as etiological agents is remarkably long: see Table 8.16 $[1,186]$.

\section{Clinical Presentation}

The vesiculation starts suddenly after contact with the causative agent, also following a long period of manipulations without lesions [186]. After contact, prominent erythematous, pomphoid and vesicular manifestations appear within a few minutes on the back of the hand and/or fingers, with progressive spread of erythema, accentuation of vesiculation and itching [131].
Table 8.16. Protein fractions of animal and vegetable origin more often causative of PCD

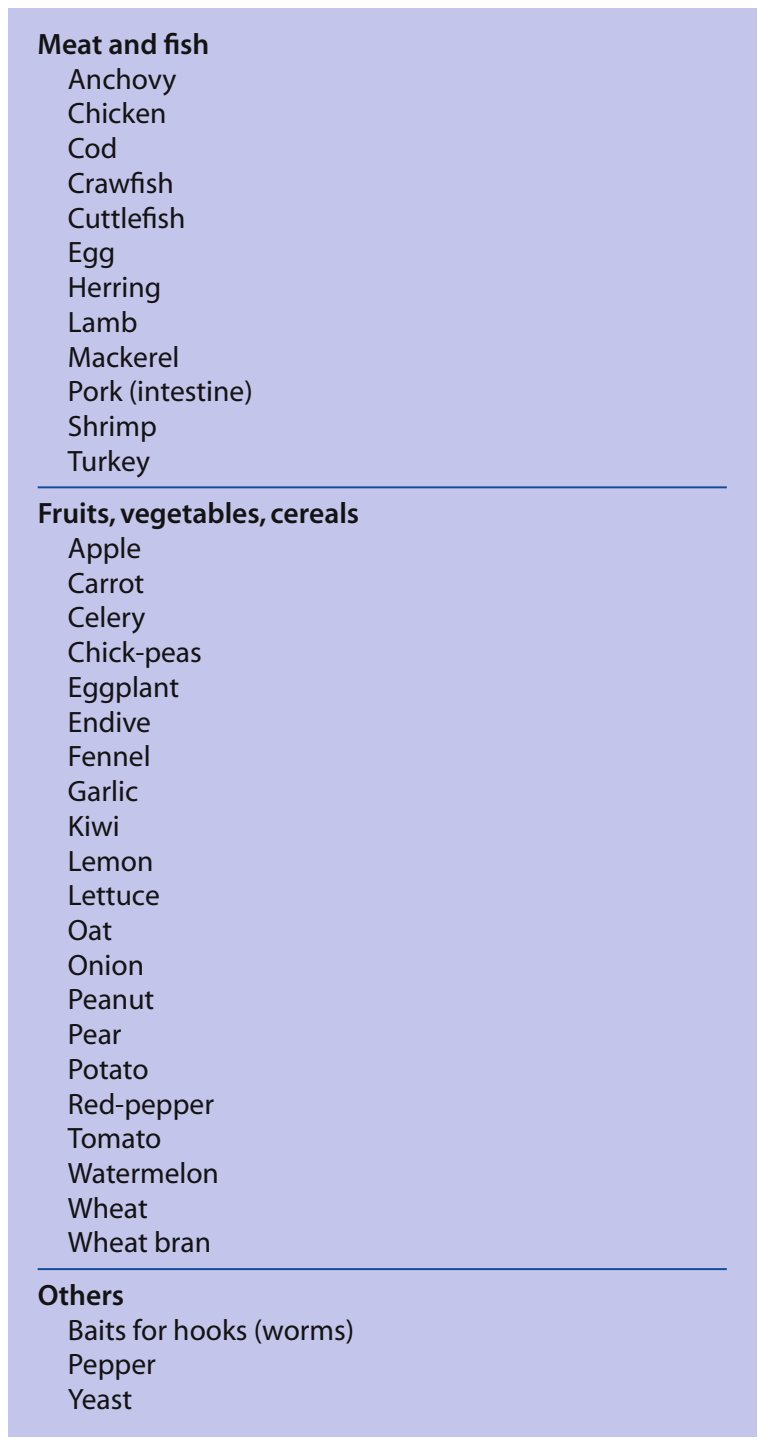

Data from $[1,186]$.

\section{Diagnosis}

SPTs are the diagnostic tests of first choice. The reactions show within 10-30 min, small vesicles that are sometimes dyshidrosiform, combined with erythema, and notably itching [131]. Better results are obtained with the prick + prick test, or the similar SAFT (skin applied food test) by employing fresh and raw foods [1]. The RAST may be reliable.

\section{Differential Diagnosis}

As discussed earlier, the offending agents are protein fractions of common foods, which distinguish PCD from the haptens responsible for ACD [186]. 


\section{Treatment}

There is no specific management. Affected subjects should protect their hands with polyvinyl gloves that cover the lower forearm or, if possible, should change jobs [1].

\section{Phytodermatitis}

Phytodermatitis is a particular type of contact dermatitis caused by plants, especially by chemical substances present in the leaves, stems, flowers, pollens and roots, particularly essential oils, components of the oleoresinous fraction, containing in turn phenols, aldehydes and aromatic alcohol, terpenes, hydrocarbons, aliphatic and aromatic esters, and kinones. The dermatitis is distinguished by the lesions provoked by irritant effects, particular to some plants such as Urticaceae, and by injecting histamine, serotonin and acetylcholine at the contact site, often leading to linear or figured aspects and bullous or pomphoid eruptions elicited by toxins of further plants, including Compositae, crucifies, lilies and Ranuculaceae (directly or following plant cutting) [7].

\section{Allergic Phytocontact Dermatitis}

Several agents cause plant contact dermatitis:

- Catechols, belonging to the family of phenols, are among the more widespread allergens in the plant world, equipped with an elevated sensitizing power. These include eugenol, used in dentistry and the manufacture of soaps, perfumes and carnation oils; vanillin; pentadecilcatechol, a potent allergen of the Rhus genus, including Rhus toxicodendron, or R. radicans and $R$. vernix, by far the most common cause of plant contact dermatitis in the US, where they are called poison oak, poison ivy and poison sumac, and are a frequent cause of ACD in children via pets, mainly long-haired dogs, which rub against the plants and transmit oleoresin to newborns and children.

- Terpenes are contained in citrus, celery, chrysanthemums, and other products such as resins and balsams.

- The plants of the Compositeae family (chrysanthemums, pansy, ragweed, sunflower), those of the Alstroemeria genus and Hydrangea species, and hepatica contain sesquiterpene lactones yielding extended contact phytodermatitis on exposed skin sites, especially in florists [2]. The pollens are common causes in the fall season via their allergenic fractions, the oleoresinous and hydrosoluble protein, which by inhalation can cause respiratory allergy. These conditions are differentiated from photodermatitis by the season and the lesions with shaded instead of clear-cut limits [7].

\section{Allergic Photodermatitis}

\section{Definition}

Allergic photodermatitis is kind of CMI to chemical substances that become antigenic when activated by sunlight. When skin is exposed to UV rays, cutaneous symptoms of various types may appear during a time when a patient is exposed to different exogenous or endogenous substances or is taking an offending medication topically, but most often systemically $[58,174]$.

\section{Prevalence}

It is connected principally with newly introduced medications and chemical substances. The manifestations have alternating phases, in epidemic form when a new therapeutic agent is commercialized. Generally as soon as its photosensitizing potential is ascertained, the product is withdrawn and the prevalence abates.

\section{Pathogenesis}

UV rays are divided into UVA, with bands comprised between 400 and $315 \mathrm{~nm}$, UVB between 315 and $280 \mathrm{~nm}$, and UVC of $<280 \mathrm{~nm}$ [58]. UV rays can induce phototraumatic reactions (basically solar erythema) and photodynamic reactions, further classified into phototoxic and allergic variants $[58,174]$.

Photoallergic Reaction. This immunologically mediated photosensitization is activated by longer wavelengths (UVA $320-450 \mathrm{~nm}$ ), which alter molecular structure, thus leading to a type IV sensitization. The radiant energy absorbed by a chromophore, for example the photoantigen, produces photochemical changes resulting in a photosensitized molecule, then conjugated with a protein carrier to occasion a complete allergen, against which is directed the immune response mediated by $\mathrm{T}$ lymphocytes, as in ACD [58]. In predisposed subjects, symptoms develop after a persistent exposure to sensitizing substances continuing for an adequately long period (up to 1-3 weeks). The wavelength of UV light is elicited by offending chemical substances. The causes are cosmetics based on natural perfumes such as bergamot (Fig. 8.17) and sandal oils and synthetic perfumes (musk and coconut), fragrance ingredients and lotions containing musk ambrette, dyes such as eosin used in lipsticks and the like, known photoallergens in sunscreen products such as oxybenzone, or correlated to PABA and methylcoumarin, disinfectants (halogenate salicylic-aniline: bithionol, fenticlor, etc.) $[58,215]$, and foods (Table 8.17) [173]. 


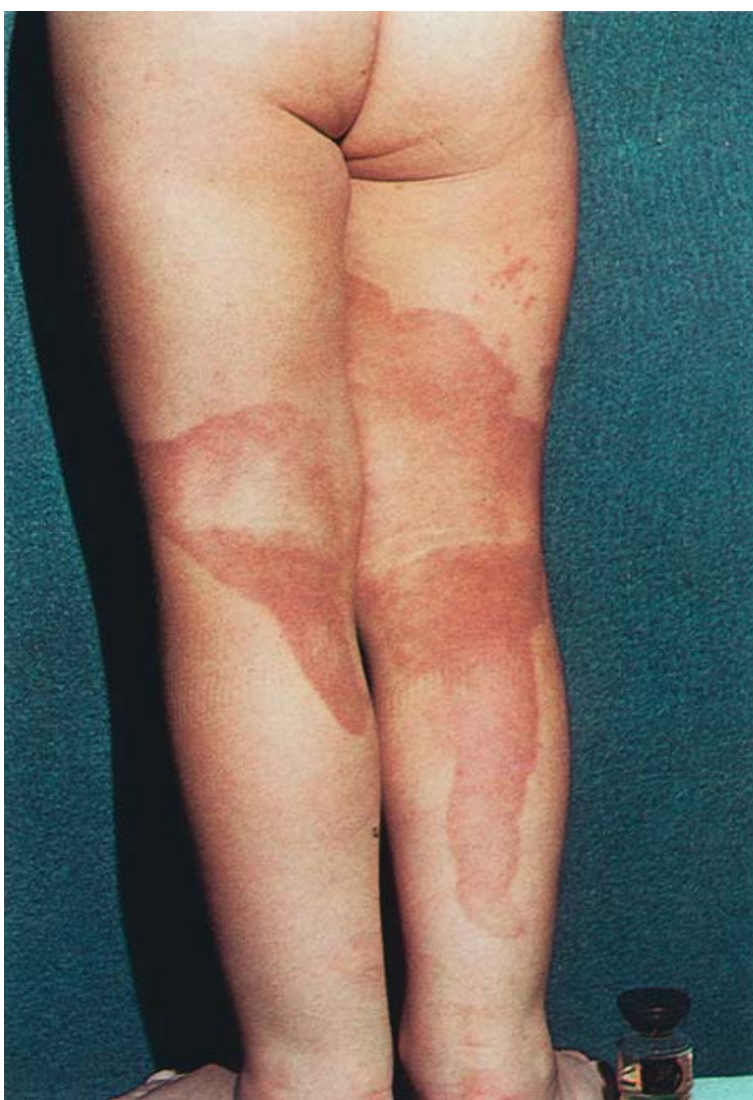

Fig. 8.17. Dermatitis caused by bergamot contained in a perfume

Table 8.17. Foods and food constituents implicated in (phyto)photodermatitis

\begin{tabular}{l} 
Foods \\
Anise \\
Carrot \\
Celery \\
Fig \\
Lemon \\
Lime \\
Parsley \\
Parsnip \\
\hline Food constituents \\
Cyclamate \\
Dyes
\end{tabular}

Modified from [173].

Phototoxic Reactions. The cause is a foreign chemical substance reaching the skin either exogenously or endogenously in combination with exposure to a sufficient amount of UV rays, in this case UVB rays, which activate nonimmunological cell damage. The pathophysiological mechanism of phototoxic drugs involves absorption and accumulation of UV energy in the skin. Photo drugs or their metabolites may combine with dermal proteins, acting as haptens solely when a significant dose of UV rays $(285-310 \mathrm{~nm})$ is present. When this dose is higher, it is likely that the energy modifies the drug to form reactive metabolites that combine with skin proteins, thus also expressing in this case a complete allergen. The period necessary to sensitization development may range from weeks to months, critical for cross-sensitizations, often triggered by low allergen doses. When it is all put together, the dependable molecule amplifies the skin sensitivity to UV rays. Phototoxic effects occur by damage to the DNA chain such as by psoralens [174]. Systemic medications and chemical substances more frequently incriminated are coal tar and derivatives, cyclamates, demeclocycline, doxycycline, griseofulvin, hexachlorophene, phenothiazine, psoralens, sulfa drugs, tetracycline and derivatives, thiazide, and photosensitizing substances such as furocoumarins (including psoralens), employed for their antimycotic action [138].

By a similar mechanism, phytophotodermatitis may develop after contact with plants containing natural furocoumarins, diffused in numerous vegetables: Umbrelliferae (celery, parsley, etc.), Rutaceae (citrus fruit), legumes, and Moraceae [174].

\section{Clinical Presentation}

- Photoallergic reactions (Fig. 8.17) are elicited after re-exposure to both the photoallergen and radiating energy, taking the aspect of an urticarial eruption appearing after several minutes, or erythematous, edematous, eczematous or exuding, also involving parts of the body not exposed to the sun $(\geq 24 \mathrm{~h})$.

- Phototoxic reactions are manifested 5-18 h after the first sun exposure and reach their maximal effect after 36-72 $\mathrm{h}$. Their typical aspect is characterized by hyperpigmentation, erythema, and vesicles. The flare-ups develop in cloth-covered sites not exposed to UV radiation and that are distant from those initially involved.

The clinical picture is therefore various. In certain cases, the reactions to UV rays produced by photoallergens may persist, even after prolonged abstention from sensitizing substances (for example, ambrette) [58], or after eradication of the plant.

Contact photocheilitis is induced after sun exposure by dyes based on fluorescin, eosin, erythrosine, or on above-mentioned natural furocoumarins and psoralens.

\section{Diagnosis}

The diagnosis, when not evident from a careful history and clinical examination, requires photopatch testing, which reveals several photoantigens including methylcoumarin, ambrette and oxybenzone $[58,223]$. However, the EU has prohibited using ambrette in cosmetics and 
Table 8.18. Differential diagnosis between toxic photodermatitis and allergic photodermatitis

\begin{tabular}{|c|c|c|}
\hline & Toxic photodermatitis & Allergic photodermatitis \\
\hline Prevalence & Common & Uncommon \\
\hline Mechanism & Nonimmunological cell damage & Immunological sensitization \\
\hline Immune mechanism & No & T-cell mediated \\
\hline Clinical picture & Solar erythema & Eczema \\
\hline $\begin{array}{l}\text { Route of exposure } \\
\text { Topical } \\
\text { Systemic }\end{array}$ & $\begin{array}{l}++ \\
+++\end{array}$ & $\begin{array}{l}+++ \\
-\end{array}$ \\
\hline Onset & Minute to days after exposure & $\begin{array}{l}\text { Days to months, once sensitized } \\
12-24 \text { h after exposure }\end{array}$ \\
\hline Occurrence at first exposure & Yes & No, requires a sensitization period \\
\hline Flare-ups of earlier reactions & No & May occur \\
\hline Drug-induced chemical modifications & No & Yes \\
\hline UV band & $285-310 \mathrm{~nm}$ & $320-450 \mathrm{~nm}$ \\
\hline Drug dosage & Dose-related & Dose-independent once sensitized \\
\hline \multicolumn{3}{|l|}{ Morphology } \\
\hline Erythema & $\pm /+++$ & $\pm /+++$ \\
\hline Edema & $+/+++$ & +++ \\
\hline Papules/papulovesicles & \pm & ++ \\
\hline Blister formation & $++/+++$ & + \\
\hline Lesion spreading & No & ++ \\
\hline Circumscribed lesions & ++ & \pm \\
\hline \multicolumn{3}{|l|}{ Histology } \\
\hline Sunburn cells & + & - \\
\hline Spongiosis & - & + \\
\hline Time course & Decreasing & Increasing \\
\hline
\end{tabular}

Data from $[58,174]$.

has introduced for furocoumarins a limit of $1 \mathrm{mg} / \mathrm{kg}$ in sun-tan lotions and in sun-tanning products in general.

Differential diagnosis takes into account, in addition to phototoxic reactions (Table 8.18 ) $[58,174]$, the extended contact phytodermatitis caused by Compositae pollens, which differ from photodermatitis since they occur in the fall season and produce the lesions with shaded instead of clear-cut limits.

\section{Treatment}

No specific management is available. When it is possible to detect an eliciting substance, allergen prophylaxis is crucial. Patients should avoid sunlight exposure while taking implicated drugs. If necessary they can protect the exposed sites with sunscreens that do not contain PABA esters [215]. Topical treatment is based on packs to alleviate pruritus and burning, and topical CSs if erythema and edema appear not to resolve, rigorously avoiding topical antihistamines, a cause of (photo)allergic reactions when applied on the skin.

\section{Contact Dermatitis by Seawater Organisms}

Contact is with toxic proteins of some Coelenterates, echinoderms, molluscs, sponges, seaweeds, cercariae, and fish of various types. Coelenterates are provided for attack and self-defense with nematocysts containing venomous urticating substances capable of remaining on the skin surface or penetrating it. Symptoms consist, in addition to urticaria and ACD, of linear erythematous or edematous eruptions that are either vesicular or hemorrhagic and toxic reactions. The forms stemming from jellyfish are characterized by erythematous wheals appearing within a few hours, subsiding spontaneously after a few days. Echinoderm prickles elicit pain, burning, erythema and edema; pain is live, pyrotic if caused by venomous substances emitted also by morays, skates, 
scorpion fishes, etc. Systemic symptoms induced by Coelenterates consist of nausea, asthenia, ataxia, muscle spasms, paresthesia, vertigo, etc. [7]. Lesions by Coelenterates should be treated with seawater or salted water, because fresh water is hypotonic and induces nematocysts to burst; it is sufficient to disinfect with alcohol. The more severe fish dermatitis and lesions should be cleaned with seawater then applying a tourniquet; application of hot water $\left(>50^{\circ} \mathrm{C}\right.$, but in practice up to the degree of tolerance) helps to inactivate the poison. Depending on the circumstances, we suggest instituting a local or systemic treatment. Echinoderm dermatitis is best treated by surgically removing the prickles or by dipping in hot water. Prophylactic approaches include the use of suitable shoes in shallow water and avoidance of touching such types of fish.

\section{Allergic Vasculitis}

Allergic vasculitis, or hypersensitivity vasculitis, affects small-caliber vessels: this vasculitis is most frequent in children, also considering the objective rarity of this allergy section [34]. The allergic origin with CIC deposits is hypothesized after the report of several immunological dysfunctions and the histological and immunological aspects similar to those seen in experimental models of Arthus reaction and acute serum sickness [34].

\section{Definition}

Allergic vasculitides in children is primarily characterized in histopathological terms by inflammation of vascular walls, possibly associated with necrosis and subsequent occlusion of vessels [24]. They are included in a heterogeneous group of vasculopathies involving arteries with different locations and diameters, veins and capillaries, whose vessel walls have in common the typical lesions of necrotizing vasculitis, or are leukocytoclastic, always associated with inflammatory cells and perivascular infiltration of polymorphonuclear (PMN) leukocytes.

\section{Classification}

Several classifications based on morphology and clinical features have been proposed [11]. However, it has thus far been impossible to formulate a global classification that takes into consideration all anatomical, clinical and etiopathogenetic characteristics. Both the etiology and clinical features are entirely different, due to a spectrum of varying causes: Table $8.19[11,17,34,122]$ classifies the principal allergic vasculitides in children. Contrary to adults, children suffer above all from SHS and to a lesser extent from hypersensitivity angiitis [31].
Table 8.19. Main types of allergic vasculitis in children

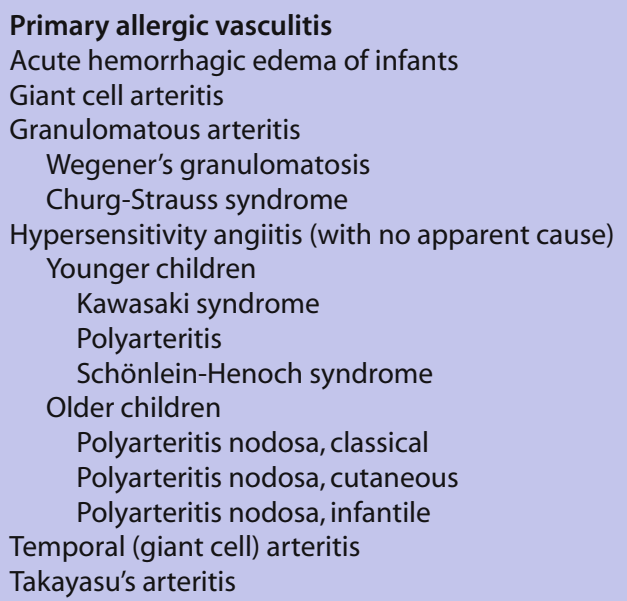

Secondary allergic vasculitis

Associated with infections

A. Microbial

Brucella, Yersinia, Rickettsia

Mycobacterium leprae

Mycobacterium tuberculosis

Mycoplasma pneumoniae

Streptococci, staphylococci, etc.

B. Viral

Cytomegalovirus

Epstein-Barr virus

Herpes simplex e zoster

HIV

Hepatitis B virus

Rubella virus

C. Parasites

Plasmodium malariae

Toxoplasma gondii

Disimmune disorders and syndromes

Chronic atrophic polychondritis

Cogan's syndrome

Congenital deficiency of complement components

Cryoglobulinemia

MacDuffie's syndrome

Associated with autoimmune disease

Behçet's syndrome

Dermatomyositis

Lupus erythematous, systemic

Rheumatoid arthritis

Scleroderma

Sjögren's syndrome

Other associations

$\alpha$-1-Antitripsin deficiency

Contact agents

Cow's milk proteins and other foods

Cystic fibrosis

Drugs

Hemorrhagic rectocolitis

Insect stings

Physical agents (cold, heat, etc.)

Sarcoidosis

Serum sickness

Data from $[11,17,34,122]$. 


\section{Prevalence}

A study referred to by Athreya [11] points to a $4 \%$ incidence, probably an underestimate because only academic centers were involved in this data collection, and pediatricians usually see and treat cases of SHS and Kawasaki syndrome, the most common vasculitides.

\section{Histological Aspects}

Dermal inflammatory phenomena are localized prevalently among capillaries; therefore the vasal endothelium plays a crucial role in these cases. The vessel wall becomes a target of immune processes, characteristic of vasculitis [34]. The vasal lesions affect the superficial dermal capillaries; endothelial cells are the seat of edema restricting the vessel lumen. Thus the wall is thickened, infiltrated by fibrin deposits that extend to adjacent connective tissue, leading to fibrinoid necrosis, which derives its name from its tintorial affinity with fibrin, characteristic of necrotizing vasculitis. A perivascular inflammatory infiltrate complicates the wall lesions, which, along with edema, are responsible for the infiltrated character of the purpura, including various amounts of PMNs, whose nuclei undergo pyknosis and disintegrate to so-called nuclear dust. PMN cell decay is known as leukocytoclasis, inconstant but with a great diagnostic value [34]. The infiltrate may also include intact eosinophils and mast cells, associated with PMNs; however, PBMCs could be recruited before PMNs. Vasculitis is a cause of dermal hemorrhages, clinically corresponding to purpura, more rarely of local ischemia, responsible for more or less ulcerate bullous lesions. Yet the pattern is not always that of a typical form [24].

\section{Pathophysiological Aspects}

CICs have a key role in the pathophysiology of leukocytoclastic vasculitis; additional elements confirm that these vasculitides depend on type III immune reactions, based on serum anticomplement power, hypocomplementemia and above all the observation, by direct immunofluorescence, of complement and/or antibodies in the vessel walls. CICs are not always demonstrable in the vessels; on the other hand, even if CICs are detected in numerous pathological conditions, only occasionally are CICs demonstrated in some forms of vasculites, or there is a parallel between CIC titer and the outcome of vessel lesions. Both antigens and antibodies found in the vessel walls are rarely detected [34].

PBMCs infiltrate in some vasculites, chiefly lymphocytes and partly monocytes, by lysosomal release of digestive enzymes that attack first the adventitia and then the media coat of vessel wall, thus destroying the cellular matrix of these vessels and surrounding tissues.
In the absence of PMN and CIC markers, the interference of CMI is also probable: active cells may be NK cells with perforins, $\mathrm{T}$ lymphocytes with direct cytotoxicity and/or DTH reactions, leading to increased vascular permeability and the accumulation of more leukocytes and proinflammatory molecules [24]. These pathogenetic models postulate that the endothelium suffers passively from the insult favored by complement activation, resulting in the production of complement breakdown products (C3a, C5a) that are chemoattractants to PMNs and PBMCs. Usually, endothelial cells are protected from potential damage originating from CICs activated by several regulating molecules at various levels of the complement cascade; consequently $90 \%$ of CICs are eliminated by the liver (Kupffer and endothelial cells) and to a lesser extent by the alternative pathway. Similarly, if CICs react directly with erythrocytes CIC-erythrocyte complexes are transported to the liver, thus decreasing the risk of epithelial damage [11]. Conversely, the endothelium could also actively contribute to the development of vasculitis in the general context of inflammation [24].

\section{Immunopathogenesis}

Although etiopathogenesis remains in great part barely recognized, recent work speculates that CICs, after binding to endothelium, increase synthesis of adhesion molecules on the cell surfaces. Leukocytes carry integrins and selectins, and endothelial cells add CD54 and CD106 to the selectins $[78,148]$, which are crucial for leukocyte migration between endothelial cells, as analyzed in Chap. 1. A new mechanism mediating the unmatched pathogenetic processes of diverse types of vasculitis is essentially the formation of anti-endothelial cell antibodies (AECAs), CIC deposition and Tymphocyte adhesion to the vascular wall. Several other mechanisms may play a major part, including the release of antibodies against antigens located in the surrounding sites, phagocyte adhesion and complement dysregulation at the tissue level [24]. It is tempting to speculate that CD4 activation by antigens presented by APC in association with HLA class II molecules mediates B lymphocyte activation with subsequent production of ANCA (anti-neutrophil circulating antibodies), formation of CICs and complement activation attracting PMNs also recruited by chemokines (Fig. 8.18) [177]. A set of Aab directed against PMN proteinase 3 (PR3) such as the c-ANCA (cytoplasmic ANCA) have been implicated in the pathogenesis of Wegener granulomatosis with a remarkable predictive significance, thus embodying a key diagnostic role [122]. That these c-ANCA recognize PR3, p-ANCA (perinuclear ANCA), MPO (myeloperoxidase) and the elastase, shown also in patients with polyarteritis nodosa, Kawasaki syndrome and SHS, where they are of IgA class, supports the hypothesis that clinically different disorders might have a 


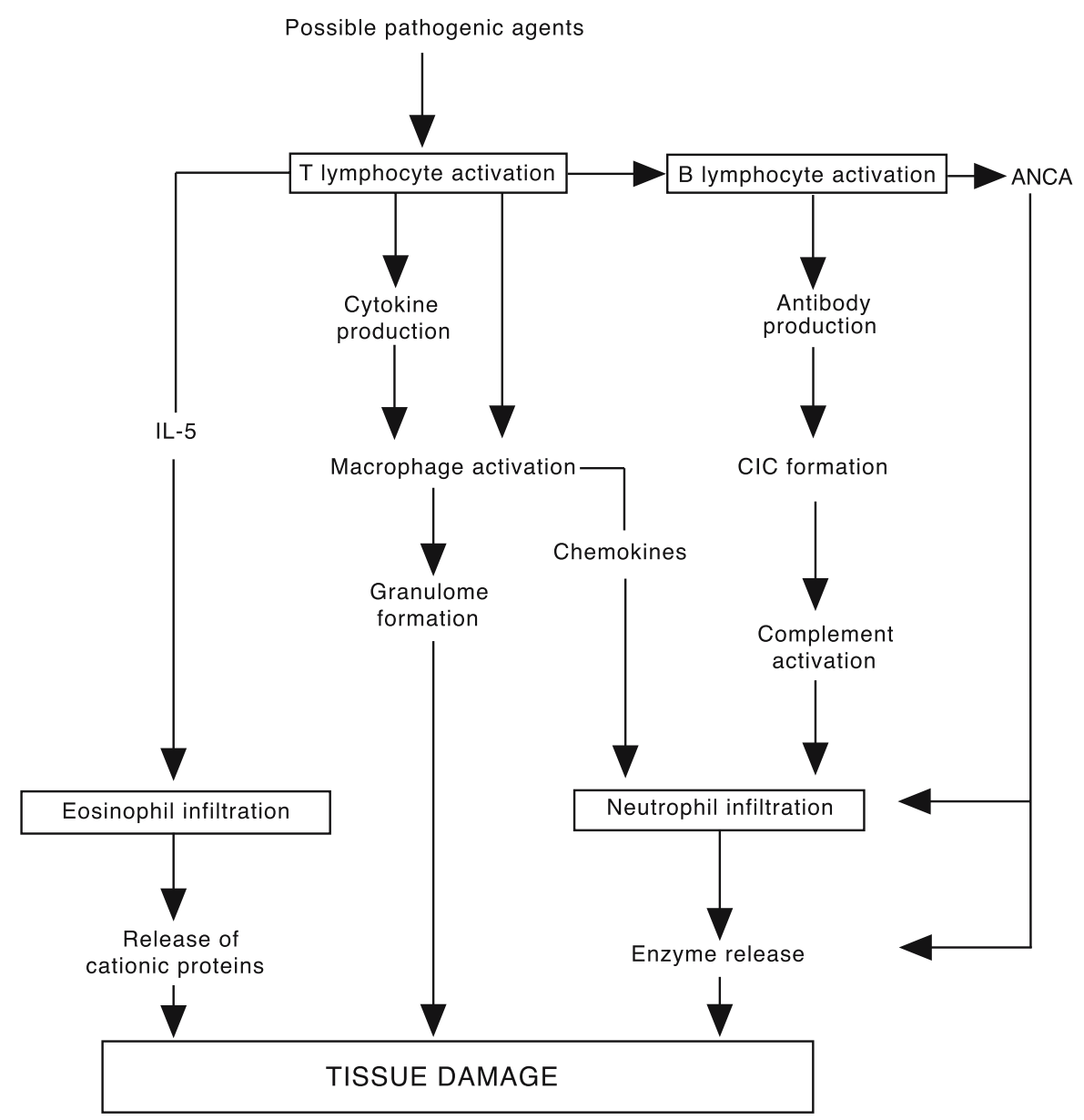

Fig. 8.18. Possible pathogenic events responsible for tissue damage during vasculitis. (Modified from [177]) common pathogenesis caused by antibody-mediated PMN activation [79], and by ANCA involvement in pathogenesis.

Microbial or viral infections may foster TNF- $\alpha$ production and thus the expression of ectoplasmatic antigens such as PR3 and MPO on PMN membrane and epithelial cells [177]. Both proteins and enzyme recognized by ANCA have also been found on granulocyte surface, and are therefore more easily attacked. In addition it is likely that ANCA antibodies bind PMN expressing PR3 on surface, thus causing degranulation with release of free $\mathrm{O}_{2}$ radicals and lysosomal enzymes on surrounding epithelial tissues, or alternatively bind enzymes released by cells damaged by the inflammatory process, facilitating their transport to the tissues where the enzymes cause further damage [79]. In parallel, the ANCA/PR3 interaction induces, by mechanisms not yet fully understood, an increased CD62E and CD106 expression, which attaching to epithelium modulates the adhesion of PMN [177], CD54 and CD102 [78, 148], which bind their contrareceptors CD11a/CD18, CD11b/ CD18 and CD11c/CD18. In this model, the integrins are necessary for leukocyte adhesion to endothelium. Figure 8.18 shows the tissues damaged by a complex interaction of cells, with a prominent role played by eosinophil cationic proteins. Additional etiological factors to be considered are genetic and local factors (lesions differentially affecting one organ rather than another), etc. [122].

\section{Clinical Presentation}

Vasculitis disorders share cutaneous and visceral symptoms [34].

\section{Cutaneous Symptoms}

Cutaneous vasculitis is a condition characterized by infiltrated palpable purpura (erythema not fading on vitropression), with predilection for the lower limbs, with tendency to symmetry and worsening following orthostatism. Of 130 children, 116 had SHS and14 had hypersensitivity vasculitis [32]. The often associated lesions are mostly polymorphous, erythematous or maculopapulous, well circumscribed, occurring in crops, have dimensions from a pinpoint to several $\mathrm{cm}$, often evolving to form hemorrhagic blisters or necrotic ulceration, lasting from 3-10 days, and affecting in par- 
ticular the lower limbs and feet. Certain lesions may complicate the diagnosis such as well circumscribed ecchymotic spots, erythematous papules (palpable purpura), often with an annular arrangement appearing as a polymorphous erythema, which are able to transform into nodules, vesicles, blisters, and/or become necrotic. Preferred sites are gravity-affected areas such as lower half of the legs and buttocks, but also forearms and hands, although in severe cases the face and trunk may be involved. Subcutaneous nodules are small, stiff, often short-lived, most often located on the back of both hands and feet, elbows and knees. Less frequent is livedo reticularis. Generally such lesions are asymptomatic, but can be accompanied by pruritus, burning sensation and pain [34].

\section{Additional Symptoms}

Articular manifestations are the most frequent and renal lesions condition the prognosis. No relationship is apparent between extension of cutaneous lesions and presence or not of renal manifestations.

- Musculoskeletal apparatus. Arthralgias are usually present in $>40 \%$ of cases.

- Kidney. Renal lesions should be investigated, although it has been suggested that the prevalence is not $25 \%-40 \%$ of cases, but $<1 \%$ of children develop persistent renal disease [11]. Proteinuria is usually associated with microscopic hematuria: symptoms may persist or subside; however, $<0.1 \%$ develop renal insufficiency. Renal biopsy results are discriminatory as far as the type and severity of injury are concerned.

- Gastrointestinal tract. Abdominal pain with nausea and vomiting are frequent ( $15 \%$ of cases); rarely does an occlusive or hemorrhagic syndrome develop.

- Central nervous system. Rare associations include hemiparesis, neuropathies and migraine.

\section{Prominent Vasculitis Syndromes in Children}

As shown by Table 8.19 , the main types of primitive allergic vasculitis in children that most frequently have an immune pathogenesis are the following:

SHS, or anaphylactoid purpura, is the most common among leukocytoclastic vasculitis patients, with an estimated annual incidence highest between the ages of 4 and 6 years $\left(99.3 \times 10^{5}\right)$ [81]. SHS peaks preferentially between 4 and 7 years (or between 5 and 6), with a greater prevalence in males and in fall season and in winter $[98,245]$. The SHS annual incidence may be $12.9 \times 10^{5}$ children $<17$ years of age [245]. However infants aged 5-24 months have been reported [5, 188]. It is an immune-mediated disease, paradigmatic of cutaneous necrotizing or leukocytoclastic vasculitis, of small dermal and visceral vessels $(<0.1 \mathrm{~mm}$ in diame- ter), which appear to be infiltrated by PMNs with nuclear fragments in various stages of necrosis, releasing proteolytic enzymes resulting in damage to vascular endothelium [11]. The inflammatory and thrombotic process is likely correlated to increased biosynthesis of vasoactive prostanoids [210].

A pediatric study has focussed on the action of these molecules and demonstrated a significant increment of thromboxane $\mathrm{A}_{2}\left(\mathrm{TXA}_{2}\right)$ and $\mathrm{PGI}_{2}$ in acute stages correlated with the degree of clinical severity [210]. The $\mathrm{TXA}_{2}$ increase is consistent with platelet activation; a lesser portion derives from activated PMNs and macrophages, while the $\mathrm{PGI}_{2}$ increase seems to reflect endothelial cell damage by local inflammatory and thrombotic process [210].

The prostanoid, the main metabolite of arachidonic acid, is a product of vascular endothelium and has potent anti-aggregate effects on platelets. It is a vasodilator and inhibits the $\mathrm{TXA}_{2}$-induced platelet activation on vascular lesions. PGI $_{2}$ of endothelial cells influences the interaction between vasal walls and leukocytes, blocking their adhesion after stimulation [210]. Prostanoid synthesis in the vascular cells can be induced by PAF and $\mathrm{IL}_{1}$, both CIC-stimulated, thus confirming the CIC activity in immune-mediated vasculitis [235]. In the acute stages of SHS, a $\mathrm{PGE}_{2}$ increase has been shown, probably derived from PMN and macrophage activation. Examined in greater detail, it is unclear whether its action amplifies or suppresses the inflammation characteristic of SHS [210]. On the one hand, it is an active mediator in inflammation, by promoting blood afflux in the inflamed area and thus leukocyte infiltration; on the otherhand, it exploits a local down-regulation by inhibiting lymphocyte activation and antibody and IL production.

In conclusion, both $\mathrm{TXA}_{2}$ and $\mathrm{PGI}_{2}$ increase allows a correlation of SHS with other affections and syndromes characterized by an increased interaction between platelets and vascular walls, so that a parallel between a wide spectrum of causes and a virtual uniformity of responses may be advocated [210]. The deposition of IgA and C3 in the small vessels of the skin and renal glomeruli is characteristic. Recently deposition of IgA has been shown in the intestine as well [106]; therefore SHS is considered an IgA-mediated vasculitis of small vessels [11]. The main clinical manifestations outlined in Tables 8.20 and $8.21[5,188]$ show that the skin manifestations, edema and purpura of both scalp and limbs, are characteristically seen in infants, while in older children the frequency of articular (arthritis may be the initial manifestation) and renal complications is increased $[5,188]$. The SHS hallmark is the purpuric rash, first macular and then erythematous maculopapules, with hemorrhagic elements (petechiae and ecchymosis), involving symmetrically the lower limbs (Fig. 8.19), associated with edema of the scalp and/or extremities. Depending on the age, abdominal pain and migratory articular manifestations are more or less frequent, the onset of glomerulopathy may even be long after SHS 
Table 8.20. Clinical Schönlein-Henoch syndrome manifestations in children aged 0-8 years

\begin{tabular}{lcccccc} 
& \multicolumn{2}{l}{ Age at onset (years) } \\
\cline { 2 - 6 } Clinical manifestations (\%) & $<2$ & $2-3$ & $\mathbf{4 - 5}$ & $\mathbf{6 - 7}$ & $\mathbf{8}$ \\
\hline Edema & 100 & 62 & 25 & 33 & 0 \\
\hline Facial purpura & 83 & 31 & 54 & 50 & 50 & 67 \\
\hline Gastrointestinal & 8 & 23 & 35 & 25 & 50 \\
\hline Renal & 17 & 69 & 65 & 83 & 100
\end{tabular}

Data from [188].

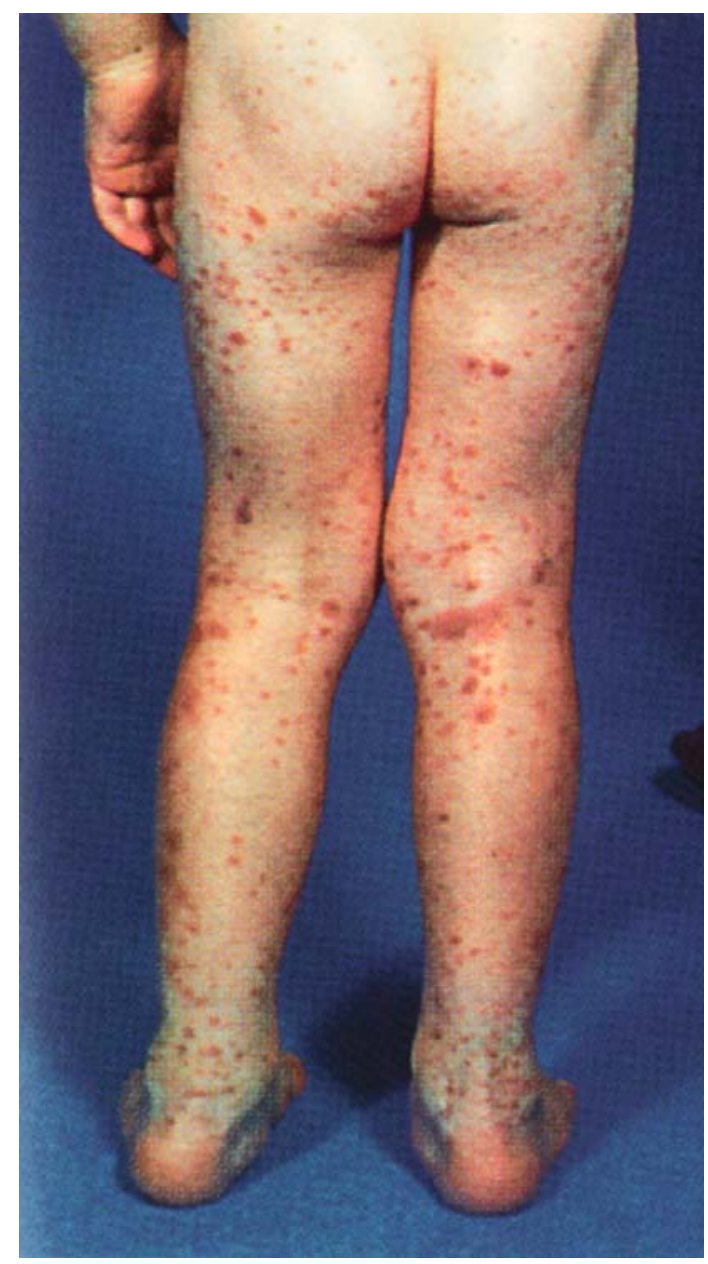

Fig. 8.19. Manifestations of Schönlein-Henoch syndrome in the lower limbs

onset. In cases not complicated by nephropathy, the prognosis is good after 24 years of follow-up; however, long-term follow-up of all patients who had severe renal symptoms at onset is needed during adulthood [171].

Hypersensitivity angiitis is another leukocytoclastic vasculitis, clinically similar to SHS, occurring mostly in children, excluding those cases in which the specific al-
Table 8.21. Diagnostic algorithm in children aged $0-3$ years

Not thrombocytopenic purpura associated with $\geq 1$ of the following symptoms

\begin{tabular}{l} 
Abdominal pain \\
\hline Edema \\
\hline Gastrointestinal hemorrhage \\
\hline Glomerulonephritis
\end{tabular}

Data from [5].

lergen (drugs, microbes, virus, insect stings, pesticides, etc.) is easily identifiable. Clinical manifestations include fever, myalgia, and arthralgias without frank arthritis and visceral involvement, and may sometimes resemble the SHS limited to the skin, with which it has in common the character of acute phases (one-shot disease). The small vessels are involved, arterioles or venules, with a variable degree of vessel wall necrosis, localized and rarely occlusive. The cutaneous lesions are typically small hemorrhagic papules, usually in sloping areas and at a similar stages of development. Inflammatory cells are usually PMN $[72,122]$.

Acute hemorrhagic edema of infancy (Fig. 8.20) is a disease with a benign course characterized by a suddenly occurring cutaneous vasculitis in children aged 4 months to $<2$ years in good general condition. Large purpuric lesions are distributed on the face, auricles and lower limbs, associated with limb edema, or they are segmental, thick or soft [153]. In some cases, extended trunk lesions may suggest a differential diagnosis with fulminant purpura. Progression is spontaneous and favorable within $2-3$ weeks $[83,120,182]$, or after a 7 -day oral CS course [87]. Vasculitis, essentially cutaneous of the leukocytoclastic type, a (very) young age, the topography of lesions, peripheral edema and common absence of arthralgias and internal organ complications (in any case benign) are diagnostic $[83,98,120]$ and should be evaluated as a benign SHS variant [182].

Kawasaki syndrome [108] is the most frequent vasculitis in infancy after SHS. An epidemiological study on 


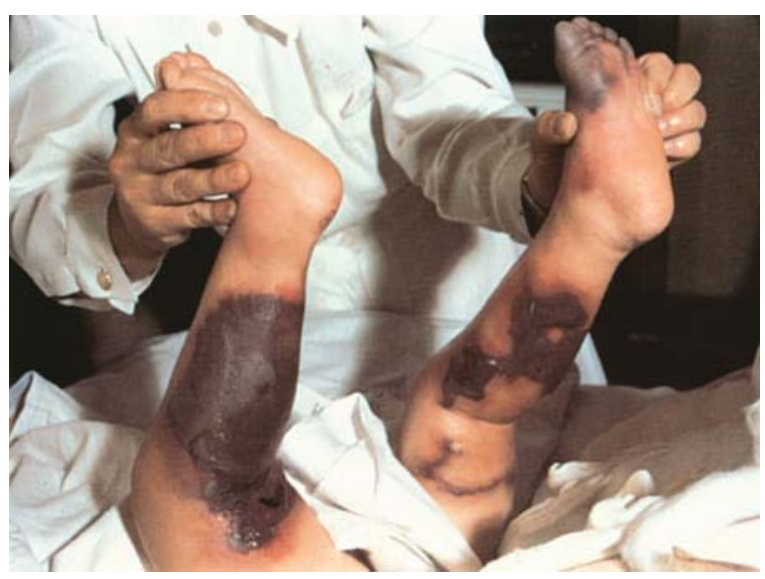

Fig. 8.20. Acute hemorrhagic edema of infancy. The condition subsides spontaneously and is not associated with severe, systemic complications

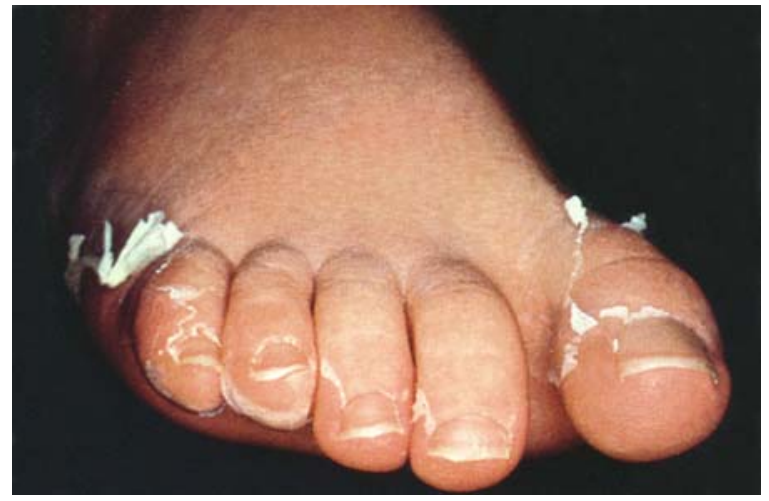

Fig. 8.21. Kawasaki syndrome: scaling of the toes

105,755 cases reported over 35 years ago in Japan [217] showed a prevalence of $4.5-8.5$ cases $\times 10^{5}$ aged $<5$, with the youngest patient aged 26 days, $0.006 \%$ of infants aged 30 days and $1.67 \%$ aged 3 months. Among newly treated children aged $<5$ years, the incidence was $102.6 \times 10^{5}$ in 1995 and $108 \times 10^{5}$ in 1996 , with a male-female ratio of 1.37 [244]. The estimated annual incidence was $5.5 \times 10^{5}$ in children $<5$ years, and was highest in Indian subcontinent Asian children $\left(14.6 \times 10^{5}\right)$ [81]. The incidence rate in Korean children $<5$ years was $\left(\times 10^{5}\right) 73.7$ in 2000, 90.8 in 2001, and 95.5 in 2002. The mean age of onset was 30.5 months [162]. This is a multisystem disorder causing substantial symptoms of vasculitis and mucocutaneous lesions with desquamation, after 2 weeks, beginning at the nail-pulp junction (Fig. 8.21). It is another CIC-induced one-shot disease, characterized by a polyvasculitis of small and mediumsized vessels, especially affecting medium-sized arteries, with a predilection for coronary arteries with thrombosis and formation of aneurysms [72], a particular risk for infants aged $<6-12$ months [178]. Ongoing antibody synthesis may foster inflammation involving
Table 8.22. Main immunological changes in Kawasaki syndrome

\begin{tabular}{|c|}
\hline Activated B cells \\
\hline Activated $\mathrm{TCD}^{+}{ }^{+}$increase \\
\hline Ongoing antibody synthesis \\
\hline Expansion of $T c R V \beta 2$ and $V \beta 8$ regions \\
\hline Microbial superantigens secreting toxins \\
\hline Monocyte-macrophage activation inducing: \\
\hline $\mathrm{IL}_{1}, \mathrm{IL}_{6}, \mathrm{IFN}-\gamma_{,}, \mathrm{TNF}-\alpha$ raised expression \\
\hline $\mathrm{IL}_{2} \mathrm{R}$ and $\mathrm{CD} 45 \mathrm{RO}$ on $\mathrm{CD} 8$ raised expression \\
\hline $\begin{array}{l}\text { Endothelial cells expressing HLA class II antigens, } \\
\text { CD54, CD62E }\end{array}$ \\
\hline Circulating autoantibodies and $\mathrm{CIC}$ \\
\hline
\end{tabular}

Data from $[21,123,147,165,235]$.

all three layers of the vascular walls, thus destroying the internal elastic lamina: Table 8.22 [21, 123, 147, 165, 235] reviews the many immunological features consistent with the pathogenesis. Another area of intensifying interest is the demonstration that ILs linked to AECA favor endothelial cell migration, thus modulating the worsening of vascular changes [180]. The changes are multiplied by the high levels of adhesion molecules on endothelium, including CD54, CD102 and von Willebrand factor $[78,148]$. Recent data have revealed toxins acting as superantigens (SAs) on $\mathrm{V} \beta 2$ and $\mathrm{V} \beta 8[51,123$, 243], produced by microorganisms of the respiratory or gastrointestinal tracts [51, 147], in particular by Staphylococcus aureus and Streptococcus pyrogenus secreting TSST-1 (toxic shock syndrome toxin-1) and SPEA/SPEB (staphylococcal pyrogenic exotoxin A and B), respectively [123]. A result still to be weighed is whether CD45RO expression is raised solely on CD8 T cells [165]. There is a tempting suggestion that the intestine encourages causative agent entry such as microorganisms $[147,243]$ that are producers of toxins with SA properties (Table 8.22). A novel human coronavirus, designated "New Haven coronavirus" (HCoV-NH) was identified in 8/11 infants with Kawasaki disease. Human coronaviruses (HCoVs) have attracted renewed interest because of the emergence of a novel $\mathrm{HCoV}$ associated with severe acute respiratory syndrome (SARS). The median time between the onset of fever and the diagnosis of HCoV-NH was 5 days; 7/11 infants and 19/22 control subjects had respiratory symptoms that were consistent with an upper respiratory tract infection (URTI) [68]. Table 8.23 [189] outlines the chief diagnostic and associated symptoms. Useful diagnostic markers could be CD8 T cells $[147,165]$ and $\mathrm{IL}_{2} \mathrm{R}$ for early diagnosis [21].

Polyarteritis nodosa (PAN), divided into classic, infantile and cutaneous PAN [122], is among the least common in childhood. This is another disease that differs in presentation and etiology from that seen in 
Table 8.23. Main diagnostic criteria for Kawasaki syndrome and main associated criteria

\section{Main diagnostic criteria}

Patients should have at least 5 or 6 main symptoms with exclusion of other diagnosis:
1. Fever with sudden onset, lasting $\geq 5$ days
2. Bilateral nonsuppurative conjunctival hyperemia
3. At least one change of the lips and oral cavity, including hyperemic or dry fissured lips, erythema of the oropharyngeal mucosa, strawberry tongue
4. At least one change in peripheral extremities, including edema of the hands, feet, or both, or erythema of the palms and soles, scaling beginning periungually or generalized
5. Polymorphous rash, especially of the trunk, with varying characteristics, without vesicles or crusts, often itching
6. Cervical lymphadenopathy, not purulent, usually unilateral, $\geq 1.5 \mathrm{~cm}$

For the diagnosis, in addition to the fever, the child must meet $4 / 5$ criteria

Main associated symptoms (in order of incidence)

1. Urethritis

2. Arthritis or arthralgia

3. Cardiac involvement, especially myocarditis or pericarditis

4. Aseptic meningitis

5. Diarrhea

6. Gallbladder hydrops

7. Obstructive jaundice

Data from [189].

adults. More frequent is cutaneous PAN, manifested by purpura, edema, linear erythema, tender palpable nodules, high fever, arthralgias and myalgias, without important organ system involvement. It has a chronic course and a better prognosis than the systemic variants $[11,72,98]$. Biopsy reveals a focal necrosis and inflammation of the walls of small and medium-sized arteries that tend to occur in a segmental way and particularly involves areas where arteries bifurcate [98].

Other types of polyarthritis vasculitis include Wegener granulomatosis, featuring the formation of granulomas around blood vessels, with typical lung and kidney involvement, which is currently classified as one of the ANCA-associated small-vessel vasculites distinguished by its predisposition to affect the upper and lower respiratory tracts and kidneys clinically and histologically by the presence of necrosis, granulomatous inflammation, and vasculitis [246]. The presence of PR3,
Table 8.24. Hypocomplementemic urticarial vasculitis: clinical aspects

\section{Lesion characteristics}

Small wheals

Evident central clearing or dusky coloration

Persistence greater than $24 \mathrm{~h}$

Residual pigmentation following regression

Painful, burning or pruritic lesions

Alternatively, presence of palpable purpura, nodules, ulcers

\section{Clinical aspects}

Recurrent, widespread urticarial lesions

Association with arthralgia, arthritis,

abdominal pain, fever

potential involvement of synovia, kidneys,

gastrointestinal and respiratory tracts,

eyes and/or CNS

Data from $[135,226]$.

normally restricted to neutrophil $\alpha$ granules, has led to the hypothesis that ANCA-induced neutrophil activation is central to a chain of events leading to T-cell activation and a CMI response involving macrophage activation, and that PR3 expression may be abnormal. The cause may remain unknown, but circumstantial evidence suggests the potential roles of ANCA and infection in the pathogenesis [246]. Recurring infections of upper airways and respiratory infections are prominent clinical manifestations, along with cough, fever, weight loss, arthritis, neuropathy, rash, and splenomegaly. ANCA-associated glomerulonephritis has been diagnosed in 20 children, the youngest aged 11 years, but early recognition and aggressive treatment of these children may prevent end-stage renal disease [219].

Churg-Strauss syndrome, an allergic granulomatous vasculitis also affecting small and medium-sized vessels has a predilection for lungs characterized by AR and/or asthma and presents with fever, headache, myalgia, weight loss, and peripheral blood and tissue eosinophilia exceeding 1,500 cells $/ \mathrm{m}^{2}$. The systemic vasculitis may involve the skin, heart, and peripheral nerves. Kidneys are spared or only mildly affected [122]. Recently three cases have been reported: a 15-year-old girl with catastrophic gastrointestinal vasculitis and multiple colonic ulcers with active bleeding [124], a 10-year-old girl with acute abdominal pain, bloody diarrhea, pulmonary infiltrates, a 6-year history of severe asthma, and marked eosinophilia [26], and a boy with poorly controlled bronchial asthma, AR, recurrent sinusitis and several episodes of hemophthisis since the age of 9 , who developed purpuric skin lesions, generalized soreness, and symptoms of mononeuritis multiplex at age 11 [234]. These cases demonstrate that the prognosis is poorer in children than in adults [124]. 
Table 8.25. Histopathology of hypocomplementemic urticarial vasculitis compared with acute and chronic urticaria

\begin{tabular}{llll} 
Manifestations & Urticarial vasculitis & Chronic urticaria & Acute urticaria \\
\hline Inflammatory cells & Predominantly PMN & Predominantly monocytes & Few PMN and monocytes \\
\hline Location & $\begin{array}{l}\text { Perivascular and } \\
\text { within vessel wall }\end{array}$ & $\begin{array}{l}\text { Perivascular few } \\
\text { within vessel wall }\end{array}$ & Perivascular \\
\hline Leukocytoclasis & Yes & No or minimal & No \\
\hline Endothelial cell swelling & Yes & No or minimal & No \\
\hline Leakage of erythrocytes & Yes & No or minimal & No
\end{tabular}

Data from $[27,226]$.

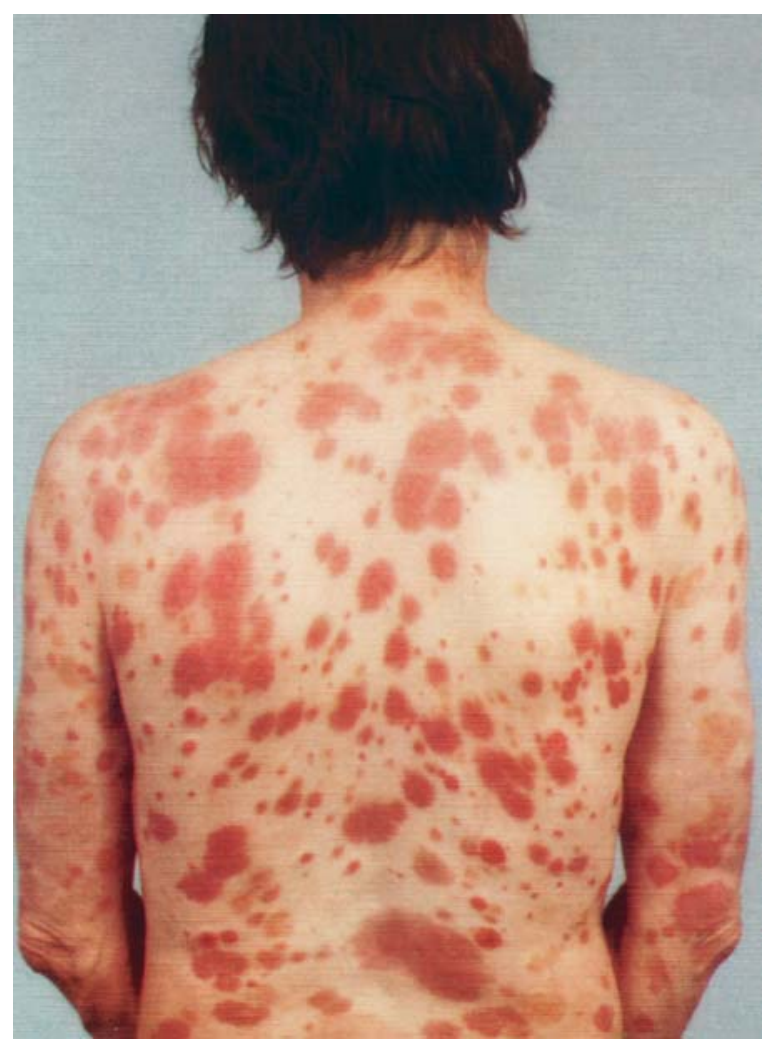

Fig. 8.22. Acute urticarial vasculitis

Wholly particular is hypocomplementemic urticarial vasculitis, of which eight pediatric cases are known [39, $55,135,232$ ], including 2 identical twins [241] and a girl with SLE [55]. Concordance in identical twins may suggest that the pathogenesis of the disease involves abnormal genetic immunoregulation [241]. CIC-induced pathogenesis has an Arthus-like pattern; there is selective depression of Clq binding IgG and lesser depression of C2, C3, C4, but the levels of Clr and Cls are almost normal $[135,232]$. Cl, C3, C4, properdin, IgM, IgG and fibrin are often present in vascular cells and basal membrane. When complement is activated, C3a and C5a are released. These anaphylotoxins with chemotactic action induce de novo synthesis of chemokines and ILs and mastocyte degranulation with consequent increase in vascular permeability, followed by $\mathrm{LTB}_{4}$ release. In both ways, PMNs are recruited, resulting in the tissue damage described above. Clinical features are those of leukocytoclastic vasculitis: clearly delimited erythematous and edematous macules are seen, and are characterized by their relatively fixed aspect, tendency to purpura, are only slightly pruritic, and the possible association with systemic manifestations or an inflammatory syndrome $[27,135,226]$. The lesions resemble urticaria and typically persist for more than $24 \mathrm{~h}$ [55]. Tables 8.24 and 8.25 $[27,135,226]$ outline the clinical and diagnostic symptoms of urticarial vasculitis, characterized by a wide spectrum of symptoms that may lead to a more severe clinical course that is life-threatening to children, including severe anemia and renal insufficiency [135], and hycomplementemic histopathology, compared with acute and chronic urticaria [27], is useful for the differential diagnosis.

Acute urticarial vasculitis related to postinfectious or drug-induced hypersensitivity starts as transient infiltrated purpura (Fig. 8.22), 2-3 weeks after antigenic aggression; several secondary types of vasculitis are induced by food additives [173, 223], CM proteins [34], other foods and vitamins [173].

\section{Diagnosis}

Vasculitis assessment should include history, physical examination, and some of the following items:

- Age and epidemiology, in order of frequency SHS (Tables 8.20, 8.21), Kawasaki syndrome (Table 8.22), leukocytoclastic vasculitis, hemorrhagic edema (Table 8.19) and urticarial vasculitis (Tables 8.24, 8.25), the last being most unusual in this age range

- Recent treatment with potentially implicated drugs

- Palpable purpura

- Maculopapular erythema

- Possible biopsy

Laboratory studies (complete blood count, ESR, CRP, platelet count, kidney and liver function studies, T subpopulations, AECA, ANCA, lymphocyte antibodies, etc.) 
Table 8.26. Frequency of c-ANCA, p-ANCA and anti-MPO in several disorders

\begin{tabular}{|c|c|c|c|}
\hline Disorders & C-ANCA & p-ANCA & Anti-MPO \\
\hline \multicolumn{4}{|l|}{ Polyarteritis } \\
\hline Classic PAN & Uncommon & $2+$ & $2-3+$ \\
\hline Microscopic PAN & $2-3+$ & $2-3+$ & $2-3+$ \\
\hline Churg-Strauss syndrome & Rare & $2+$ & $2-3+$ \\
\hline Wegener granulomatosis & $4+$ & $1+$ & $1+$ \\
\hline \multicolumn{4}{|l|}{ Generalized } \\
\hline Active & $2+$ & - & $?$ \\
\hline Remission & $3+$ & - & $?$ \\
\hline \multicolumn{4}{|l|}{ Limited } \\
\hline Active & $2+$ & - & $?$ \\
\hline Remission & $2+$ & - & $?$ \\
\hline Polyangiitis overlap & $1+$ & $1+$ & $?$ \\
\hline $\begin{array}{l}\text { Idiopathic necrotizing and se } \\
\text { glomerulonephritis without } \\
\text { (pauci-immune) }\end{array}$ & $1+$ & $4+$ & $4+$ \\
\hline \multicolumn{4}{|l|}{ Inflammatory bowel disease } \\
\hline Ulcerative colitis & Rare & $2-4+$ & Absent \\
\hline Crohn's disease & Rare & Absent & Absent \\
\hline
\end{tabular}

Data from [11].

are useful to confirm the diagnosis. Table 8.26 [11] gives the frequency of c-ANCA, p-ANCA and anti-MPO in several vasculitis.

\section{Treatment}

The reader is referred to reviews on therapeutic details [11, 226, 235]. Intravenous immunoglobulins (IVIg) were administered to two children aged 2.5-3.5 with Kawasaki syndrome associated with severe AD at the dose of 4-6 g daily for 5 days with remission of hyperthermia (Chap. 7). The IVIg positive effect, to be started promptly and continued for the 5 days of Kawasaki syndrome [244], lies in the inhibition of endothelial cell migration with destructive effects [180], likely favoring the reparative phase.

\section{Pediatricians and Other Cutaneous Allergies}

This chapter presents pediatricians with a large number of different diseases and syndromes of childhood, the background to a very extensive and differentiated task. This includes several kinds of foods, additives, drugs, and insects that induce urticaria and the countless and dissimilar physical forms, as well as foods and inhalants inducing angioedema. Since urticaria covers a clinical spectrum, it should not be surprising that several skin disorders have urticarial lesions. ACD involving young children is provoked by buttons, clasps, jewels, cosmetics, topical medications, and the ubiquitous latex with latex-fruit and latex-vegetable syndromes and even in the materials employed by dentists. The most important preventive measure for patients with latex allergy or at risk for it is minimizing direct exposure to latex products, most notably latex gloves. Recent operating room studies indicate that simple preventive measures can dramatically reduce intraoperative reactions [30]. Although rare, the different forms of infantile vasculitis are undoubtedly a challenge for most colleagues. The clinical and laboratory findings are variable, frequently nonspecific or overlapping. Therefore early and correct diagnosis is imperative, but one should never delay initiation of treatment, while trying to finalize the diagnosis. These disorders are therefore found in several chapters of infantile allergy and immunology and will put to the test more than ever not only the diagnostic and therapeutic skill of pediatricians, but also their cooperation in light of understandable parental anxieties. With treatment methods designed both to avoid side effects and limit costs, effective approaches will be centered. However, clinical experience will untie several Gordian knots, thus justifying neither frustration nor polypragmatism, especially when faced by the tempting plethora of current therapeutic options. 


\section{References}

1. Acciai MC, Brusi C, Francalanci S, Gola M, Sertoli A (1991) Skin tests with fresh foods. Contact Dermatitis 24:67-68

2. Adams RM (1991) Recent advances in contact dermatitis. Ann Allergy 67:552-566

3. Akasawa $\mathrm{A}$, Matsumoto $\mathrm{K}$, Saito $\mathrm{H}$ et al Incidence of latex allergy in atopic children and hospital workers in Japan. Int Arch Allergy Appl Immunol 1993; 101:177-181

4. Alangari AA, Twarog FJ, Shih MC, Schneider LC (2004) Clinical features and anaphylaxis in children with cold urticaria. Pediatrics 113:e313-317

5. Amitai Y, Gillis D, Wasserman D, Kochman RH. HenochSchönlein purpura in infants. Pediatrics 1993; 92:865-867

6. Andri L, Senna GE, Faccioni F, Givanni S, Betteli C, Cavalleri MP (1992) Patologia allergica in odontoiatria. G Ital Allergol Immunol Clin 2:75-85

7. Angelini G, Meneghini CL (1987) Contact allergy in children. Pediatr Dermatol News 6:195-204

8. Armstrong JL, Lantz AB, Jerath RS, Meyer CF (2001) Urticaria, angioedema, and an elevated eosinophil count in an adolescent. Ann Allergy Asthma Immunol 87:457-460

9. Artik S, Haarhuis K, Wu X, Begerow J, Gleichmann E (2001) Tolerance to nickel: oral nickel administration induces a high frequency of anergic T cells with persistent suppressor activity. J Immunol 167:6794-6803

10. Asero R, Lorini L, Tedeschi A (2004) Chronic autoreactive urticaria at six years of age. J Invest Allergol Clin Immunol 14:343-345

11. Athreya BH (1995) Vasculitis in children. Pediatr Clin North Am 42:1238-1262

12. Azana JM, Torrelo A, Mediero IG, Zambrano A (1994) Urticaria pigmentosa: a review of 67 pediatric cases. Pediatr Dermatol 11:102-106

13. Balaban J (2002) Medicaments as the possible cause of urticaria in children. Acta Dermatovenerol Croat 10:155-159

14. Balato N, Patruno C, Lembo G, Auricchio L, Ayala F (1989) Dermatiti da contatto in età pediatrica. Med Bambino 8:504-511, 554

15. Barakat A, Castaldo AJ (1993) Hereditary angioedema: danazol therapy in a 5-year-old child. Am J Dis Child 147:931-932

16. Bardana EJ, Montanaro A (1991) Formaldehyde: an analysis of its respiratory, cutaneous, and immunologic effects. Ann Allergy 66:441-452

17. Bardare M, Cohen E, Vaccari A (1989) Current views on the pathogenesis of vasculitis in children. Pediatr Med Chir 11 [Suppl 1]:3-6

18. Bardare M, Magnolfi C (1985) Orticaria cronica in età pediatrica. Med Bambino 4:712-714

19. Barlow RJ, Ross EL, Macdonald DM, Kobza Black A, Greaves MW (1995) Mast cells and T lymphocytes in chronic urticaria. Clin Exp Allergy 25:317-322

20. Barnetson RStC, Gawkrodger DJ (1993) Eczema and contact dermatitis - pathophysiology. In: Holgate ST, Church MK (eds) Allergy. Gower Medical Publishing, London, pp 23.1-10

21. Barron KS, Montalvo JF, Joseph AK et al (1990) Soluble interleukin-2 receptors in children with Kawasaki syndrome. Arthritis Rheum 33:1371-1377

22. Baur X, Chen Z, Rozynek P, Düser M, Raulf-Heimsoth M (1995) Cross-reacting IgE antibodies recognizing latex allergens, including $\mathrm{Hev}$ b 1, as well as papain. Allergy 50:604-609
23. Baxevanis CN, Papadopoulos NG, Katsarou-Katsari A, Papamichail M (1994) Regulation of allergen-specific immune response by CD4+CD45+ cells in patients with allergic contact dermatitis. J Allergy Clin Immunol 94:917-927

24. Bazzoni G, Dejana E (1991) Molecole coinvolte nelle interazioni tra endotelio e leucociti Atti $20^{\text {th }}$ Congresso della SIAIC. OIC Medical Press, Rome, pp 303-307

25. Beezhold DH, Hickey VL, Kostyal DA et al (2003) Lipid transfer protein from Hevea brasiliensis ( $\mathrm{Hev} b \mathrm{12}$ ), a cross-reactive latex protein. Ann Allergy Asthma Immunol 90:439-445

26. Berlioz M, Triolo V, Sirvent N, Albertini M (2001) ChurgStrauss syndrome revealed by acute abdominal pain. Pediatr Pulmonol 32:92-94

27. Berg RE, Kantor GR, Bergfeld WF (1988) Urticarial vasculitis. Int J Dermatol 27:468-472

28. Beyer K, Castro R, Feidel C, Sampson HA (2002) Milk-induced urticaria is associated with the expansion of $\mathrm{T}$ cells expressing cutaneous lymphocyte antigen. J Allergy Clin Immunol 109:688-693

29. Bilbao A, Garcia JM, Pocheville I et al (1999) Round table: urticaria in relation to infections. Allergol Immunopathol (Madr) 27:73-85

30. Birmingham PK, Suresh S (1999) Latex allergy in children: diagnosis and management. Indian J Pediatr 66:717-724

31. Blanco C, Carrillo T, Castillo R, Quiralte J, Cuevas M (1994) Latex allergy: clinical features and cross-reactivity with fruits. Ann Allergy 73:309-314

32. Blanco R, Martinez-Taboada VM, Rodriguez-Valverde V, Garcia-Fuentes M (1998) Cutaneous vasculitis in children and adults. Associated diseases and etiologic factors in 303 patients. Medicine (Baltimore) 77:403-418

33. Blauvelt A, Hwang ST, Udey MC (2003) 11. Allergic and immunologic diseases of the skin. J Allergy Clin Immunol 111:S560-570

34. Bodemer C (1992) Vascularites allergiques chez l'enfant. Ann Pédiatr 39:426-434

35. Boyle RJ, Nikpour M, Tang MLK (2005) Hereditary angiooedema in children: A management guideline. Pediatr Allergy Immunol 16:288-294

36. Brehler R, Theissen U, Mohr C, Luger T (1997) Latex-fruit syndrome: frequency of cross-reacting IgE antibodies. Allergy 52:404-410

37. Bressler RB (1995) Pathophysiology of chronic urticaria. Immunol Allergy Clin North Am 15:659-677

38. Bruckner AL, Weston WL, Morelli JG (2000) Does sensitization to contact allergens begin in infancy? Pediatrics 105:e3

39. Cadnapaphornchai MA, Saulsbury FT, Norwood VF (2000) Hypocomplementemic urticarial vasculitis: report of a pediatric case. Pediatr Nephrol 14:328-331

40. Cantani A, Gagliesi D (1996) Severe reactions to cow's milk in very young infants at risk of atopy. Allergy Asthma Proc 17:205-208

41. Cantani A, Bellioni B, Ragno V, Businco L (1990) Epidemiologia e storia naturale dell'allergia alimentare: Follow-up di 88 bambini fino a 14 anni. Aggiorn Pediatr 41:321-332

42. Casale TB, Sampson HA, Hanifin J et al (1988) Guide to physical urticarias. J Allergy Clin Immunol 82:758-763

43. Ceuppens JL, Van Durme P, Dooms-Gossens A (1992) Latex allergy in patient with allergy to fruit (letter). Lancet 339: 493

44. Champion RH (1990) A practical approach to the urticarial syndromes - a dermatologist's view. Clin Exp Allergy 20: 221-224

45. Charlesworth EN (1996) Urticaria and angioedema: a clinical spectrum. Ann Allergy Asthma Immunol 76:484-495 
46. Claveau J, Lavoie A, Brunet C, Bédard P-M, Hébert J (1993) Chronic idiopathic urticaria: possible contribution of histamine-releasing factor to pathogenesis. J Allergy Clin Immunol 92:132-137

47. Cohen PR, Cardullo AC, Ruszkowski AM, DeLeo VA (1990) Allergic contact dermatitis to nickel in children with atopic dermatitis. Ann Allergy 65:73-79

48. Conde Salazar L, del Rio E, Guimaraens D, GonzalezDomingo A (1993) Type IV allergy to rubber additives: a 10-year study of 686 cases. J Am Acad Dermatol 29:176-180

49. Crespo JF, Pascual C, Dominguez C, Ojeda I, Muñoz FM, Esteban MM (1995) Allergic reactions associated with airborne fish particles in IgE-mediated fish hypersensitive patients. Allergy 50:257-261

50. Cuisset L, Drenth JPH, Berthelot JM et al (1999) Genetic linkage of the Muckle-Wells syndrome to chromosome 1q44. Am J Hum Genet 65:1054-1059

51. Curtis N, Zheng R, Lamb JR, Levin M (1995) Evidence for a superantigen mediated process in Kawasaki disease. Arch Dis Child 72:308-311

52. Czarnetzki BM (1986) Urticaria. Springer Verlag Berlin Heidelberg New York

53. Czarnetzki BM (1989) Is urticaria an allergic disease? Allergologie 12:155-157

54. Dalal I, Levine A, Somekh E, Mizrahi A, Hanukoglu A (2000) Chronic urticaria in children: expanding the "autoimmune kaleidoscope". Pediatrics 106:1139-1141

55. DeAmicis T, Mofid MZ, Cohen B, Nousari HC (2002) Hypocomplementemic urticarial vasculitis: report of a 12-year-old girl with systemic lupus erythematosus. J Am Acad Dermatol 47 [5 Suppl]:S273-S274

56. De Greef H, Dooms-Goossens A (1987) Dermatite allergica da contatto in età infantile in Belgio. Pediatr Dermatol News 6:209-211

57. De Groot AC (1990) Labelling cosmetics with their ingredients. BMJ 300:1636-1638

58. DeLeo VA (1997) Photocontact dermatitis. Immunol Allergy Clin North Am 17:451-469

59. De Martino M, Peruzzi M, Galli L, Lega L, Zammarchi E, Vierucci A (1992) Food-additive intolerance and its correlation with atopy in children with recurrent or intermittent urticaria-angioedema. Pediatr Allergy Immunol 3:33-38

60. De Martino M, Peruzzi M, Rossi ME, Galli L, Novembre E, Vierucci A (1991) Meccanismi etiopatogenetici della sindrome orticaria-angioedema nel bambino. Prosp Pediatr 21:37-48

61. DeVillez RL (1995) Urticaria pigmentosa. Immunol Allergy Clin North Am 15:775-784

62. Dodé C, Le Dû N, Cuisset L et al (2002) New mutations of CIAS1 that are responsible for Muckle-Wells syndrome and familial cold urticaria: a novel mutation underlies both syndromes. Am J Hum Genet 70:1498-1506

63. Dotterud LK, Falk ES (1995) Contact allergy in relation to hand eczema and atopic diseases in north Norwegian schoolchildren. Acta Pædiatr 84:402-406

64. Dover J, Black A, Ward A, Greaves MW (1988) Delayed pressure urticaria: clinical features, laboratory investigation, and response to therapy in 44 patients. J Am Acad Dermatol 18:1289-1298

65. Ehlers I, Niggemann B, Binder C, Zuberbier T (1998) Role of nonallergic hypersensitivity reactions in children with chronic urticaria. Allergy 53:1074-1077

66. Eseverri JL, Botey J, Cozzo M, Pena M, Marin AM (1999) Prevalence of allergy to latex in the pediatric population. Allergol Immunopathol (Madr) 27:133-1440
67. Eseverri JL, Cozzo M, Castillo M, Marin A (1999) Round table: immunological urticaria mediated by IgE. Allergol Immunopathol (Madr) 27:104-111

68. Esper F, Shapiro ED, Weibel C, Ferguson D, Landry ML, Kahn JS (2005) Association between a novel human coronavirus and Kawasaki disease. J Infect Dis 191:499-502

69. Fabiani JA, Avigliano A, Dupont JA (2000) Hereditary angioedema. Long-term follow-up of 88 patients. Experience of the Argentine Allergy and Immunology Institute. Allergol Immunopathol 28:267-271

70. Farkas H, Harmat G, Fust G, Varga L, Visy B (2002) Clinical management of hereditary angio-oedema in children. Pediatr Allergy Immunol 13:153-161

71. Ferguson TA, Dube P, Griffith TS (1994) Regulation of contact hypersensitivity by interleukin 10. J Exp Med 179: 1597-1604

72. Fink CW (1986) Vasculitis. Pediatr Clin North Am 33:12031219

73. Fiocchi A, Restani P, Ballabio C et al (2001) Severe anaphylaxis induced by latex as a contaminant of plastic balls in play pits. J Allergy Clin Immunol 108:298-300

74. Fisher AA (1990) Adverse nail reactions and paresthesia from "photobonded acrylate sculptured nails". Cutis 45: 293-294

75. Fisher AA (1994) Allergic contact dermatitis in early infancy. Cutis $54: 300-302$

76. Fisher AA (1994) Patch testing in children including early infancy. Cutis $1994 ; 54: 387-388$

77. Fisher TI, Hansen J, Kreilgård B, Maibach HI (1989) The science of patch test standardization. Immunol Clin North Am 9:417-434

78. Furukawa S, Imai K, Matsubara T et al (1992) Increased levels of circulating intercellular adhesion molecule 1 in Kawasaki disease. Arthritis Rheum 35:672-677

79. Gabrielli A (1991) Diagnosi immunologica delle vasculiti. Atti 200 Congresso della Società Italiana di Allergologia ed Immunologia Clinica. OIC Medical Press, Rome, pp 316-321

80. Galimberti M, Cantone R, Parachini F, Forgnone A (1989) L'allergia da contatto ha un ruolo nelle dermatiti del infanzia? Notiz Allergol 8:212-217

81. Gardner-Medwin JM, Dolezalova P, Cummins C, Southwood TR (2002) Incidence of Henoch-Schonlein purpura, Kawasaki disease, and rare vasculitides in children of different ethnic origins. Lancet 360:1197-1202

82. Gaspari AA (1997) The role of keratinocytes in the pathophysiology of contact dermatitis. Immunol Allergy Clin North Am 17:377-605

83. Gelmetti C, Barbagallo C, Cerri D, De Mattia D, Bonifazi E (1985) Acute haemorrhagic oedema of the skin in infants, clinical and pathogenic observations in seven cases. Bull Dermatol Pediatr 4:23-24

84. Giordano-Labadie F, Rance F, Pellegrin F, Bazex J, Dutau G, Schwarze HP (1999) Frequency of contact allergy in children with atopic dermatitis: results of a prospective study of 137 cases. Contact Dermatitis 40:192-195

85. Gonçalo S, Gonçalo M, Azenha A et al (1992) Allergic contact dermatitis in children. Contact Dermatitis 26:113-115

86. Goodman M, Sulzberger M (1938) Acquired specific hypersensitivity to simple chemicals, eczematous sensitivity to clothing and cosmetics, with special reference to dyes. J Allergy 9:136-157

87. Govoni MR, Strumia R, De Rosa E, Malgutti L, De Sanctis V (2001) Edema emorragico acuto dell'infanzia. Presentazione di un caso clinico. Riv Ital Pediatr 27:811-813 
88. Grattan CEH, Francis DM, Hide M, Greaves MW (1991) Detection of circulating histamine releasing autoantibodies with functional properties of anti-IgE in chronic urticaria. Clin Exp Allergy 21:696-704

89. Greaves MW (1993) Chronic urticaria. N Engl J Med 332: 1767-1772

90. Guillet MH, Guillet C (1993) Food urticaria in children. Allergol Immunol 25:333-338

91. Haas N, Hermes B, Henz BM (2001) Adhesion molecules and cellular infiltrate: histology of urticaria. J Investig Dermatol Symp Proc 6:137-138

92. Hide M, Francis DM, Grattan CEH, Hakimi J, Kochan JP, Greaves MW (1993) Autoantibodies against the highaffinity $\operatorname{IgE}$ receptor as a cause of histamine release in chronic urticaria. N Engl J Med 28:1599-1604

93. Hoffman HM, Gregory SG, Mueller JL et al (2003) Fine structure mapping of CIAS1: identification of an ancestral haplotype and a common FCAS mutation, L353P. Hum Genet 112:209-216

94. Hollenberger H, Gruber E, Frank B (2002) Severe anaphylactic shock without exanthema in a case of unknown latex allergy and review of the literature. Paediatr Anaesth 12:544-551

95. Hossny E, Aboul-Magd M, Bakr S (2001) Increased plasma eotaxin in atopic dermatitis and acute urticaria in infants and children. Allergy 56:996-1002

96. Jacques P, Lavoie A, Bédard PM, Brunet C, Hébert J (1992) Chronic idiopathic urticaria: profiles of skin mast cell histamine release during active disease and remission. J Allergy Clin Immunol 89:1139-1143

97. Jaeger D, Kleinhans D, Czuppon AB, Baur X (1992) Latexspecific proteins causing immediate-type cutaneous, nasal, bronchial, and systemic reactions. J Allergy Clin Immunol 89:759-768

98. Jones EM, Callen JP (1991) Collagen vascular diseases of childhood. Pediatr Clin North Am 38:1019-1039

99. Kaeser P, Revelly ML, Frei PC (1994) Prevalence of IgE antibodies specific for food allergens in patients with chronic urticaria of unexplained origin. Allergy 49:626-629

100. Kalogeromitros D, Katsarou A, Armenaka M, Polizou E, Zografakis I, Stratigos I (1995) Familial cold urticaria: a father and daughter with typical clinical and laboratory features. Ann Allergy Asthma Immunol 74:295-298

101. Kamide R, Niimura M, Ueda $\mathrm{H}$ et al (1989) Clinical evaluation of ketotifen for chronic urticaria: multicenter double-blind comparative study with clemastine. Ann Allergy 62:322-325

102. Kaniwa MA, Isama K, Nakamura A et al (1994) Identification of causative chemicals of allergic contact dermatitis using a combination of patch testing and chemical analysis. Application to cases from rubber footwear. Contact Dermatitis 30:26-34

103. Kaplan AP (1998) Urticaria and angioedema. In: Middleton E Jr, Reed CE, Ellis EF, Adkinson NF Jr, Yunginger JW, Busse WW (eds) Allergy: principles and practice, 5th edn. CV Mosby, St Louis, pp 1104-1122

104. Kapsenberg ML, Wierenga EA, Stiekma FE, Tiggelman AM, Bos JD (1992) TH1 lymphokine production profiles of nickel-specific CD4+ T-lymphocyte clones from nickel contact allergic and non-allergic individuals. J Invest Dermatol 98:59-63

105. Kapsenberg ML, Wierenga EA, van der Heijden FL et al (1992) Allergen-specific CD4+ T lymphocytes in contact dermatitis and atopic dermatitis. In: Wüthrich B (ed) Highlights in allergy and clinical immunology. Hogrefe \& Huber, Bern, pp 242-246
106. Kato S, Ebina K, Naganuma H, Sato S-i, Maisawa S-i, Nakagawa H (1996) Intestinal IgA deposition in HenochSchönlein purpura with severe gastro-intestinal manifestations. Eur J Pediatr 155:91-95

107. Katz SI (1990) Mechanisms involved in allergic contact dermatitis. J Allergy Clin Immunol 86:670-672

108. Kawasaki T (1967) Acute febrile mucocutaneous syndrome with lymphoid involvement with specific desquamation of the fingers and toes in children. Jpn J Allergy $16: 178-222$

109. Kelly KJ (1995) Management of the latex-allergic patient. Immunol Allergy Clin North Am 15:139-157

110. Kivity S, Schwartz Y, Wolf R, Topilsky M (1990) Systemic cold-induced urticaria. Clinical and laboratory characterization. J Allergy Clin Immunol 85:52-54

111. Kontou-Fili K, Borici-Mazi R, Kapp A et al (1997) Physical urticaria: classification and diagnostic guidelines. An EAACI position paper. Allergy 52:504-513

112. Kwittken PL, Sweinberg S, Campbell DE, Pawlowski NA (1995) Latex hypersensitivity in children: clinical presentation and detection of latex-specific immunoglobulin E. Pediatrics 95:693-699

113. La Rosa M, Leonardi S, Marchese G et al (2001) Doubleblind multicenter study on the efficacy and tolerability of cetirizine compared with oxatomide in chronic idiopathic urticaria in preschool children. Ann Allergy Asthma Immunol 87:48-53

114. Lagier F, Vervloet D, Lhermet I, Poyen D, Charpin D (1992) Prevalence of latex allergy in operating room nurses. J Allergy Clin Immunol 90:319-322

115. Lahti A, Maibach HI (1989) Immediate contact reactions. Immunol Allergy Clin North Am 9:463-478

116. Landsteiner K, Jablons B (1914) Über die Bildung von Antikörpern gegen verändertes arteigenes Serumeiweiß. Z Immunitätsforsch Exp Ther 20:618-621

117. Lawlor F (1993) Urticaria - diagnosis and treatment. In: Holgate ST, Church MK (eds) Allergy. Gower Medical Publishing, London, pp 22.1-22.12

118. Lazarous MC, Kerdel FA (2002) Topical tacrolimus protoptic. Drugs Today (Barc) 38:7-15

119. Lefvert AK (1993) Recurrent angioedema caused by circulating immune complexes containing antibodies against bovine proteins. Int Arch Allergy Clin Immunol 102:112116

120. Legrain V, Legian S, Taieb A, Battin J, Maleville J (1991) Juvenile acute hemorrhagic edema of the skin: study of ten cases. J Am Acad Dermatol 24:17-22

121. Leiferman K, Norris P, Murphy G, Hawk J, Winkelmann RK (1989) Evidence for eosinophil degranulation with deposition of granule major basic protein in solar urticaria. J Am Acad Dermatol 21:75-80

122. Lepore L (1990) Le vasculiti. Inquadramento generale. Med Bambino 9:563-568

123. Leung DYM, Meissner HC, Fulton DR, Murray DL, Kotzin BL, Schlievert PM (1993) Toxin shock syndrome toxinsecreting Staphylococcus aureus in Kawasaki syndrome. Lancet 342:1385-1388

124. Lin TL, Wang CR, Liu MF et al (2001) Multiple colonic ulcers caused by Churg-Strauss syndrome in a 15 -year-old girl. Clin Rheumatol 20:362-364

125. Lisi $P$ (1993) Dermatite da contatto endogeno ai metalli di origine alimentare. G Ital Allergol Immunol Clin 3:215222

126. Llátser R, Zambrano C, Guillaumet B (1994) Anaphylaxis to natural rubber latex in a girl with food allergy. Pediatrics 94:736-737 
127. Lorenzi S, Vezzani C, Vincenzi C, Tosti A (1994) Sensibilizzazione del alcol oleilico da cosmetici e medicamenti topici. Boll Dermatol Allergol Profess 9:185-189

128. Luger TA, Schwarz T (1995) The role of cytokines and neuroendocrine hormones in cutaneous immunity and inflammation. Allergy 50:292-302

129. Luong KVQ, Nguyen LT (1998) Aquagenic urticaria: report of a case and review of the literature. Ann Allergy Asthma Immunol 80:483-485

130. MacGregor DM (2001) The risks of ear piercing in children. Scott Med J 46:9-10

131. Maibach HI, Dannaker CJ, Lahti A (1993) Contact skin allergy. In: Middleton E Jr, Reed CE, Ellis EF, Adkinson NF Jr, Yunginger JW, Busse WW (eds) Allergy: principles and practice, 4th edn. CV Mosby, St Louis, pp 1605-1647

132. Mäkinen-Kiljunen S, Sorva R, Juntunen-Backman K (1992) Latex dummies as allergens (letter). Lancet 339: 1608-1609

133. Mäkinen-Kiljunen S, Reunala T, Turjanmaa K, Cacioli $\mathrm{P}$ (1993) Is cow's milk casein an allergen in latex-rubber gloves? (letter). Lancet 342:863-864

134. Martin-Munoz MF, Munoz-Robles ML, Gonzalez P, Martin-Esteban M (2002) Immediate heat urticaria in a child. Br J Dermatol 147:813-815

135. Martini A, Ravelli A, Albani S, De Benedetti F, Massa M, Wisnieski JJ (1994) Hypocomplementemic urticarial vasculitis syndrome with severe systemic manifestations. J Pediatr 124:742-744

136. Martorell A, Sanz J (1999) Round table: urticaria with a physical cause. Allergol Immunopathol (Madr) 27:85-96

137. Matsumoto T, Miyazaki T (2004) Systemic urticaria in an infant after ingestion of processed food that contained a trace quantity of wheat. Ann Allergy Asthma Immunol 93:98-100

138. Meneghini CL, Angelini G (1982) Le dermatiti da contatto. Lombardo Editore, Rome

139. Meneghini CL, Bonifazi E (1983) Dermatologia pediatrica pratica. Clinica Dermatologica, Università di Bari, Bari

140. Miller SD, Pritchard D, Crowley JP (1992) Blood histamine levels following graded cold challenge in atypical acquired cold urticaria. Ann Allergy 68:27-29

141. Monfrecola G, Masturzo E, Riccardo AM, Balato F, Ayala F, Di Costanzo MP (2000) Solar urticaria: a report on 57 cases. Am J Contact Dermat 11:89-94

142. Morales C, Peñarrocha M, Bagán JV, Burchés E, Pelaez A (1994) Immunological study of Melkersson-Rosenthal syndrome. Lack or response to food additive challenge. Clin Exp Allergy 25:260-264

143. Morris-Jones R, Robertson SJ, Ross JS, White IR, McFadden JP, Rycroft RJ (2002) Dermatitis caused by physical irritants. Br J Dermatol 147:270-275

144. Mortureux P, Leaute-Labreze C, Legrain-Lifermann V, Lamireau T, Sarlangue J, Taieb A (1998) Acute urticaria in infancy and early childhood: a prospective study. Arch Dermatol 134:319-323

145. Mortz CG, Andersen KE (1999) Allergic contact dermatitis in children and adolescents. Contact Dermatitis 41: 121-130

146. Mouterde O, Mallet E, Spriet J (1997) Syncope during bathing in infants, a pediatric form of water-induced urticaria? Arch Pediatr 4:1111-1115

147. Nagata S, Yamashiro Y, Maeda M, Ohtsuka Y, Yabuta K (1993) Immunohistochemical studies on small intestinal mucosa in Kawasaki disease. Pediatr Res 33:557-563
148. Nash MC, Shah V, Dillon MJ (1995) Soluble cell adhesion molecules and von Willebrand factor in children with Kawasaki disease. Cell Exp Immunol 101:13-17

149. Nethercott JR, Holness DL (1989) The positive predictive value of patch tests in the evaluation of patients with suspected contact dermatitis. Immunol Clin North Am 9: 549-554

150. Nieto A, Pamies R, Mazon A (2002) Peculiarities of latex allergy and preventive measures in the pediatric age group. Allergol Immunopathol (Madr) 30:148-156

151. Norris P, Murphy G, Hawk J, Winkelmann RK (1988) A histological study of the evolution of solar urticaria. Arch Dermatol 124:80-83

152. Novembre E, Bernardini R, Brizzi I et al (1997) The prevalence of latex allergy in children seen in a university hospital allergy clinic. Allergy 50:101-105

153. Offidani A, Cellini A, Bossi G (2001) Acute haemorrhagic oedema of the skin in infancy. Eur J Dermatol 11:63-64

154. Oranje AP, Bruijnzeel DP, Stenveld HJ, Dieges PH (1994) Immediate- and delayed-type contact hypersensitivity in children older than 5 years with atopic dermatitis: a pilot study comparing different tests. Pediatr Dermatol 11:209215

155. Orfan NA, Kolski GB (1992) Angioedema and C1 inhibitor deficiency. Ann Allergy 69:167-172

156. Orfan NA, Kolski GB (1993) Physical urticarias. Ann Allergy 71:205-212

157. Ormerod AD (1993) Urticaria - pathophysiology. In: Holgate ST, Church MK (eds) Allergy. Gower Medical Publishing, London, pp 21.1-21.12

158. Osler W (1888) Hereditary angio-neurotic oedema. Am J Med Sci 1888; 95:362-367

159. Ostrov MR (1995) Dramatic resolution of chronic rounds. Ann Allergy Asthma Immunol 75:227-231

160. Ownby DR (1995) Manifestations of latex allergy. Immunol Allergy Clin North Am 15:31-43

161. Pachor ML, Urbani G, Cortina P et al (1989) Is the Melkersson-Rosenthal syndrome related to the exposure to food additives? Oral Surg Oral Med Oral Pathol 667: 393-395

162. Park YW, Han JW, Park IS et al (2005) Epidemiologic picture of Kawasaki disease in Korea, 2000-2002. Pediatr Int 47:382-387

163. Parker RK, Crowe MJ, Guin JD (1992) Aquagenic urticaria. Cutis 50:283-284

164. Pascual C, Martin Esteban M, Crespo JF (1992) Fish allergy: evaluation of the importance of cross-reactivity. J Pediatr 121:S29-S34

165. Pietra BA, De Inocencio J, Giannini EH, Hirsch R (1994) T cell receptor $\mathrm{V} \beta$ family repertoire and $\mathrm{T}$ cell activation markers in Kawasaki disease. J Immunol 153:1881-1888

166. Pigatto P, Finzi AF (1986) Up-date on urticaria. Minerva Med 77:1401-1406

167. Pittman T, Kiburz J, Gabriel K, Steinhardt G, Williams D, Slater J (1995) Latex allergy in children with spina bifida. Pediatr Neurosurg 22:96-100

168. Putterman C, Barak V, Caraco Y, Neuman T, Shalit M (1993) Episodic angioedema with eosinophilia: a case associated with $\mathrm{T}$ cell activation and cytokine production. Ann Allergy 70:243-248

169. Plumb J, Norlin C, Young PC et al (2001) Exposures and outcomes of children with urticaria seen in a pediatric practice-based research network: a case-control study. Arch Pediatr Adolesc Med 155:1017-1021

170. Rademaker M, Forsyth A (1991) Contact dermatitis in children. Contact Dermatitis 20:104-107 
171. Ronkainen J, Nuutinen M, Koskimies O (2002) The adult kidney 24 years after childhood Henoch-Schonlein purpura: a retrospective cohort study. Lancet 360:666-670

172. Raika G (1987) Allergic contact dermatitis in children. Pediatr Dermatol News 6:205-208

173. Ring J (1988) Dermatologic diseases secondary to food allergy and pseudoallergy. Nestlé Nutr Workshop Ser 17:271-287

174. Ring J, Przybilla B (1989) UV irradiation and allergy. Allergologie 12:75-79

175. Roberts TE, Pearson DJ (1991) Urticaria and angioedema. World of allergy. Fisons, London, pp 11-14

176. Rodriguez M, Vega F, Garcia MT et al (1993) Hypersensitivity to latex, chestnut, and banana. Ann Allergy 70:31-34

177. Romagnani S, Emmi L, Almerigogna F. Vasculiti. In: Romagnani S, Almerigogna F, Emmi L (eds) Malattie del sistema immunitario. McGraw-Hill Libri Italia, Milan, pp 282-314

178. Rosenfeld EA, Corydon KE, Shulman ST (1995) Kawasaki disease in infants less than one year of age. J Pediatr 126:524-529

179. Roul S, Ducombs G, Taieb A (1999) Usefulness of the European standard series for patch testing in children. A 3-year single-centre study of 337 patients. Contact Dermatitis 40:232-235

180. Sakata K, Kita M, Imanishi J, Onouchi Z, Liu Y, Mitsui Y (1995) Effect of Kawasaki disease on migration of human umbilical vein endothelial cells. Pediatr Res 38:501-505

181. Santaolalla Montoya M, Martinez Molero MI, Santaolalla San Juana F, Baeza ML, Alonso Lebrero E, Zapatero Remon L (2002) Cold urticaria:review of 12 cases. Allergol Immunopathol (Madr) 30:259-262

182. Saraclar Y, Tinaztepe K, Adalioglu G, Tuncer A (1990) Acute hemorrhagic edema of infancy (AHAI): a variant of Henoch Schönlein purpura or a distinct clinical entity? J Allergy Clin Immunol 86:473-483

183. Schafer CM (1995) Physical urticaria. Immunol Allergy Clin North Am 15:679-699

184. Schneider AT, Silverman BA (1988) Skin manifestations. In: Chiaramonte LT, Schneider AT, Lifshitz F (eds) Food allergy. Marcel Dekker, New York, pp 193-211

185. Sevila A, Romaguera C, Vilaplana J, Botella R (1994) Contact dermatitis in children. Contact Dermatitis 30: 292-294

186. Sertoli A, Francalanci S, Gola M (1989) Patologia cutanea da contatto con proteine. Notiz Allergol 8:182-187

187. Shah UK, Jacobs IN (1999) Pediatric angioedema: ten years' experience. Arch Otolaryngol Head Neck Surg 125: 791-795

188. Sheyyab-Al M, Shanti-El H, Ajlouni S, Sawalha D, Daoud A (1995) The clinical spectrum of Henoch-Schönlein purpura in infants and young children. Eur J Pediatr 154: 969-972

189. Shulman ST, De Inocencio J, Hirsch R (1995) Kawasaki disease. Pediatr Clin North Am 42:1205-1222

190. Silvers WS (1992) Exercise-induced allergies: the role of histamine release. Ann Allergy 68:58-63

191. Simons FE (2001) Prevention of acute urticaria in young children with atopic dermatitis. J Allergy Clin Immunol 107:703-706

192. Simons FER, Sussman GL, Simons KJ (1995) Effect of the $\mathrm{H}_{2}$-antagonist cimetidine on the pharmacokinetics and pharmacodynamics of the $\mathrm{H}_{1}$-antagonists hydroxyzine and cetirizine in patients with chronic urticaria. J Allergy Clin Immunol 95:685-693
193. Slater JE (1994) Latex allergy. J Allergy Clin Immunol 94:139-150

194. Smith CH, Soh C, Lee TH (1992) Cutaneous histamine metabolism in urticaria. J Allergy Clin Immunol 89:944-950

195. Sommer S, Wilkinson SM, Beck MH, English JS, Gawkrodger DJ, Green C (2002) Type IV hypersensitivity reactions to natural rubber latex: results of a multicentre study. Br J Dermatol 146:114-117

196. Sorva R, Mäkinen-Kiljunen S, Suvilehto K, JuntunenBackman K, Haahtela T (1995) Latex allergy in children with no known risk factor for latex sensitization. Pediatr Allergy Immunol 6:36-38

197. Stafford CT (1990) Urticaria as a sign of systemic disease. Ann Allergy 64:264-272

198. Stern G (1927) Überempfindlickeit gegen Kautschuk als Ursache von Urticaria and Quinckeschem Ödem. Klin Wochenschr 6:1096-1097

199. Stingeni L, Lapomarda V, Assalve D, Caraffini S, Lisi P (1995) Dermatite da contatto in età adolescenziale. G Ital Allergol Immunol Clin 5:91-94

200. Storrs FJ (1991) Contact dermatitis caused by drugs. Immunol Allergy Clin North Am 11:509-523

201. Supramanian G, Warner JO (1986) Artificial food additive intolerance in patients with angio-edema and urticaria. Lancet ii:907-909

202. Sussman GL, Yang WH, Steinberg S (1992) MelkerssonRosenthal syndrome: clinical, pathologic, and therapeutic considerations. Ann Allergy 69:187-194

203. Taub DD, Conlon K, Lloyd AR, Oppenheim JJ, Kelvin DJ (1993) Preferential migration of activated CD4+ and CD8+ T cells in response to MIP-1a and MIP-1 $\beta$. Science 260:355-358

204. Theriault A, Whaley K, McPhaden AR, Boyd E, Connor JM (1990) Regional assignment of the human C1-inhibitor gene to 11q11-q13.1. Hum Genet 84:477-479

205. Tomazic VJ, Shampaine EL, Lamanna A, Withrow TJ, Adkinson NF Jr, Hamilton RG (1994) Cornstarch powder on latex products is an allergen carrier. J Allergy Clin Immunol 93:751-758

206. Thestrup-Pedersen K (1997) Contact allergy in monozygous twins. Contact Dermatitis 36:52-53

207. Thestrup-Pedersen K, Larsen CG, Ronnevig J (1989) The immunology of contact dermatitis. Contact Dermatitis 20:81-92

208. Tillie-Leblond I, Gosset Ph, Janin A et al (1988) Increased interleukin-production during the acute phase of the syndrome of episodic angioedema and hypereosinophilia. Clin Exp Allergy 28:491-496

209. Tillie-Leblond I, Gosset Ph, Janin A et al (1994) Tumor necrosis factor- $\alpha$ release during systemic reaction in cold urticaria. J Allergy Clin Immunol 93:501-509

210. Tönshoff B, Momper R, Scweer H, Schärer K, Seyberth HW (1992) Increased biosynthesis of vasoactive prostanoids in Schönlein-Henoch purpura. Pediatr Res 32:137-140

211. Torres P, Guerra F, Miguel R, Moreno C, Santamaría M, Sanches-Guijo P (1993) Study of lymphocyte subpopulations at different stages of contact dermatitis. J Invest Allergol Clin Immunol 3:294-299

212. Tosti A, De Padova MP, Manuzzi P, Bardazi F (1987) Contact cheilitis in children. Pediatr Dermatol News 6:212215

213. Treudler R, Tebbe B, Steinhoff M, Orfanos CE (2002) Familial aquagenic urticaria associated with familial lactose intolerance. J Am Acad Dermatol 47:611-613 
214. Trevisan G, Briscik E, Kokelj F (1987) Shoe-induced contact cheilitis in children. Pediatr Dermatol News 6:220223

215. Trevisi P, Vincenzi C, Chieregato C, Guerra L, Tosti A (1994) Sunscreen sensitization: a three-year study. Dermatology 189:55-57

216. Truscott W (1995) The industry perspective on latex. Immunol Allergy Clin North Am 15:89-121

217. Tsuchida S, Yamanaka T, Tsuchida R, Nakamura Y, Yashito M, Yanagawa H (1996) Epidemiology of infant Kawasaki disease with a report of the youngest neonatal case ever reported in Japan. Acta Pædiatr 85:995-997

218. Turjanmaa K, Mäkinen-Kiljunen S, Reunala T, Alesius H, Palosuo T (1995) Natural rubber latex allergy. Immunol Allergy Clin North Am 15:71-88

219. Valentini RD, Smoyer WE, Sedman AB et al (1998) Outcome of antineutrophil cytoplasmic autoantibodies-positive glomerulonephritis and vasculitis in children: a single-center experience. J Pediatr 132:325-328

220. Vallier P, Balland S, Harf R, Valenta R, Deviller P (1995) Identification of profilin as an IgE-binding component in latex from Hevea brasiliensis: clinical implications. Clin Exp Allergy 25:332-339

221. Van Hoogstraten IMW, Andersen KE, von Blomberg BME et al (1991) Reduced frequency of nickel allergy upon oral nickel contact at an early age. Clin Exp Immunol 85:441445

222. Vega ML, Vega J, Vega JM, Moneo I, Sanchez E, Miranda A (2003) Cutaneous reactions to pine processionary caterpillar (Thaumetopoea pityocampa) in pediatric population. Pediatr Allergy Immunol 14:482-486

223. Veien NK, Krogdahl A (1991) Cutaneous vasculitis induced by food additives. Acta Derm Venereol 71:73-74

224. Veien NK, Bochorst E, Hattel T, Lauerberg G (1994) Stomatitis or systemically-induced contact dermatitis from metal wire in orthodontic materials. Contact Dermatitis 30:210-213

225. Vena GA, Cassano N, D'Argento V, Foti C, Angelini G (1996) Orticaria cronica e fisica:patogenesi e trattamento. Boll Dermatol Allergol Profess 11:89-104

226. Venzor J, Baer SC, Huston DP (1995) Urticarial vasculitis. Immunol Allergy Clin North Am 15:761-774

227. Vervloet D, Charpin D, Pradal M (1992) Atopy and drug allergy. ACI News 4:43-48

228. Vita D, Passalacqua G, Caminiti L, Barberio G, Pajno GB (2004) Successful combined therapy for refractory chronic urticaria in a 10-year-old boy. Allergy 59:10021-1022

229. Volonakis M, Katsarou-Katsari A, Stratigos J (1992) Etiologic factors in childhood chronic urticaria. Ann Allergy 69:61-65

230. Waage Nielsen E, Thidemann Johansen H, Holt J, Mollnes TE (1994) C1 inhibitor and diagnosis of hereditary angioedema in newborns. Pediatr Res 35:184-187

231. Wahlgren C-F (1992) Pathophysiology of itching in urticaria and atopic dermatitis. Allergy 47:65-75

232. Waldo FB, Leist PA, Strife CF, Forristal J, West CD (1985) Atypical hypocomplementemic vasculitis syndrome in a child. J Pediatr 106:745-750

233. Wanderer AA (1995) The spectrum of cold urticaria. Immunol Allergy Clin North Am 15:701-723
234. Wang SJ, Yang YH, Lin YT, Tsai MJ, Chiang BL (2000) Childhood Churg-Strauss syndrome: report of a case. J Microbiol Immunol Infect 33:263-266

235. Warren RW, Perez MD, Wilking AP, Myones BL (1994) Pediatric rheumatic diseases. Pediatr Clin North Am 41:783818

236. Wasserman D, Preminger A, Zlotogorski A (1994) Aquagenic urticaria in a child. Pediatr Dermatol 11:29-34

237. Weidenbach H, Beckh KH, Lerch MM, Adler G (1993) Precipitation of hereditary angioedema by infectious mononucleosis (letter). Lancet 342:934-935

238. Weinreb BD, Jamper R, Hood AF, Brusilo SW, Eggleston PA (1987) Pruritus and rash after bathing in a 12-year-old girl. Ann Allergy 59:254-255; 307-312

239. Williams PB, Buhr MP, Weber RW, Voiz Ma, Koepke JW, Selner JC (1995) Latex allergen in respirable particulate air pollution. J Allergy Clin Immunol 95:88-95

240. Williams-Arya P, Hogan MB, Wilson NW (1996) Solar urticaria in a 6-year-old child. Ann Allergy Asthma Immunol 76:141-143

241. Wisnieski JJ, Emancipator SN, Korman NJ, Lass JH, Zaim TM, McFadden ER (1994) Hypocomplementemic urticarial vasculitis syndrome in identical twins. Arthritis Rheum 37:1105-1111

242. Wüthrich B, Bianchi-Kusch E, Johansson SGO (1996) Allergic urticaria and angioedema caused by a hemostatic sponge of bovine fibrin used in tooth extraction. Allergy 51:49-51

243. Yamashiro Y, Nagata S, Oguchi S, Shimizu T (1996) Selective increase of $\mathrm{V} \beta 2+\mathrm{T}$ cells in the small intestinal mucosa in Kawasaki disease. Pediatr Res 39:264-266

244. Yanagawa H, Nakamura Y, Yashiro M et al (1998) Results of the nationwide epidemiologic survey of Kawasaki disease in 1995 and 1996 in Japan. Peditrics 102:E65

245. Yang YJ, Hung CF, Hsu CR et al (2005) A nationwide survey on epidemiological characteristics of childhood Henoch-Schonlein purpura in Taiwan. Rheumatology (Oxford) 44:618-622

246. Yi ES, Colby TV (2001) Wegener's granulomatosis. Semin Diagn Pathol 18:34-46

247. Yilmaz M, Kendirli SG, Altintas D, Bingol G (2000) Hereditary angioedema: case report of a family. Turk J Pediatr 42:230-233

248. Ying S, Kikuchi Y, Meng Q, Kay AB, Kaplan AP (2002) TH1/ $\mathrm{TH} 2$ cytokines and inflammatory cells in skin biopsy specimens from patients with chronic idiopathic urticaria: comparison with the allergen-induced late-phase cutaneous reaction. J Allergy Clin Immunol 109:694-700

249. Zuberbier T, Schwarz S, Hartman K, Pfrommer C, Czarnetzki BM (1996) Histamine releasability of basophils and skin mast cells in chronic urticaria. Allergy 51:24-28

250. Zuraw BL (1993) C1 inhibitor deficiency and autoimmunity. Immunol Allergy Clin North Am 13:441-457

251. Zweiman B (1992) The skin as a site of allergic reactions. In: Godard P, Bousquet J, Michel FB (eds) Advances in allergology and clinical immunology. Parthenon, Lancs, pp 497-505

252. Zweiman B, Valenzano M, Atkins PC, Tanus T, Getsy JA (1996) Characteristics of histamine-releasing activity in the sera of patients with chronic idiopathic urticaria. J Allergy Clin Immunol 88:89-98 